\title{
Aspirations Failure and Formation in Rural Nepal
}

\section{Authors: Sarah A. Janzen, Nicholas Magnan, Sharma Sudhindra, and William M. Thompson}

NOTICE: this is the author's version of a work that was accepted for publication in Journal of Economic Behavior and Organization. Changes resulting from the publishing process, such as peer review, editing, corrections, structural formatting, and other quality control mechanisms may not be reflected in this document. Changes may have been made to this york since t was submitted for publication. A qefinitive version was subsequently published in Journal of Economic Behavior and Organization, VOL\# 139, April 2017 DOI\# 10.1016/j.jebo.2017.04.003

Janzen, Sarah A. , Nicholas Magnan, Sudhindra Sharma, and William M. Thompson. "Aspirations Failure and Formation in Rural Nepal." Journal of Economic Behavior and Organization (April 2017 ). DOI: 10.1016/j.jebo.2017.04.003.

Made available through Montana State University's ScholarWorks scholarworks. montana.edu 


\title{
Aspirations failure and formation in rural Nepal
}

\author{
Sarah A. Janzen ${ }^{\mathrm{a}, *}$, Nicholas P. Magnan ${ }^{\mathrm{b}}$, Sudhindra Sharma ${ }^{\mathrm{c}}$, \\ William M. Thompson ${ }^{\mathrm{b}}$ \\ ${ }^{a}$ Montana State University, United States \\ ${ }^{\mathrm{b}}$ University of Georgia, United States \\ c Interdisciplinary Analysts, Nepā School of Social Sciences and Humanities, Nepal
}

\begin{abstract}
Aspirations, or a lack thereof, have recently gained the attention of economists as a behavioral constraint to future-oriented behavior and investment. In this paper we empirically test the theories of aspirations failure and formation articulated in Appadurai (2004), Ray (2006), and Genicot and Ray (2015) using a unique dataset from rural Nepal. We ask two questions: (1) What is the relationship between aspirations and future-oriented behavior? and (2) To what extent are an individual's aspirations associated with the observable characteristics of those around her? We find that aspirations correspond with future-oriented economic behavior as predicted by theory: investment in the future increases with aspirations up to a certain point, but if the gap between one's current status and aspirations becomes too large, investment subsequently declines. We also find that one's aspirations are associated with outcomes of those in her social network of higher, but not lower, status. Together these findings provide empirical evidence that aspirations, which may be a social phenomenon, can either stimulate development or reinforce poverty.
\end{abstract}

\section{Introduction}

Poor households frequently do not save or invest, even when returns to these actions appear high. This apparent failure to optimize is often attributed to the presence of binding external constraints: thin or missing markets for inputs, outputs, credit or insurance; inadequate vehicles for savings; asymmetric information; and social sharing norms are examples. But external constraints often provide incomplete or unsatisfying explanations for a lack of future-oriented behavior. Internal behavioral constraints may also be important, and have received growing attention in recent years (Ashraf et al., 2006; Bertrand et al., 2004; Duflo et al., 2011; Mullainathan and Thaler, 2000). In this paper we use unique data from rural Nepal to empirically analyze the role aspirations play in determining future-oriented behavior, as well as their social origins.

Recent theoretical work has revealed a complex relationship between aspirations, investment, and poverty (Dalton et al., 2016; Ray, 2006; Genicot and Ray, 2017; Bogliacino and Ortoleva, 2013; Lybbert and Wydick, in press; Mookherjee et al., 2010). A key hypothesis arising from this literature concerns the existence of a non-monotonic relationship between aspirations and investment introduced by Ray (2006) and further developed by Genicot and Ray (2017). This theory suggests 


\title{
Aspirations failure and formation in rural Nepal
}

\author{
Sarah A. Janzen ${ }^{\mathrm{a}, *}$, Nicholas P. Magnan ${ }^{\mathrm{b}}$, Sudhindra Sharma ${ }^{\mathrm{c}}$, \\ William M. Thompson ${ }^{\mathrm{b}}$ \\ a Montana State University, United States \\ b University of Georgia, United States \\ ' Interdisciplinary Analysts, Nepā School of Social Sciences and Humanities, Nepal
}

\begin{abstract}
Aspirations, or a lack thereof, have recently gained the attention of economists as a behavioral constraint to future-oriented behavior and investment. In this paper we empirically test the theories of aspirations failure and formation articulated in Appadurai (2004), Ray (2006), and Genicot and Ray (2015) using a unique dataset from rural Nepal. We ask two questions: (1) What is the relationship between aspirations and future-oriented behavior? and (2) To what extent are an individual's aspirations associated with the observable characteristics of those around her? We find that aspirations correspond with future-oriented economic behavior as predicted by theory: investment in the future increases with aspirations up to a certain point, but if the gap between one's current status and aspirations becomes too large, investment subsequently declines. We also find that one's aspirations are associated with outcomes of those in her social network of higher, but not lower, status. Together these findings provide empirical evidence that aspirations, which may be a social phenomenon, can either stimulate development or reinforce poverty.
\end{abstract}

\section{Introduction}

Poor households frequently do not save or invest, even when returns to these actions appear high. This apparent failure to optimize is often attributed to the presence of binding external constraints: thin or missing markets for inputs, outputs, credit or insurance; inadequate vehicles for savings; asymmetric information; and social sharing norms are examples. But external constraints often provide incomplete or unsatisfying explanations for a lack of future-oriented behavior. Internal behavioral constraints may also be important, and have received growing attention in recent years (Ashraf et al., 2006; Bertrand et al., 2004; Duflo et al., 2011; Mullainathan and Thaler, 2000). In this paper we use unique data from rural Nepal to empirically analyze the role aspirations play in determining future-oriented behavior, as well as their social origins.

Recent theoretical work has revealed a complex relationship between aspirations, investment, and poverty (Dalton et al., 2016; Ray, 2006; Genicot and Ray, 2017; Bogliacino and Ortoleva, 2013; Lybbert and Wydick, in press; Mookherjee et al., 2010). A key hypothesis arising from this literature concerns the existence of a non-monotonic relationship between aspirations and investment introduced by Ray (2006) and further developed by Genicot and Ray (2017). This theory suggests 
the amount an individual invests in the future depends on an individual's aspirations relative to their current status. If aspirations barely exceed current status, then the investment required to meet them is relatively low. This low investment is defined by Ray (2006) as an aspirations failure. As aspirations increase, failure is averted as optimal investment increases. But if aspirations are too large (relative to current status), the required investment becomes overly burdensome, investment is suspended, and aspirations also fail.

If internal constraints like aspirations inhibit economic behavior in a way that perpetuates poverty, then there is scope to design interventions that target internal constraints as well as external ones. Recent empirical papers on this topic have demonstrated how a variety of interventions can lengthen people's planning horizon (Laajaj, 2017), close the gender gap in aspirations for children's education and employment outcomes (Beaman et al., 2012), increase aspirations (Bernard et al., 2014; Lybbert and Wydick, 2016), and improve expectations and attitudes about the future (Macours and Vakis, 2014). These studies also estimate intervention impacts on future-oriented economic behavior, and thus provide a rich body of evidence that behavioral constraints limit investment, and that these constraints are mutable. In contrast, our study employs observational data on both aspirations and investment to empirically analyze the potentially complex and non-monotonic relationship described above.

It is also important to understand how aspirations are formed. The theoretical literature generally assumes that aspirations are influenced by observing neighbors and peers (Appadurai, 2004; Genicot and Ray, 2017). ${ }^{1}$ The empirical literature demonstrates that one's relative status (generally in terms of income) does impact their aspirations (Fafchamps and Shilpi, 2008; Ferrer-i-Carbonell, 2005; Knight and Gunatilaka, 2012; Stutzer, 2004). If aspirations are socially determined and affect behavior, there is scope for interventions that generate spillover effects by altering aspirations within a community. Indeed, several recent studies demonstrate the potential of aspiration-improving interventions to generate multiplier effects through social linkages (Macours and Vakis, 2014; Bernard et al., 2014).

In this paper we (1) use unique measures of aspirations for income and children's education to evaluate if and how aspirations contribute to future-oriented economic behavior, and (2) use detailed network data to examine social influences on aspirations. We find evidence supporting the hypothesized inverse-U relationship between income aspirations and future oriented financial behavior. The probability of engaging in saving activities increases with income and (to a lesser extent) asset aspirations up to a point, but then falls as predicted by the model. We do, however, not see the opposite relationship between spending on temptation goods and aspirations. We also observe the hypothesized relationship between education aspirations and expenditures on education as predicted by theory. This inverse-U relationship is slightly stronger for girls than boys. In addition, we find that one's aspirations for income and children's education are associated with higher levels of observable wealth and children's education within her network, but uncorrelated with lower levels.

The paper proceeds as follows. In Sections 2 and 3 we discuss the relevant theoretical and empirical literature, presenting a theoretical model of aspirations failure (Section 2) and formation (Section 3) adapted from Genicot and Ray (2017). In Section 4 we describe the study setting and data. In Sections 5 and 6 we present our empirical approach and findings regarding aspirations failure and formation respectively. Section 7 concludes.

\section{Understanding aspirations failure}

Poor households often fail to make even small investments thought to have large returns in the long run, suggesting that they face constraints that prevent them from doing so. Many policies intended to increase investment among the poor focus on easing external constraints. Examples include programs and policies designed to increase savings through informal village banking systems such as ROSCAs (Besley et al., 1993), decrease transaction costs to access formal banking (Jack and Suri, 2011; Flory, 2012), improve information on the benefits of education (Nguyen, 2008; Jensen, 2010), and encourage investment in education using conditional cash transfer programs (Skoufias et al., 2001). However, despite the removal of external constraints through these kinds of programs, low levels of investment often persist.

Recent work recognizes that internal constraints, in addition to external ones, may hinder investment and other futureoriented behavior. A lack of the capacity to aspire and/or hope are examples of internal constraints identified as being critically important to investment and poverty dynamics. In a seminal contribution, anthropologist Arjun Appadurai (2004) argued that policies designed to strengthen the poor's capacity to aspire could "contest and alter the conditions of their poverty." Several recent theoretical papers explore such a relationship between aspirations, investment behavior, and poverty. Dalton et al. (2016), Genicot and Ray (2017), Bogliacino and Ortoleva (2013), and Lybbert and Wydick (in press) employ various assumptions as to how aspirations are formed and enter the utility function, yet all suggest low aspirations generate low levels of investment. In both Dalton et al. (2016) and Bogliacino and Ortoleva (2013), a critical "low" aspirations threshold exists above which investment grows with aspirations, and below which aspirations "fail" and optimal investment is low. Genicot and Ray (2017) also suggest that investment will be relatively low for low levels of aspirations, and subsequently grow with aspirations, but their model suggests a critical "high" aspirations threshold at which point aspirations also "fail" and investment plummets.

\footnotetext{
${ }^{1}$ According to Appadurai (2004), "Aspirations are never simply individual... They are always formed in interaction and in the thick of social life." Ray (2006) develops this concept further: "individual desires and standards of behavior are often defined by experience and observation; they don't exist in social isolation." Genicot and Ray (2017) demonstrate how socially driven aspirations influence inequality in society.
} 


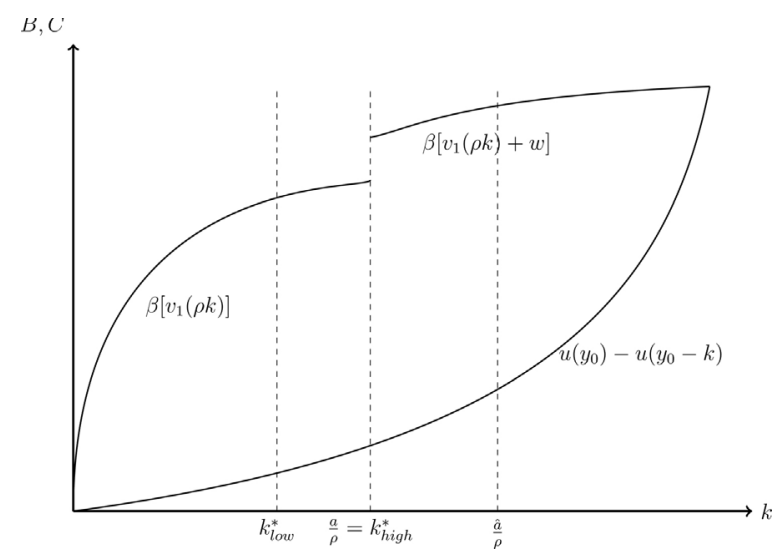

Fig. 1. Benefits and costs of investment with aspirations.

As explained in greater detail in the following section, the Genicot and Ray (2017) model predicts an inverse-U shaped relationship between aspirations and investment, a hypothesis that first appears in Appadurai (2004) and Ray (2006). In the next section we employ a version of the model presented in Genicot and Ray (2017), formalizing the intuition and providing necessary context for our empirical test of the aspirations failure theory. In Section 2.2 we review recent empirical literature related to the aspirations failure hypothesis.

\subsection{A model of aspirations failure}

To motivate our empirical analysis of aspirations failures, we employ the model presented in Genicot and Ray (2017) with minor adaptations. While their model is multi-generational, we suppose that an individual maximizes her own utility over two periods of her life, the present and the future. Starting with a wealth endowment of $y_{0}$, the individual can either consume $(c)$ or invest in the future $(k)$ so that $y_{0}=c+k$. She receives a return of $\rho$ on her investment so that she has income in the subsequent period $y_{1}=\rho k$.

The agent also has aspirations $a$, which for now are assumed to be exogenous. In the first period she derives utility only from consumption. In the second period she derives utility from income, and also from exceeding aspirations. This "bonus" utility from exceeding aspirations is written as w. Genicot and Ray (2017) treat $w$ as an increasing function of the amount by which aspirations are exceeded, starting at zero. We instead treat $w$ as a constant amount of utility gained if aspirations are met or exceeded, irrespective of by how much. We do this so that the marginal returns to consumption are not higher above the aspirations threshold than they are below, while maintaining a region of increasing marginal returns to investment where aspirations are met. In this way, our model is similar to models that treat aspirations as reference points using prospect theory (e.g., Bogliacino and Ortoleva, 2013). ${ }^{2}$

The agent maximizes the following 2-period utility function:

$$
u(c, k)=v_{0}(c)+\beta\left[v_{1}(\rho k)+w * I(\rho k \geq a)\right]
$$

where $\beta$ is a personal discount factor. We assume that $v_{0}$ and $v_{1}$ are smooth, increasing, and strictly concave.

When deciding how much to invest in the future, the agent compares the benefits and costs of investment. The costs of investment, in terms of forgone present consumption, are the same regardless of whether her aspirations are satisfied:

$$
C(k)=v_{0}\left(y_{0}\right)-v_{0}\left(y_{0}-k\right)
$$

Because $v_{0}^{\prime}(k)>0$ and $v_{0}^{\prime \prime}(k)<0$, it follows that $C^{\prime}(k)>0$ and $C^{\prime \prime}(k)>0$. To assess the benefits of investing, she must consider two scenarios: one where her aspirations are met (her aspirations are "satisfied", in the words of Genicot and Ray) and one where they are not (her aspirations are "frustrated"). This yields the following benefit function:

$$
B(k)= \begin{cases}\beta\left[v_{1}(\rho k)\right] & \text { if } \rho k<a(\text { frustrated) } \\ \beta\left[v_{1}(\rho k)+w\right] & \text { if } \rho k \geq a \text { (satisfied) }\end{cases}
$$

We depict the relationship between investment benefits and costs in Fig. 1. The individual will choose the level of investment $k^{*}$ that maximizes the net benefits of investment, $N B(k)=B(k)-C(k)$. As demonstrated in equation (3), there

\footnotetext{
2 The standard prospect theory model first established in Kahneman and Tversky (1979)) assumes a utility function that is convex up to the reference point. Following Genicot and Ray (2017) we do not assume convexity prior to the reference point, but unlike Genicot and Ray (2017) our model does accommodate loss aversion in the sense that there is a large jump in utility at the reference point. It can be shown that the key insights of the model hold if a more traditional prospect theory model such as the one presented in Bogliacino and Ortoleva (2013) were instead applied.
} 


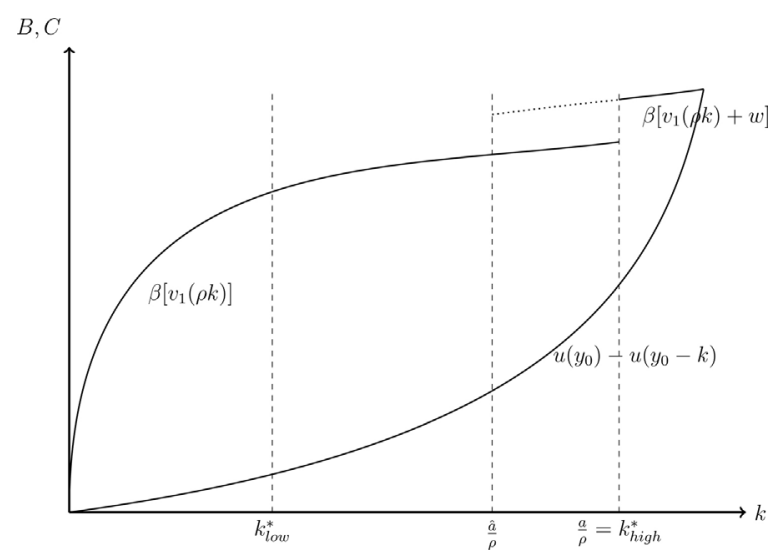

Fig. 2. Low investment when aspirations are above $\hat{a}$.

exists a discontinuity in $B(k)$, and therefore in $N B$, where $k=\frac{a}{\rho}$. This discontinuity yields two local solutions: $k_{l o w}^{*}$ maximizes $N B$ to the left of $\frac{a}{\rho}$ and $k_{\text {high }}^{*}$ maximizes $N B$ at or to the right of $\frac{a}{\rho}$. From $k_{\text {low }}^{*}$ and $k_{\text {high }}^{*}$, the individual selects $k^{*}$ to maximize net benefits. For simplicity of exposition, we limit our use of the model to cases where $\frac{\partial v_{1}}{\partial k} \geq \frac{\partial C}{\partial k} \mid k=\frac{a}{\rho}$, which is the region where aspirations are not exceeded by default. In this case, $k_{\text {high }}^{*}=\frac{\alpha}{\rho}>k_{\text {low }}^{*}$. For completeness, we examine the case where $\frac{\partial v_{1}}{\partial k}<\frac{\partial C}{\partial k} \mid k=\frac{a}{\rho}$ in Appendix A.

As indicated by Genicot and Ray (2017), there is some unique threshold level of aspirations $\hat{a}$, depicted in Figs. 1 and 2 , at which the individual is indifferent between selecting $k_{\text {high }}^{*}$ to satisfy her aspirations and selecting $k_{\text {low }}^{*}$ in frustration. If $a<\hat{a}, k_{\text {high }}^{*}$ is the optimal choice as in Fig. 1, and aspirations are satisfied. If $a>\hat{a}, k_{\text {low }}^{*}$ is the optimal choice as in Fig. 2, and aspirations are frustrated.

The relationship between $a, k_{l o w}^{*}, k_{h i g h}^{*}$, and $k^{*}$ is depicted in Fig. 3. When aspirations are very low they are easily satisfied by setting $k^{*}=k_{\text {high }}^{*}$ at levels not much higher than $k_{\text {low }}^{*}$. As aspirations increase, so does $k^{*}$ up until some threshold level $\hat{a}$. Beyond $\hat{a}$, the cost of achieving aspirations will outweigh the benefits and the individual will become frustrated, setting $k^{*}=k_{\text {low }}^{*}$. Recall that at $\hat{a}, N B\left(k_{\text {low }}^{*}\right)=N B\left(k_{\text {high }}^{*}\right)$, i.e., the individual is indifferent between satisfying her aspirations or not. This indifference holds if:

$$
\beta\left[v_{1}\left(\rho k_{\text {low }}^{*}\right)\right]+v_{0}\left(y_{0}-k_{\text {low }}^{*}\right)=\beta\left[v_{1}(\hat{a})+w\right]+v_{0}\left(y_{0}-\frac{\hat{a}}{\rho}\right) .
$$

From this equation it is clear that the behavioral threshold â depends on the agent's initial endowment, discount factor, the rate of return on investment, and individual characteristics that enter the utility function. Using the implicit function theorem, we find that $\frac{\partial \hat{a}}{\partial \beta}>0, \frac{\partial \hat{a}}{\partial y_{0}}>0$, and $\frac{\partial \hat{a}}{\partial \rho}>0$ (calculations in Appendix B). In other words, individuals who are more

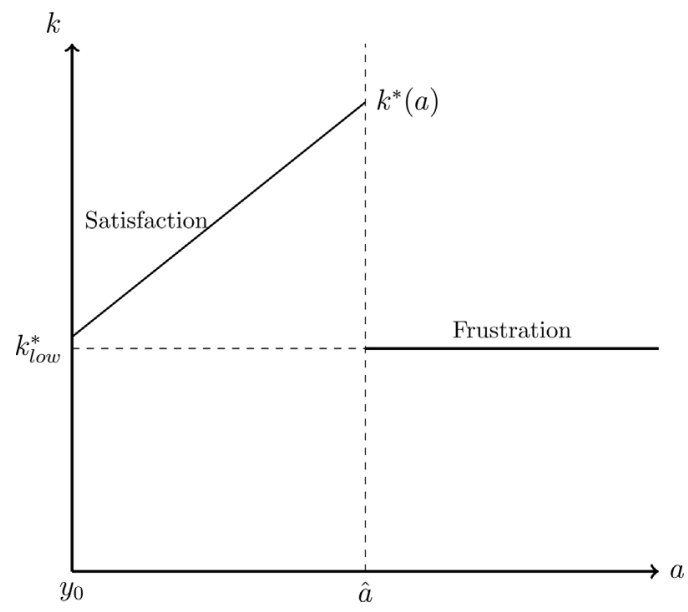

Fig. 3. Investment as a function of aspirations. 
patient, initially better off, and have a higher rate of return on investment are more likely to choose $k_{\text {high }}^{*}$ over $k_{\text {low }}^{*}$ for a given level of aspirations $a$.

Note that differences between individuals' levels for $\hat{a}$ are distinct from differences in aspirations. In Section 3 we will discuss how aspirations form. What is important here is the relationship between $a$ and $\hat{a}$ : If $a>\hat{a}$, the individual will invest $k_{l o w}^{*}$, and if $a<\hat{a}$ she will invest $k_{\text {high }}^{*}$ (at $a=\hat{a}$ she is indifferent). Empirically, if $\hat{a}$ were similar for each individual in the sample it might be possible to estimate the relationship depicted in Fig. 3. But because â depends on individual characteristics, this is unlikely to be the case. If â varies among individuals, empirical analysis is likely to yield something resembling an inverted-U relationship between aspirations and investment.

To understand why this is true, consider the following thought exercise: At any level of $\hat{a}$ some proportion of individuals exhibit $a<\hat{a}$ and invest $k_{\text {high }}^{*}$, and the rest exhibit $a>\hat{a}$ and invest $k_{\text {low }}^{*}$. As $a$ increases, more of the population will invest $k_{l o w}^{*}$, resulting in a downward sloping relationship between $a$ and $k$ but no precipitous drop. This will be true for both discrete and continuous measures of future oriented behavior.

We use a simple simulation exercise to demonstrate this point. For the exercise, we assume $k_{\text {high }}=a$ and $k_{\text {low }}=1$. To fix ideas, we first set $\hat{a}$ equal to 50 . Fig. $4 \mathrm{a}$ presents the investment policy function under these parameters for individuals with aspirations varying between 0 and 100 with a behavioral switching point at $\hat{a}=50$. In our first simulation, for each possible level of aspirations $a$, we consider a sample of 100 individuals with values of $a$ taken from a random normal distribution with a mean of 50 and a standard deviation of 25. In the second simulation, for each possible level of aspirations $a$, we consider a sample of 100 individuals with values of $\hat{a}$ randomly drawn from a uniform distribution from 0 to 100 . The aggregate relationships between aspirations and average (or expected) investment are presented in Fig. $4 \mathrm{~b}$ (normally distributed $\hat{a}$ ) and Fig. 4c (uniformly distributed $\hat{a}$ ). Regardless of our assumptions about the distribution of $\hat{a}$, theory predicts a clear inverse-U relationship between aspirations and average investment.

In earlier work, Ray (2006) supposes that it is not aspirations per se, but the difference between the aspired-to outcome and current status that matters for investment. This difference has been articulated as an "aspirations gap" (Ray, 2006) and an "aspirations ratio" (Genicot and Ray, 2017). The aspirations gap, $g$, is the percent difference between an individual's realized level or status of some outcome, $s$, and their aspired-to level, $a$; i.e. $g=\frac{a-s}{a}$. Because an individual should aspire to be at least as well off in the future as they are in the present, $g$ must be positive and between zero and one. In our empirical analysis that follows, we test for the hypothesized inverted-U shape between the aspirations gap and observed investment. ${ }^{3}$ Using the gap for empirical applications, as opposed to simply aspirations or the the difference between aspirations and current status, facilitates meaningful comparisons across individuals with different current status levels.

\subsection{Empirical evidence of aspirations failure}

Several recent papers suggest that future-oriented behavior can be improved by increasing aspirations. Macours and Vakis (2014) present evidence from a randomized cash transfer program suggesting that improved aspirations led to increased investment in Nicaragua. Laajaj (2017) describes a particular type of aspirations failure as the inability to think about a future of bleak prospects, resulting in a lack of investment. Using a randomized control trial, he shows that a positive shock in the form of agro-input subsidies lengthens poor farmers' planning horizons in Mozambique. Bernard et al. (2011) find evidence of aspirations failure in the fatalism exhibited by Ethiopian farmers, and show that this failure is correlated with negatively future-oriented economic behavior. Bernard et al. (2014) and (Lybbert and Wydick, 2016) find short inspirational documentary films increase aspirations, and in some instances increase investment, in Ethiopia and Mexico, respectively. Beaman et al. (2012) exploit a randomized policy experiment in India that reserved a certain number of village leadership roles for women to demonstrate how educational investment in girls increases when aspirations increase.

While these empirical analyses demonstrate the effectiveness of interventions designed to encourage future-oriented behavior by alleviating internal constraints, they are not designed to estimate the non-monotonic relationship between aspirations and investment described in the theoretical literature. Besides the analysis presented here, we are aware of only two working papers that explicitly test the hypothesized inverse-U hypothesis between aspirations and future-oriented behavior. Ross (2016) and Sierneels and Dercon (2014) both proceed from the same body of theoretical work that we consider here and examine a related set of outcomes: the relationship between parents' aspirations for children's education and educational attainment. Both papers provide some support for the inverse-U hypothesis between education aspirations and educational attainment.

Despite these similarities, this paper differs from those two papers in several important ways. First, we explore the links between aspirations and investment (which may lead to an outcome) and not aspirations and the outcome itself, resulting in a more direct test of the theory. Second, in addition to testing an investment response to the aspirations gap with respect to education, we offer further evidence of the inverted-U with respect to aspirations for income and corresponding

\footnotetext{
${ }^{3}$ The aspirations ratio, $r$, is the current level or status of the outcome divided by their aspirations; i.e. $r=\frac{s}{a}=1-g$. Fig. 3 can be easily altered to accommodate the inverse aspirations ratio $\left(r^{-1}\right)$ by dividing the values on both the $\mathrm{x}$-and $\mathrm{y}$-axis by $s$, such that the value on the $\mathrm{y}$-axis becomes percent of current level invested. Because $r^{-1}$ and $g$ move in the same direction with respect to $a$, we would expect to see the same relationship between $a$ and $k$ as we do between $r^{-1}$ and $k$, and similarly between $g$ and $k$.
} 


\section{(a) Individual}

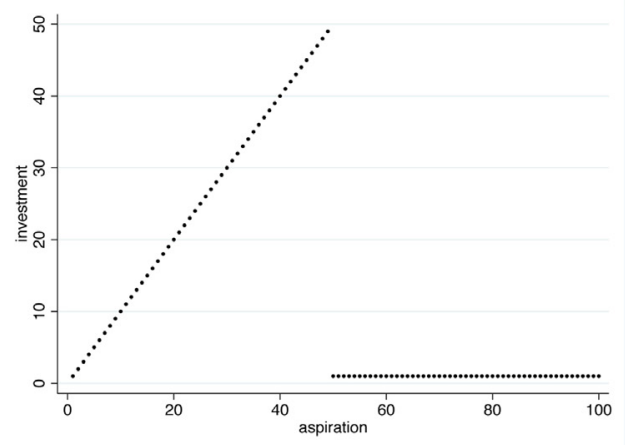

(b) Aggregate behavior (normal distribution)

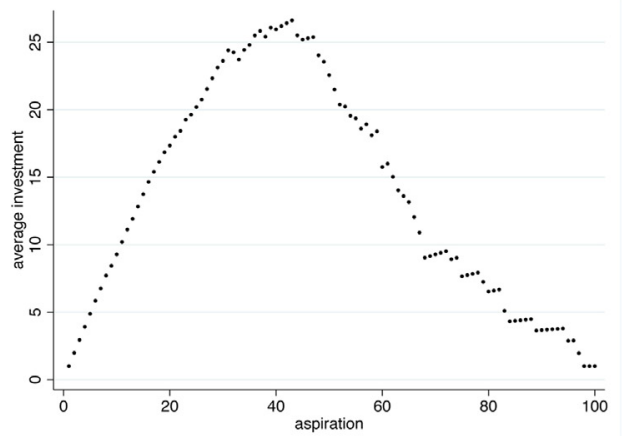

(c) Aggregate behavior (uniform distribution)

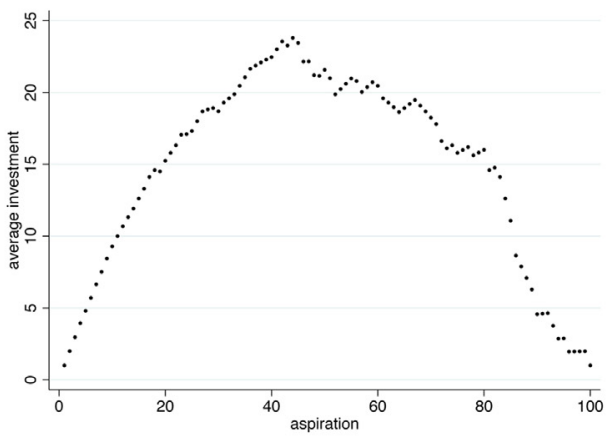

Fig. 4. Model Implications on Individual and Aggregate Behavior.

investments. Third, we offer a complimentary analysis of the social component for aspirations formation, which we develop in the following section.

\section{Understanding aspirations formation}

In his seminal work, Ray (2006), suggests that people "draw [their] aspirations from the lives, achievements, and ideals of those who exist in [their] aspirations window." In other words, an individual's aspirations are formed socially. ${ }^{4}$ In particular, Ray posits that it is the "similar" or "attainable" people who exist in an individual's "cognitive neighborhood" that frame one's aspirations.

${ }^{4}$ The theoretical model presented by Dalton et al. (2016) focuses on the internal drivers of aspirations, but represents an exception in the theoretical literature which more often considers external forces. 
If aspirations are formed externally or socially, then aspiration-based spillovers of development interventions may influence non-beneficiary investment (either positively or negatively) through aspirational channels. Some evidence of positive spillovers exists. Bernard and Taffesse (2014) find that showing aspirational videos (depicting a pathway to a better future) to Ethiopian farmers increased investment in education not only for those who viewed the videos, but also for peers in their social network..$^{5}$ Macours and Vakis (2014) find that the impact of receiving a productive investment package is stronger, in terms of positive attitudes and happiness, when community leaders also receive the package. They conclude that having a village leader receive the package improves other recipients' capacity to inspire. These studies provide evidence that aspirations are, at least in part, formed from external influences.

The literature on subjective well-being also contains substantial evidence that aspirations are socially influenced. Several papers examining the importance of relative status to happiness demonstrate a social aspect of aspirations formation. Stutzer (2004) finds that average community income increases individuals' income aspirations in Switzerland, and that these heightened aspirations decrease happiness. In a similar study, Knight and Gunatilaka (2012) find that in rural China, income aspirations are pushed upward by both own current income and reference group income. Neither of these papers directly capture income aspirations, but proxy for them using the minimum income level on which the respondent deems adequate to get by. While not explicitly dealing with aspirations, Ferrer-i-Carbonell (2005) finds subjective well-being decreases with reference group income in Germany, and Fafchamps and Shilpi (2008) find that the probability individuals considers their own household consumption adequate decreases with the total consumption of households in their reference group in Nepal.

The papers mentioned in the previous paragraph all assume that aspirations are a combination of internal factors (the individual's current status and past experience) and external ones (the status of people in their reference group). Accordingly, Genicot and Ray (2017) suggest that aspirations formation can be modeled as:

$$
a=(1-\gamma) y_{0}+\gamma \Psi\left(y_{0}, F\right)
$$

In Eq. (5), $\gamma$ is the weight one places on their position relative to others, $F$ represents the distribution of the outcome within their reference group, and $\Psi$ is a function by which an individual's position in the reference distribution affects their aspirations. The composition of an individual's reference group is an empirical question, and may depend heavily on context. Most of the papers mentioned at the beginning of this section assume the reference group was determined at least in part geographically. Ferrer-i-Carbonell (2005) use people of similar age and education level living in the same region. Knight and Gunatilaka (2012) and Fafchamps and Shilpi (2008) use the village as the reference group. In a second empirical model, Fafchamps and Shilpi (2008) use the district of birth as the reference group for migrants. In this paper we test reference groups based on geography (neighborhood) and social network as defined by the individual.

The specification in Eq. (5) is agnostic with respect to how $F$ and $y_{0}$ enter the aspirations formation function $\Psi$, and Genicot and Ray (2017) put forth three possibilities. First, the social component of an individual's aspirations for an outcome could simply be the maximum level of that outcome in her reference group. Second, it could be the average level of the outcome in her reference group. This has been the most common assumption in the existing empirical literature (Fafchamps and Shilpi, 2008; Knight and Gunatilaka, 2012; Stutzer, 2004). Third, it could be the average outcome of individuals in her reference group with a higher level of the outcome. This possibility is based on the Deusenberry (1949) hypothesis, and has been demonstrated empirically by Ferrer-i-Carbonell (2005). In the empirical section of this paper, we test a model that is flexible enough to allow for either the second or third possibility.

\section{Context and data}

Aspirations failure and formation have mostly evaded empirical analysis for two reasons: First, aspirations are not easily observable, difficult to measure, and rarely captured in household surveys. Second, using reference groups based on observable data such as geography or religion may present a very rough representation of social connectivity. Social network data can provide a more accurate representation, but is seldom collected in standard surveys. This paper takes advantage of a unique household dataset that includes respondents' aspirations and detailed social networks data. In the following subsection we describe the study setting and the overall survey instrument. Because the aspirations data and social networks data are both critical and unique to our analysis, we describe both in greater detail in sections 4.2 and 4.3 respectively.

\subsection{Data from rural Nepal}

Between June and September 2014 we collected data from nearly 3300 rural women eligible to participate in an asset transfer program across three regions of Nepal. ${ }^{6}$ Nepal is the poorest country in South Asia and the 13th poorest country in the world. Nepal has made significant strides towards poverty alleviation in recent years, yet poverty persists, especially

\footnotetext{
5 Bernard et al.(2014) find increases in aspirations among viewers but not their peers, potentially suggesting the indirect effects may be due to non-viewers following the behavior of their peers who watched the videos rather than having their own aspirations improved.

${ }^{6}$ In addition to serving as the dataset used in this paper, the data serves as baseline data for an impact evaluation of the asset transfer program.
} 
in the countryside; 55 percent of Nepalese survive on less than $\$ 1.25$ a day, and that number climbs sharply in the rural mountain and hill districts where more than 70 percent of people rely on agriculture for their livelihoods (USAID, 2013).

There are several reasons why a focus on women's aspirations in Nepal is important. The condition of women, and their empowerment relative to men, is a development priority, as evidenced by the third Millennium Development Goal and more recently, the World Bank 2012 World Development Report (World Bank, 2011). Recent studies from Nepal demonstrate that greater female control over income (Malapit et al., 2015) and assets (Allendorf, 2007) is correlated with better maternal and child nutrition in Nepal.

Data used for this study are from the baseline survey of an RCT conducted in conjunction with an NGO. Because the survey was conducted prior to any intervention associated with the RCT, it can largely be ignored here. However, the stratified sampling required for the RCT has implications for the dataset, particularly the social network data. The sample includes 45 treatment village development committees (VDCs) and 15 control VDCs spread across 7 districts. ${ }^{7}$ In treatment and control VDCs we sampled 20-25 women selected by the NGO to potentially receive benefits as part of the RCT. These women were selected based on geography only. Essentially, the NGO identified all women living in a neighborhood (called a tole) within a ward, and all of these women $(N=945)$ were included in the sample. In addition, we randomly sampled 15 women living in the same ward outside the targeted tole. In treatment wards only, we randomly selected an additional 10 women each from two other wards in the same VDC. Our full sample size is therefore 3280 women.

Data collection took place in two phases. First, a team administered an extensive household survey including questions about income, asset ownership and control, financial decisions, education, health and nutrition, food security, women's empowerment, and aspirations. In what follows, income is yearly individual income, as reported by the respondent. Asset value is the total value of land and housing belonging to the household. ${ }^{8}$ At this first interview, enumerators took photographs of respondents to be compiled into community photo directories containing all sampled individuals within a VDC.

In the second phase of data collection, these photo directories were used to collect social networks data for all women in targeted treatment wards, including those inside and outside the targeted targeted tole. In the analysis involving social networks data, we only consider women residing in targeted toles for two reasons. First, connectivity is highest within these groups; 21 percent of possible connections are realized links where individual $i$ and individual $j$ both claim each other, whereas only five percent of possible connections are realized links if one or both women reside outside the targeted tole. Second, we sampled 100 percent of women in these toles. As a result, the probability that a link within the tole is observed in our sample is one, whereas it is considerably lower for links beyond the targeted tole. This holds for links between women $i$ residing within the targeted tole and women $j$ outside the targeted tole, as well as for links between women $i$ outside the targeted tole to women $j$ outside the targeted tole. In other words, for each observed link to a woman outside the targeted tole, individual $i$ likely has several others not captured in the data. Limiting the sample to the 45 targeted toles thus yields a complete social network within these toles and a total network sample size of 944 women.

Table 1 contains descriptive statistics for the full sample and the subsample for whom we have network data. The table is organized into three panels: (A) basic demographic and economic variables, (B) investment behavior, and (C) aspirations. Mean respondent age is approximately 40 years. On average respondents had 2.76 years of formal education, but median years of education is zero. The women chosen for the study are generally poor (although some are considerably better off than others). Average personal yearly income was around 60,000 NPR (approximately 600 USD) ${ }^{9}$ and respondents estimated their household land and home to be worth 1.4 million NPR, but there is substantial variance. Note that this data was collected one year prior to a devastating earthquake that destroyed the homes and assets of many of the households in our sample. Economic migration to urban areas and foreign countries (typically Gulf states) is very common in Nepal. In our sample, 60 percent of households had an outgoing migrant.

Unfortunately, the survey did not directly capture investment. We use savings behavior, spending on temptation goods, and annual education-related expenditures as indicators of future-oriented behavior and investment. To measure savings, we consider whether the respondent is in a savings group, whether she or any member of the household put any money into savings in the prior month, and how much the household saved in the previous month. Notice that income data is available for the individual, while savings behavior - excluding membership in a savings group - was collected at the household level. Savings for future expenditures and/or investment is quite common: 42 percent of respondents are in a savings group, which exist in nearly every VDC in rural Nepal, and 54 percent of households saved at least some money in the month leading up to the survey. On average, the amount saved was 1,500 NPR (15 USD). Only 23 percent of respondents indicate they have any input into how much money is put into savings, something we will control for in the analysis to follow. Despite having very little education themselves, women in the sample invest substantially in their children's education. On average, women with at least one child under the age of 15 spent 9,000 NPR (90 USD) per child in the year before the survey.

An alternative to investment is to spend money on non-productive temptation goods. We use expenditures on tobacco, cigarettes and alcohol as an alternative non-investment good. Approximately 60 percent of households in our sample

\footnotetext{
7 There are 75 districts in Nepal, each containing on average 42 VDCs. Each VDC is a cluster of 9 wards, and wards contain 100 households on average (although this varies considerably).

${ }^{8}$ While pre-testing the survey, this was determined to be the most important indicator of a household's asset base.

${ }_{9}$ At the time of the study the exchange rate was roughly 100 NPR to 1 USD.
} 
Table 1

Sample descriptive statistics

\begin{tabular}{|c|c|c|}
\hline Variable & Full sample & Network sample \\
\hline & $(\mathrm{N}=3280)$ & $(\mathrm{N}=944)$ \\
\hline \multicolumn{3}{|l|}{ Panel A: Basic characteristics. } \\
\hline \multirow[t]{2}{*}{ Age } & 40.53 & 40.41 \\
\hline & $(13.98)$ & $(14.02)$ \\
\hline \multirow[t]{2}{*}{ Years of education } & 2.76 & 2.76 \\
\hline & $(4.35)$ & $(4.35)$ \\
\hline \multirow[t]{2}{*}{ Max child's years of education } & 7.19 & 7.18 \\
\hline & $(4.35)$ & $(4.27)$ \\
\hline \multirow[t]{2}{*}{ Max boy's years of education } & 5.99 & 6.03 \\
\hline & $(4.72)$ & $(4.66)$ \\
\hline \multirow[t]{2}{*}{ Max girl's years of education } & 3.79 & 3.63 \\
\hline & $(4.28)$ & $(4.13)$ \\
\hline \multirow[t]{2}{*}{ Current personal income (NPR/year) } & 59,689 & 66,043 \\
\hline & $(189,398)$ & $(264,186)$ \\
\hline \multirow[t]{2}{*}{ Respondent reports no income } & 0.32 & 0.31 \\
\hline & $(0.47)$ & $(0.46)$ \\
\hline \multirow[t]{2}{*}{ Current value of household land and home (NPR) } & $1,410,821$ & 985,453 \\
\hline & $(6,079,916)$ & $(2,923,084)$ \\
\hline \multirow[t]{2}{*}{ Household has a migrant } & 0.62 & 0.62 \\
\hline & $(0.49)$ & $(0.48)$ \\
\hline \multicolumn{3}{|l|}{ Panel B: Saving and investment } \\
\hline \multirow[t]{2}{*}{ Respondent controls savings } & 0.24 & 0.24 \\
\hline & $(0.42)$ & $(0.42)$ \\
\hline \multirow[t]{2}{*}{ Membership in a savings group } & 0.42 & 0.44 \\
\hline & $(0.49)$ & $(0.50)$ \\
\hline \multirow[t]{2}{*}{ Saved money last month } & 0.54 & 0.57 \\
\hline & $(0.50)$ & $(0.50)$ \\
\hline \multirow[t]{2}{*}{ Amount saved last month (NPR) } & 1,536 & 1,494 \\
\hline & $(30,781)$ & $(26,335)$ \\
\hline \multirow[t]{2}{*}{ Temptation goods spending last month (NPR) } & 878 & 861 \\
\hline & $(2,641)$ & $(2,087)$ \\
\hline \multirow[t]{2}{*}{ Any education spending } & 0.83 & 0.83 \\
\hline & $(0.38)$ & $(0.38)$ \\
\hline \multirow[t]{2}{*}{ Education spending last year (NPR) } & 21,145 & 17,151 \\
\hline & $(68,845)$ & $(34,600)$ \\
\hline \multicolumn{3}{|l|}{ Panel C: Aspirations } \\
\hline \multirow[t]{2}{*}{ Aspired personal income (NPR/year) } & 153,064 & 129,005 \\
\hline & $(1,043,751)$ & $(507,166)$ \\
\hline \multirow[t]{2}{*}{ Aspired land and home value (NPR) } & $3,185,397$ & $2,755,110$ \\
\hline & $(16,813,091)$ & $(19,487,914)$ \\
\hline \multirow[t]{2}{*}{ Aspired years of education for children } & 14.05 & 13.73 \\
\hline & $(3.85)$ & $(4.06)$ \\
\hline \multirow[t]{2}{*}{ Aspired years of education for boys } & 14.07 & 13.78 \\
\hline & $(4.13)$ & $(4.43)$ \\
\hline \multirow[t]{2}{*}{ Aspired years of education for girls } & 13.47 & 13.14 \\
\hline & (4.39) & $(4.66)$ \\
\hline
\end{tabular}

Standard deviations in parentheses. 100 NPR equals approximately 1 USD.

purchased some tobacco, cigarettes and/or alcohol in the month prior to being surveyed. Average monthly expenditures in this category is approximately 900 NPR (9 USD).

\subsection{Measuring aspirations}

As noted by Bernard and Taffesse (2014), economists have recently measured aspirations using mostly ad-hoc indicators, with little consistency across studies. Stutzer (2004) and Knight and Gunatilaka (2012) use the minimum level of income a respondent said would be adequate to proxy for aspirations. While this indicator is in the money metric, it does not capture the outer bound of what someone thinks is possible. Other studies use attitudes about the future thought to be linked to aspirations: Macours and Vakis (2014) use a depression scale; Bernard et al. (2011) use two simple measures of locus of control and self-efficacy based on Rotter (1966); and Laajaj (2017) uses planning horizon for future expenditures.

Each of the proxy variables used in the above studies are distinct from aspirations in the model presented in section 2. Beaman et al. (2012) consider an arguably more direct approach toward measuring aspirations by asking parents about the desired educational attainment for their children, desired age of marriage for children, preferred occupation of children at the age of 25, and whether the parent wished for a female child to become a village leader. Building on this more direct approach, Bernard and Taffesse (2014) propose a novel instrument constructed by asking directly about aspirations across multiple dimensions, where each dimension is given a weight by the respondent so an aggregate index can be created. 
Our analysis uses two components of the Bernard and Taffesse (2014) aspirations index: aspirations over personal income and children's education. We also collected data on the third and fourth components employed in the Bernard and Taffesse (2014) index - wealth and social status - but do not employ them here. We use income aspirations rather than asset aspirations because we believe income is a better measure of financially-related aspirations. ${ }^{10}$ While we could construct and use the composite index itself, the decision to use aspirational dimensions rather than an aggregate index reflects our desire to explicitly test the theoretical model presented in Sections 2 and 3. First, we are testing a hypothesis linking aspirations in a specific dimension to investment outcomes in that same dimension. There are clear investment-related behaviors linked to income and education aspirations, whereas for status aspirations, there is no direct way to observe investment in status. Second, we expect the formation of aspirations to vary across dimensions.

For both income and education aspirations, we ask four questions. Following Manski's (2004) suggestions for measuring expectations, the first two questions are intended to help respondents delineate a realistic range before stating their own current status and their aspirations. The third question records the personal status for that dimension. The fourth question is interpreted as the individual's aspiration.

Following Bernard and Taffesse (2014), the questions related to income aspirations are: (1) "What is the maximum level of income that a person in your community might expect to earn in a year?" (2) "What is the minimum level of income that a person in your community might expect to earn in a year?" (3) "What is your present personal level of income?" and (4) "What level of yearly income do you personally think you might be able to achieve in the future?" Aspirations for children's education are measured similarly, replacing income with "level of education for your children" so the fourth question eliciting aspirations becomes, "What level of education would you like your children to achieve?" Notice that this question asks generally about all children. If the respondent has different aspirations for different children, it is up to the respondent to interpret and answer the question however they deem suitable. In particular, we might expect aspirations to differ by gender of the child. For this reason the survey also asked about aspirations separately for boys and girls. Rather than ask about children's current education level (which is child-specific and depends on the age of children in the household), the module asked about the education of the respondent in the third question of the series.

One concern is that our measurement of aspirations is potentially conditioned by agency or self efficacy, which are closely related to expectations. The difference between aspirations and expectations is nuanced. An aspiration is defined as, "a hope or ambition to achieve something," whereas an expectation is defined as, "a strong belief that something will happen or be the case" (Oxford English Dictionary, 2016). The questions we use to capture aspirations, based on Bernard and Taffesse (2014) and adapted to the local context, are written to capture the outer edge of what is possible, rather than the most likely outcome. The choice of wording resulted from extensive discussion with the Nepali enumeration team. In Ethiopia, Bernard and Taffesse (2014) use the term "wish," as in "what level of income do you wish to achieve?" In Nepali, the words for "wish" or "hope" are quite strong. Our understanding is that even the simple phrase "like to" evokes a tendency to think wishfully and even completely unrealistically - about money. We determined that this wording was too strong in Nepali and would yield unrealistic figures. Instead, for income and asset aspirations, we ask what the woman might be able to achieve. Unlike amounts of money, the level of education children can achieve is inherently bounded, so we were advised by the Nepali enumeration team to ask what the woman would like her children to achieve.

The responses to these questions suggest respondents were stating their aspired outcomes rather than their expected ones, as they were much higher than their current levels. On average, respondents aspired for a yearly personal income of approximately 150,000 NPR (1500 USD) or 2.5 times their current income. Similarly, respondents aspired for wealth equal to approximately 3 million NPR (30,000 USD), twice the current value of home and landholdings. While few women in our sample have any formal schooling, the average aspired education for their children is much higher than their own educational experience (Table 1, panel C). Among women with a child under the age of 15 irrespective of whether the child is enrolled currently, mean aspired education for children generally is 14 years, and 90 percent of women aspired to at least 10 years of education for their children. Aspirations are lower on average by about half a school year (13.4) for girls than they are for boys (14).

Fig. 5a and c plot the distribution of income aspirations (top coded at the 98th percentile) and education aspirations. Fig. 5a demonstrates particularly high variance, even after top coding. The aspirations gap, i.e. aspirations relative to current status $\left(g=\frac{a-s}{a}\right)$, is a useful concept empirically because it limits the range of possible values and allows for more meaningful comparisons across individuals. Note that $g$ will be one if a household has zero income and any nonzero level of aspirations. In order to avoid this mechanical relationship and distinguish someone with $s=0$ and high aspirations from someone with $s=0$ and low aspirations, we convert zero entries for $s$ and $a$ to one prior to constructing the gap. After making this transformation, Fig. $5 \mathrm{~b}$ and $\mathrm{d}$ plot the distribution of the income aspirations gap and the education aspirations gap.

\footnotetext{
${ }^{10}$ Essentially, the asset measure requires a more complicated internal calculation involving a stream of income and decisions regarding savings and expenditures. Furthermore, asset aspirations are defined as the "value of home and land," which is an incomplete measure of total assets or wealth. Our results are qualitatively similar using either measure, although employing asset aspirations results in substantially less precision.
} 
(a) Income aspirations

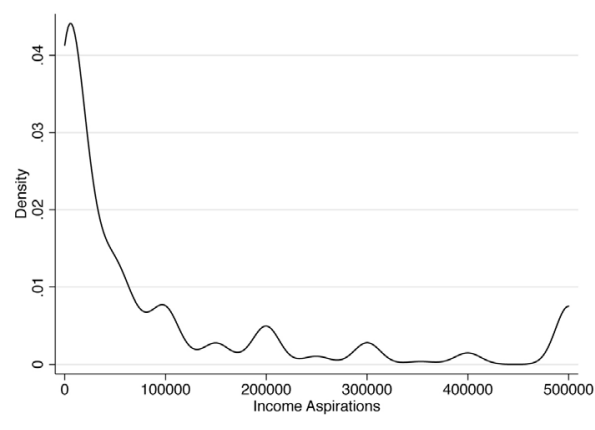

(c) Education aspirations

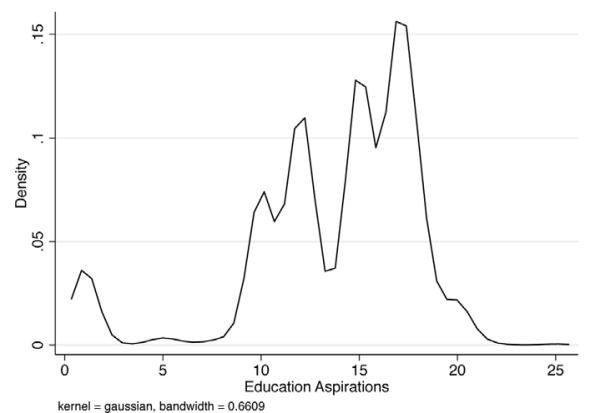

(b) Income aspirations gap

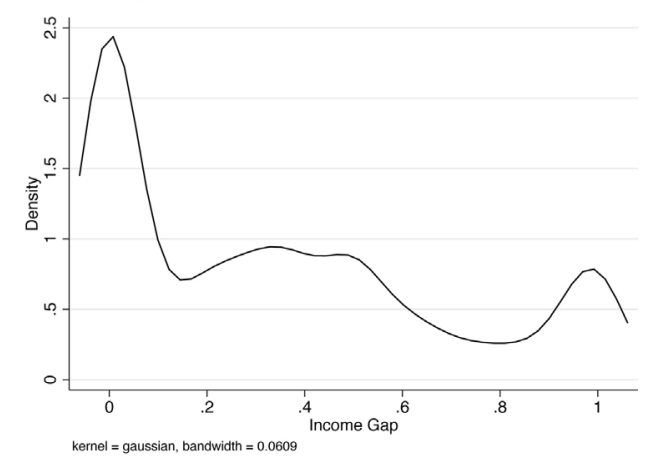

(d) Education aspirations gap

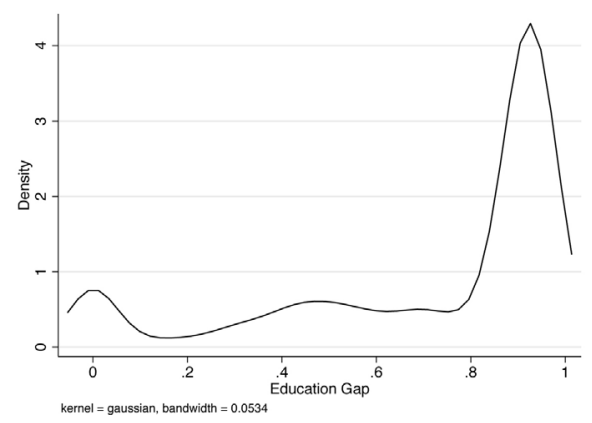

Fig. 5. Distributions of aspirations and aspirations gaps.

\subsection{Constructing the aspirations window}

In Section 3 we discussed possibilities for how the status of others in one's reference group, the aspirations "window," guide aspirations formation. Defining the relevant reference group is challenging, particularly if that reference group is not determined by easily observable characteristics like geography, religion or caste. We first consider a reference group for which data is typically available: all residents within a certain geographical boundary. Specifically, we consider all women residing within the same tole, which is like a neighborhood. We then define the reference group using social network data within the tole.

In the past decade or so, a host of studies have used detailed social network data to examine the role of peercommunication on technology diffusion (Bandiera and Rasul, 2006; Banerjee et al., 2013; Conley and Udry, 2010, and others), and in at least one case to study spillover effects of an intervention targeting aspirations (Bernard et al., 2014). We capture social linkages by showing respondents a community photo directory, and asking each respondent to identify any individuals whom she knows, and then specify the relationship; i.e., whether each known individual is a close family member, a relative, a neighbor, a friend, an acquaintance, or a familiar face. For our analysis we ignore links identified as an "acquaintance" or a "familiar face."

A common issue with dyadic network data is misreporting and/or asymmetrical reporting where individual $i$ claims individual $j$ as a network link, but $j$ does not claim $i$ (Comola and Fafchamps, 2014, 2017). For this study, we are particularly concerned with individuals citing those they aspire to be linked to rather than those they are actually linked to, as these aspirational links may be related to their aspirations for income and children's education. We therefore consider individuals $i$ and $j$ to be linked only if each cites the other as a link. ${ }^{11}$ Individual $i$ 's social network is thus composed of all individuals within the targeted tole whom $i$ knows and claim to know $i$ reciprocally.

Once the relevant reference group has been defined, the aspirations window captures the distribution of observable outcomes within it. Because the relevant observable outcomes are likely to vary across aspirational dimensions, the window will be defined separately for each dimension. For income aspirations, we consider the income of others in the potential window. For education aspirations, we consider the education attained by others' children. Selecting a single variable to define children's education outcomes for a household with multiple children is complicated, especially when most children

\footnotetext{
${ }^{11}$ We require $i$ and $j$ to each cite the other as any type of link under consideration (family, relative, friend, or neighbor); we do not require them to claim the same type of link as there may be considerable overlap among link types.
} 
Descriptive statistics on potential aspirations window variables

\begin{tabular}{|c|c|c|c|}
\hline Variable & Same tole & Links & Ex links \\
\hline \multicolumn{4}{|l|}{ Panel A: Income window for all women, $N=944$} \\
\hline \multirow[t]{2}{*}{ Average income in window (NPR) } & 65,762 & 67,843 & 65,176 \\
\hline & $(105,954)$ & $(203,771)$ & $(223,806)$ \\
\hline \multirow[t]{2}{*}{ Average income above (NPR) } & 184,750 & 139,958 & 118,273 \\
\hline & $(425,269)$ & $(425,503)$ & $(343,722)$ \\
\hline \multirow[t]{2}{*}{ Average income below (NPR) } & 12,809 & 25,427 & 29,903 \\
\hline & $(26,311)$ & $(116,419)$ & $(155,205)$ \\
\hline \multicolumn{4}{|c|}{ Panel B: Children's education window (child 15 years old or younger), $N=731$} \\
\hline \multirow[t]{2}{*}{ Average max years child's education in window } & 7.07 & 7.05 & 7.01 \\
\hline & $(1.94)$ & $(3.27)$ & $(3.51)$ \\
\hline \multirow[t]{2}{*}{ Average max children's education above } & 10.38 & 9.22 & 8.90 \\
\hline & $(2.60)$ & $(3.42)$ & $(3.60)$ \\
\hline \multirow[t]{2}{*}{ Average max children's below } & 3.53 & 4.54 & 4.71 \\
\hline & $(2.68)$ & $(3.56)$ & (3.67) \\
\hline
\end{tabular}

Standard deviations in parentheses. 100 NPR equals approximately 1 USD.

have not yet finished their schooling. Since aspirations are forward-looking, we consider the maximum level of education attained by any child in each reference household, whether or not schooling is complete.

Finally, we define the window for each possible reference group using two separate components: the (mean) level of outcomes in one's reference group that are higher than one's own status, and the (mean) level of outcomes in one's reference group that are lower. Following Ferrer-i-Carbonell (2005), this disaggregation accommodates estimation of "upwardlooking" aspirations as hypothesized by Deusenberry (1949). For ease of exposition, we refer to a woman with a higher income (or higher education achievement by children) as being "above," and a woman with the same or lower income (or lower educational achievement by children) as "below." If individual $i$ does not have anyone in her reference group above/below her, that value is replaced with her own current level of the outcome.

Table 2 presents descriptive statistics of the aspirations windows using the various reference groups. Average annual income in the reference groups is near the sample average of 65,000 NPR (650 USD) shown in Table 1. Average income among those above is between 118,000-184,000 NPR (1180 USD-1840 USD); the average asset value for those below is between 13,000-29,000 NPR (130 - 290 USD). For education aspirations windows, we limit the sample to women with at least one child age 15 or under. Likewise, in the gender-disaggregated analysis, we limit the sample to women with a son (daughter) age 15 or under. For households with at least one child age 15 or under, the highest level of education attained by any child in the household, whether or not they have completed their schooling, is seven years on average. The average maximum education level obtained by any child is approximately 10 years for those above and between four years for those below.

\section{Aspirations failure in Nepal}

In this section we empirically test for the theoretical relationship described in Section 2 . We first describe our empirical approach in Section 5.1. We then present evidence of an inverse-U relationship between income aspirations and futureoriented savings and investment behavior (Section 5.2), and between educational aspirations and educational expenditures (Section 5.3).

\subsection{Testing for aspirations failure}

The theoretical model developed in Section 2.1 predicts an inverse-U relationship between aspirations and investment. In the analysis that follows we consider two approaches to test for this non-monotonic relationship across two different aspirational dimensions: income and education. For each dimension we estimate the following linear regression model of investment on the aspirations gap, $g$, for individual $i$ from $\operatorname{VDC} v$, where $g$ enters the right hand side of the equation as a quadratic term:

$$
k_{i v}=\alpha+\beta_{1} g_{i v}+\beta_{2} g_{i v}^{2}+\beta_{3} s_{i v}+\beta_{4} d_{i v}+\boldsymbol{x}_{\boldsymbol{i v}}^{\prime} \boldsymbol{\delta}+v_{v}+\varepsilon_{i v} .
$$

Current status $s$ is a component of the aspirations gap, yet it is essential to control for $s$ on its own for two reasons. First, current status is likely to be correlated with future-oriented behavior through non-aspirational channels (when you have more or earn more you can save more). Second, the behavioral switching point $\hat{a}$, which determines at what point the aspirations gap becomes large enough to cause aspirations failure, is increasing in one's current status.

We also control for $d$, a dummy variable equal to one if the individual's current status (before converting zeros to ones) for a given dimension is zero. This is important because of the way the gap is constructed. Even though we convert zeros to ones for anyone with $s=0$, households with zero current status are clustered at either one end of the aspirations gap spectrum or the other. Specifically, those with zero aspirations and zero current status have $g=0$ and those with non-zero 
Table 3

Relationship between income aspirations gaps and financial decisions.

\begin{tabular}{|c|c|c|c|c|}
\hline & $\begin{array}{l}\text { (1) } \\
\text { Savings group }\end{array}$ & $\begin{array}{l}\text { (2) } \\
\text { Saved last month }\end{array}$ & $\begin{array}{l}\text { (3) } \\
\text { Amt Saved }\end{array}$ & $\begin{array}{l}(4) \\
\text { Amt Temp Spending }\end{array}$ \\
\hline Income aspirations gap & $\begin{array}{l}0.33^{* *} \\
(0.13)\end{array}$ & $\begin{array}{l}0.26^{* *} \\
(0.10)\end{array}$ & $\begin{array}{l}1.28^{* *} \\
(0.60)\end{array}$ & $\begin{array}{l}-0.11 \\
(0.68)\end{array}$ \\
\hline Income gap squared & $\begin{array}{l}-0.34^{* *} \\
(0.13)\end{array}$ & $\begin{array}{l}-0.25^{* *} \\
(0.11)\end{array}$ & $\begin{array}{l}-1.16^{*} \\
(0.63)\end{array}$ & $\begin{array}{l}0.20 \\
(0.73)\end{array}$ \\
\hline Zero income & $\begin{array}{l}0.18^{* *} \\
(0.088)\end{array}$ & $\begin{array}{l}0.054 \\
(0.081)\end{array}$ & $\begin{array}{l}0.98^{* *} \\
(0.45)\end{array}$ & $\begin{array}{l}0.22 \\
(0.60)\end{array}$ \\
\hline Current monthly income & $\begin{array}{l}0.028^{* * * *} \\
(0.0085)\end{array}$ & $\begin{array}{l}0.015^{*} \\
(0.0077)\end{array}$ & $\begin{array}{l}0.16^{*+*} \\
(0.045)\end{array}$ & $\begin{array}{l}0.00014 \\
(0.059)\end{array}$ \\
\hline Years of education (respondent) & $\begin{array}{l}0.0063^{* *} \\
(0.0027)\end{array}$ & $\begin{array}{l}0.0036 \\
(0.0027)\end{array}$ & $\begin{array}{l}0.051^{* * *} \\
(0.016)\end{array}$ & $\begin{array}{l}-0.11^{* * * *} \\
(0.020)\end{array}$ \\
\hline Age (respondent) & $\begin{array}{l}-0.0012^{*} \\
(0.00070)\end{array}$ & $\begin{array}{l}-0.0030 \\
(0.00080)\end{array}$ & $\begin{array}{l}-0.017^{* * *} \\
(0.0043)\end{array}$ & $\begin{array}{l}-0.010^{\circ} \\
(0.0058)\end{array}$ \\
\hline Household has a migrant & $\begin{array}{l}0.051^{* * *} \\
(0.019)\end{array}$ & $\begin{array}{l}0.045^{* *} \\
(0.017)\end{array}$ & $\begin{array}{l}0.31^{* * *} \\
(0.093)\end{array}$ & $\begin{array}{l}-0.33^{* *} \\
(0.13)\end{array}$ \\
\hline Respondent controls savings & $\begin{array}{l}0.049 \\
(0.034)\end{array}$ & $\begin{array}{l}0.15^{*+*} \\
(0.031)\end{array}$ & $\begin{array}{l}0.99^{* * *} \\
(0.17)\end{array}$ & $\begin{array}{l}0.25 \\
(0.16)\end{array}$ \\
\hline Constant & $\begin{array}{l}0.23^{* *} \\
(0.088)\end{array}$ & $\begin{array}{l}0.47^{+* * *} \\
(0.092)\end{array}$ & $\begin{array}{l}0.82 \\
(0.51)\end{array}$ & $\begin{array}{l}3.83^{* * *} \\
(0.67)\end{array}$ \\
\hline $\begin{array}{l}\text { Observations } \\
R^{2}\end{array}$ & $\begin{array}{l}3277 \\
0.127\end{array}$ & $\begin{array}{l}3277 \\
0.159\end{array}$ & $\begin{array}{l}3277 \\
0.195\end{array}$ & $\begin{array}{l}3277 \\
0.099\end{array}$ \\
\hline U-test Results: & & & & \\
\hline Turning Point & 0.498 & 0.522 & 0.552 & 0.269 \\
\hline Fieller 95\% Confidence Interval & {$[0.40,0.72]$} & {$[0.40,0.94]$} & {$[-\infty,+\infty]$} & {$[-\infty,+\infty]$} \\
\hline Sasabuchi $p$-value & 0.013 & 0.023 & 0.066 & 0.437 \\
\hline Slope at Min & 0.335 & 0.258 & 1.283 & -0.108 \\
\hline Slope at Max & -0.337 & -0.236 & -1.042 & 0.295 \\
\hline
\end{tabular}

All specifications control for VDC fixed effects.

Cluster (VDC) robust standard errors in parentheses

${ }^{*} p<0.1$.

$p<0.05$.

*** $p<0.01$.

aspirations have $g$ near one. These zero status households are likely to have low investment levels for reasons other than aspirations, potentially even after controlling for status linearly in equation (6). The inclusion of $d$ ensures our results are not driven entirely by these low status individuals' at either end of the aspirations gap range. ${ }^{12}$ Finally, we control for a vector of covariates $\boldsymbol{x}$, and VDC fixed effects $\left(v_{v}\right)$. We estimate equation (6) using OLS for continuous and dichotomous outcomes; for the latter, results are robust to the problt specification.

Given equation (6), and the fact that $g$ is constrained to be between zero and one, an inverse-U shape requires that the slope of the curve is positive when $g=0$ (i.e., $\beta_{1}>0$ ), and negative when $g=1$ (i.e., $\beta_{1}+2 \beta_{2}<0$ ), with one extreme turning point in between. To test for an inverse-U shape, we employ Lind and Mehlum's (2010) test for an inverse-U shape. We report the results from this test, including the Sasabuchi p-value, the estimated slope at $g=0$ and $g=1$, the estimated turning point, and the 95 percent Fieller confidence interval for the turning point.

The regression strategy outlined in equation (6) provides a useful first step approach, however, the hypothesized inverted$\mathrm{U}$ relationship may be better captured using semi-parametric techniques. For our second approach we estimate the partially linear model described by:

$$
k_{i v}=\alpha+f(g)+\beta s_{i v}+\boldsymbol{x}_{\boldsymbol{i v}}^{\prime} \boldsymbol{\delta}+v_{v}+\varepsilon_{i v}
$$

The only difference between equations (6) and (7) is in how the gap enters the estimation. In equation (6) we assumed the quadratic relationship. Equation (7) provides a more flexible alternative for modeling the nonlinear relationship between $g$ and $k$.

\subsection{Evidence of aspirations failure for income}

Table 3 reports estimation results for equation (6) for income aspirations, where in columns $1-3 k$ is savings, an indicator of future-oriented investment behavior. Column 1 uses a dependent variable equal to one if the individual is a member of a savings group, column 2 uses a dependent variable equal to one if the individual reported any savings in the past month,

\footnotetext{
12 Note also that $g=0$ whenever $a=s=0$ (zero income with no aspirations for income/wealth) or $a=s>0$ (aspirations are satisfied by current income/wealth).
} In both cases we expect low investment, as captured by our hypothesis. 
(a) Savings group membership

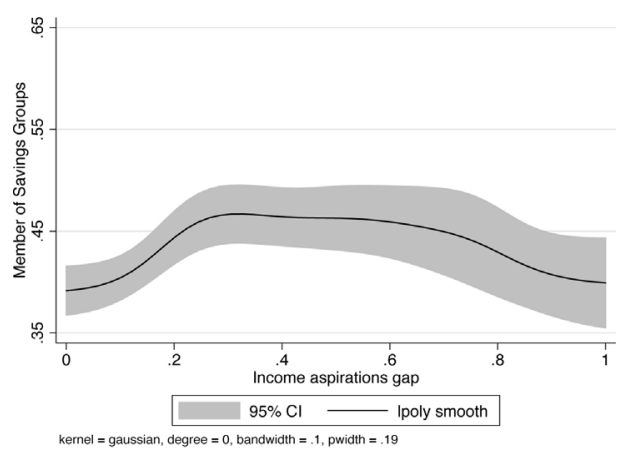

(c) Amount savings

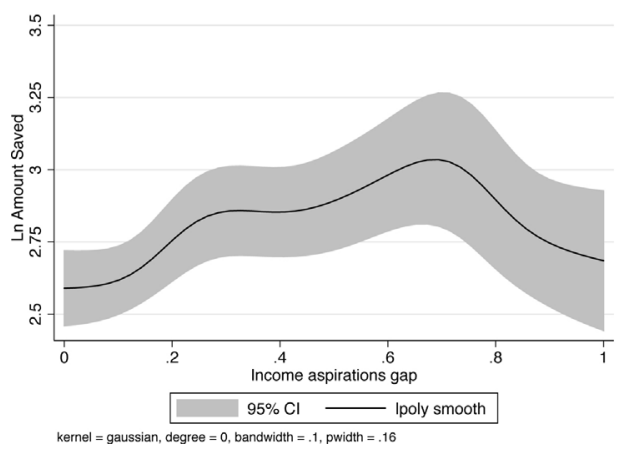

(b) Any savings

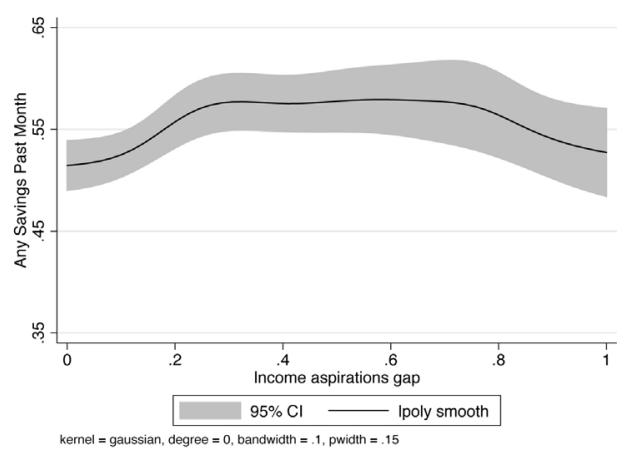

(d) Spending on temptation goods

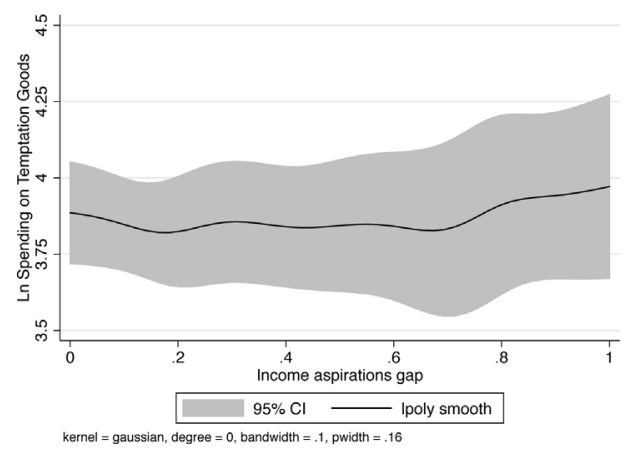

Fig. 6. Nonparametric relationship of income aspirations gaps and financial decisions.

and column 3 considers the (ln) amount saved in the previous month as the dependent variable. ${ }^{13}$ In each regression we control separately for current income, or "status" and include a dummy variable for individuals with zero income. ${ }^{14}$ We also control for the respondent's education and age, if the household has a migrant, if the respondent has input into the savings decision, and VDC fixed effects. Standard errors are clustered at the VDC level.

The results presented in columns 1-3 show the income aspirations gap is indeed positively correlated with savings. Aspiring for income levels that are higher than one's current income is associated with a higher likelihood that one is a member of a savings group and/or actively saves for the future. As predicted by theory, there is also strong evidence that the relationship between the income-aspirations gap and savings is an inverse-U. The coefficient $\beta_{2}$ estimating the relationship between $g^{2}$ and $k$ is negative, as expected. Results from Lind and Mehlum's (2010) test for an inverse-U shape yield a plausible turning point (around $g=0.5$ ), appropriately signed slopes at 0 and 1 , and a highly significant $p$-value.

Another indicator of future-oriented behavior, or lack thereof, is spending on non-productive temptation goods (tobacco, cigarettes and alcohol). The idea is that such spending crowds out savings or investment in productive activities. If that's true, in a regression of temptation spending on aspiration gaps, rather than an inverse-U relationship, we now expect a regular-U relationship. However, the fourth column of Table 3 provides no strong evidence of a $U$ relationship between the income aspirations gap and expenditures on temptation goods. The signs of the estimated coefficients for the quadratic are what we would expect, but the coefficients are far from statistically significant. Results from Lind and Mehlum's (2010) test for a regular-U shape again suggest a plausible turning point (around $g=0.3$ ), appropriately signed slopes at 0 and 1 , but an insignificant p-value.

As outlined in Section 5.1, we also employ semi-parametric techniques to test for an inverse-U relationship between income aspirations and savings-related financial decisions, and a normal-U relationship between income aspirations and temptation goods. In Fig. 6a-d we present the nonparametric component of estimating Eq. (7). The approach follows that taken in the linear model; we consider the same three savings outcome variables alongside spending on temptation goods. The results from the semi-parametric approach are strongly indicative of an inverse-U relationship between income

\footnotetext{
${ }^{13}$ We use the $\ln (X+1)$ transformation for monetary variables to account for long right tails and zero values. All results are robust using the inverse hyperbolic sine transformation.

${ }_{14} 31$ percent of households report zero income.
} 
aspirations and savings. Alternatively, in Fig. $6 \mathrm{~d}$ we see no discernable evidence of the hypothesized regular-U relationship between the income aspirations gap and spending on temptation goods.

\subsection{Evidence of aspirations failure for education}

In this section we explore the relationship between the education aspirations gap and education-related expenditures in the past year. The expenditures we consider include transportation costs to attend school, school tuition, school uniforms, and school supplies. The data includes education aspirations for all children and disaggregated by gender, allowing for gender-disaggregated analysis. However, for the analysis of education aspirations failure, several challenges exist, and the empirical approach is not as straightforward as it is in Section 5.2.

Defining the education aspirations gap is considerably more difficult than defining the income aspirations gaps. Our data on educational aspirations are for all of the respondent's children, i.e., one aspiration for all of her children (but only her own children, and not other children in the household). However, educational status, achievement and aspirations can be unique for each child. To address this challenge as best we can, we define the education aspirations gap as the difference between the woman's stated aspired level of education for her children and the current education level of her most educated child.

A second challenge is that the education aspirations gap may not pertain to the exact same group of children as education spending. Education expenditures are expressed as the sum of all household education-related expenditures, and may also include expenditures for children that are not the respondent's (e.g., grandchildren, younger siblings, nephews and nieces). Household education spending likely increases with the number of children in the household, and educational aspirations are likely correlated with the number of children in the household (with the theoretical direction of correlation uncertain). For households with multiple children, there is nothing we can do to parse out spending on a particular child, or even the respondent's own children. To deal with this problem as best as we can, we control for the total number of children in the household using a series of dummy variables as explained below.

One solution to these challenges is to limit the sample to households with an only child. This ensures the education expenditures and aspirations are related to the same child. ${ }^{15}$ The tradeoff to this approach is twofold. First, 662 households have an only child; this much smaller sample size will diminish power. This tradeoff is especially stark for the genderdisaggregated analysis where data is available for only 283 single-daughter households and 378 single-son households. ${ }^{16}$ Second, the results can only be interpreted for the restricted sample, that is, households with an only child. In what follows, we will report results from both the full and restricted (one child) samples.

A final challenge in estimating education aspirations is how to account for current educational status $s$, and especially $s=0$. Educational expenditures are explicitly linked to having at least one child in school. Consider two children of similar age. One is in school (positive investment), and one is not (zero investment). Conditional on age we are interested in the educational investment decision, which is a combination of sending children to school and (conditional on going to school) expenditures. If we control for $s=0$ (no child has attended, or is attending, school), then we control for households who are choosing to not invest in education - but this is an important component of the relationship we're interested in. Educational aspirations also likely increase with a child's age, conditional on enrollment. To address each of these issues we control for the age of all children in the household (and simultaneously the number of children) using a vector $\boldsymbol{a}$ of age dummy variables, that take on a value of 1 if the household has a child of a particular age. In doing so, we control for the exogenous part of educational status (child's age), but not the endogenous part (child's enrollment). With these changes, Eq. (6) adapted to education becomes:

$$
k_{i v}=\alpha+\beta_{1} g_{i v}+\beta_{2} g_{i v}^{2}+\boldsymbol{a}_{\boldsymbol{i v}}^{\prime} \boldsymbol{\gamma}+\boldsymbol{x}_{\boldsymbol{i v}}^{\prime} \boldsymbol{\delta}+v_{v}+\varepsilon_{i v}
$$

Table 4 reports the results of estimating equation (8) for educational aspirations and investment using the full sample. The dependent variable takes two forms: columns 1-3 employ a dummy variable if expenditures are positive (i.e., any investment $)^{17}$, and columns 4-6 consider the (ln) amount spent on education-related expenses in the previous year. The table reports the estimated relationship for the full sample (columns 1 and 4 ), girls only (columns 2 and 5 ), and boys only (columns 3 and 6). All specifications control for household income, respondent age and education, if the households has a migrant, and VDC fixed effects. As in the previous section, we report results from Lind and Mehlum's (2010) test. Table 5 reports the same specifications using the restricted sample (households with an only child).

The results presented in Table 4 provide strong evidence of an inverse-U relationship between the education-aspirations gap and investment in children's education, both on aggregate and for boys and girls separately. Across all specifications, the estimated coefficients suggest that a quadratic relationship between $g_{i v}$ and $k_{i v}$ provides a better approximation than a linear one. Results from Lind and Mehlum's (2010) test for an inverse-U shape suggest plausible turning points (0.41 to 0.57 ), appropriately signed slopes at 0 and 1 , and a highly significant $\mathrm{p}$-value. The results are quite robust to using only the

\footnotetext{
15 It is still possible that aspirations are expressed for an unobserved child not living with the household, or for child yet to be born. We think these are both unlikely possibilities.

${ }^{16}$ One child is of unknown gender.

17 These results are also robust to probit specification.
} 
Relationship between education aspirations gaps and education investment: Full sample

\begin{tabular}{|c|c|c|c|c|c|c|}
\hline & $\begin{array}{l}\text { (1) } \\
\text { Any Investment } \\
\text { All children }\end{array}$ & $\begin{array}{l}(2) \\
\text { Any Investment } \\
\text { Girls only }\end{array}$ & $\begin{array}{l}(3) \\
\text { Any Investment } \\
\text { Boys only }\end{array}$ & $\begin{array}{l}(4) \\
\text { Amt Spent } \\
\text { All children }\end{array}$ & $\begin{array}{l}\text { (5) } \\
\text { Amt Spent } \\
\text { Girls only }\end{array}$ & $\begin{array}{l}(6) \\
\text { Amt Spent } \\
\text { Boys only }\end{array}$ \\
\hline Education gap & $\begin{array}{l}0.25^{*} \\
(0.14)\end{array}$ & & & $\begin{array}{l}3.50^{* * *} \\
(1.29)\end{array}$ & & \\
\hline Education gap squared & $\begin{array}{l}-0.29^{* *} \\
(0.13)\end{array}$ & & & $\begin{array}{l}-4.30^{* * *} \\
(1.20)\end{array}$ & & \\
\hline Female education gap & & $\begin{array}{l}0.51^{* * * *} \\
(0.15)\end{array}$ & & & $\begin{array}{l}5.62^{* * *} \\
(1.51)\end{array}$ & \\
\hline Female education gap squared & & $\begin{array}{l}-0.51^{* * *} \\
(0.13)\end{array}$ & & & $\begin{array}{l}-6.13^{* * *} \\
(1.26)\end{array}$ & \\
\hline Male education gap & & & $\begin{array}{l}0.40^{* *} \\
(0.18)\end{array}$ & & & $\begin{array}{l}3.80^{* *} \\
(1.83)\end{array}$ \\
\hline Male education gap squared & & & $\begin{array}{l}-0.36^{* * *} \\
(0.15)\end{array}$ & & & $\begin{array}{l}-3.34^{* *} \\
(1.51)\end{array}$ \\
\hline Current monthly income & $\begin{array}{l}0.0039^{* * *} \\
(0.0013)\end{array}$ & $\begin{array}{l}0.0042^{* *} \\
(0.0016)\end{array}$ & $\begin{array}{l}0.0037^{* *} \\
(0.0015)\end{array}$ & $\begin{array}{l}0.053^{* * *} \\
(0.012)\end{array}$ & $\begin{array}{l}0.065^{* * *} \\
(0.016)\end{array}$ & $\begin{array}{l}0.051^{* * *} \\
(0.013)\end{array}$ \\
\hline (mean) edu2 & $\begin{array}{l}0.0014 \\
(0.0019)\end{array}$ & $\begin{array}{l}-0.00091 \\
(0.0021)\end{array}$ & $\begin{array}{l}0.0024 \\
(0.0023)\end{array}$ & $\begin{array}{l}0.11^{* * *} \\
(0.020)\end{array}$ & $\begin{array}{l}0.077^{* * *} \\
(0.021)\end{array}$ & $\begin{array}{l}0.12^{* * *} \\
(0.024)\end{array}$ \\
\hline Age (respondent) & $\begin{array}{l}-0.0049^{* * *} \\
(0.0011)\end{array}$ & $\begin{array}{l}-0.0061^{* * *} \\
(0.0013)\end{array}$ & $\begin{array}{l}-0.0027^{* *} \\
(0.0011)\end{array}$ & $\begin{array}{l}-0.037^{* * *} \\
(0.011)\end{array}$ & $\begin{array}{l}-0.054^{* * *} \\
(0.013)\end{array}$ & $\begin{array}{l}-0.014 \\
(0.011)\end{array}$ \\
\hline Household has a migrant & $\begin{array}{l}-0.0072 \\
(0.012)\end{array}$ & $\begin{array}{l}-0.0059 \\
(0.016)\end{array}$ & $\begin{array}{l}-0.0096 \\
(0.013)\end{array}$ & $\begin{array}{l}0.097 \\
(0.13)\end{array}$ & $\begin{array}{l}0.095 \\
(0.17)\end{array}$ & $\begin{array}{l}0.036 \\
(0.15)\end{array}$ \\
\hline Constant & $\begin{array}{l}1.05^{* * *} \\
(0.070)\end{array}$ & $\begin{array}{l}0.95^{* * *} \\
(0.082)\end{array}$ & $\begin{array}{l}0.81^{* * *} \\
(0.074)\end{array}$ & $\begin{array}{l}8.46^{* * *} \\
(0.69)\end{array}$ & $\begin{array}{l}8.19^{* * * *} \\
(0.85)\end{array}$ & $\begin{array}{l}6.99^{* * *} \\
(0.70)\end{array}$ \\
\hline Observations & 1924 & 1316 & 1470 & 1924 & 1316 & 1470 \\
\hline$R^{2}$ & 0.152 & 0.169 & 0.164 & 0.181 & 0.213 & 0.194 \\
\hline U-test Results: & & & & & & \\
\hline Turning Point & 0.435 & 0.502 & 0.561 & 0.407 & 0.486 & 0.569 \\
\hline Fieller 95\% Confidence Interval & {$[0.178,0.658]$} & {$[0.375,0.600]$} & {$[0.234,0.732]$} & {$[0.212,0.517]$} & {$[0.337,0.535]$} & {$[0.140,0.848]$} \\
\hline Sasabuchi $p$-value & 0.033 & 0.001 & 0.016 & 0.004 & 0.000 & 0.021 \\
\hline Slope at Min & 0.253 & 0.514 & 0.404 & 3.502 & 5.618 & 3.800 \\
\hline Slope at Max & -0.330 & -0.509 & -0.316 & -5.093 & -6.634 & -2.877 \\
\hline
\end{tabular}

All specifications control for VDC fixed effects.

Cluster (VDC) robust standard errors in parentheses.

${ }^{*} p<0.1$.

** $p<0.05$

*** $p<0.01$.

restricted sample, as shown in Table 5. The main exception is that the gender-disaggregated results for females, although qualitatively similar, are no longer statistically significant.

We conduct semi-parametric regressions for the relationship between education aspirations and education spending similar to Section 5.2. The nonlinear relationship between education aspirations and education-related expenses are shown in Figs. 7 and 8. First, Fig. 7a and b shows the results for all children using any education expenses and the logged amount spent, respectively. An inverse-U relationship is apparent. The subsequent two Figs. (7c and 7d) replicate the first two figures using only the restricted sample; the results are robust.

Fig. 8 presents the gender-disaggregated results using logged expenditures as the dependent variable. Fig. 8a shows the results using one's educational aspirations for daughters, while Fig. 8b shows the same results using aspirations for sons. Both show a strong inverse-U relationship. These results are robust to including only the restricted sample, as shown in Fig. $8 \mathrm{c}$ and $\mathrm{d}$, but there are some differences. The full sample results show similar investment for boys and girls for those with a small to moderate aspirations gap (around 0.5), but as the gap becomes large investment for girls diminishes whereas for boys it does not. The restricted sample results reveal similar investment for boys and girls when the mother has a small or large aspirations gap, but investment by those with a moderate aspirations gap is higher for boys. These results combined suggest that a "failure" of educational investment is more likely to occur for girls than for boys. When aspirations are moderate, larger investments are made in boys education compared to girls education. When aspirations are either too large or too small, girls are more likely to be affected by lower investment.

\section{Aspirations formation in Nepal}

In this section we investigate the formation of aspirations. We first describe our basic empirical specification (Section 6.1), and then present our analysis of social influences on aspirations for income (Section 6.2) and children's education (Section $6.3)$. 
(a) Any investment, full sample

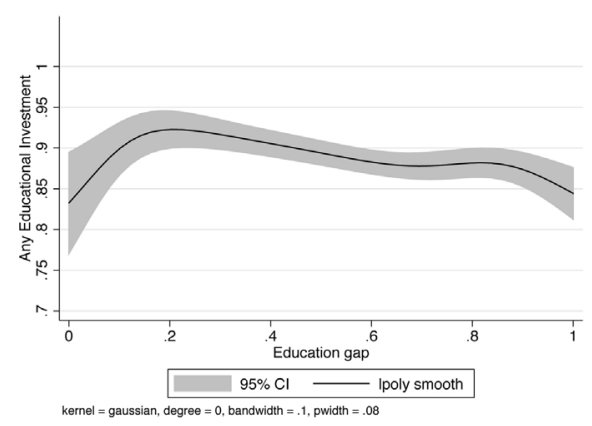

(c) Any investment, restricted sample

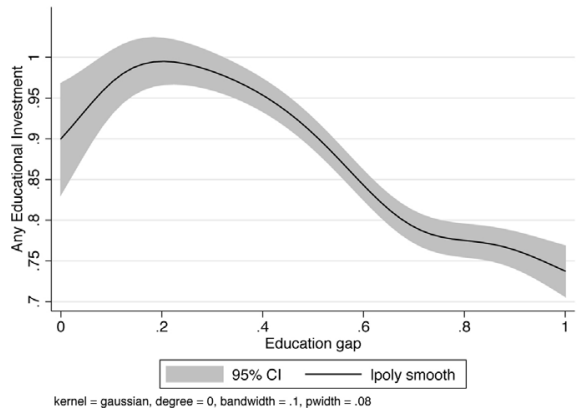

(b) Education expenditures, full sample

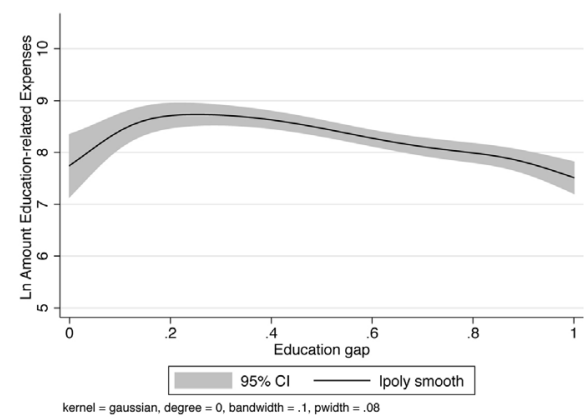

(d) Education expenditures, restricted sample

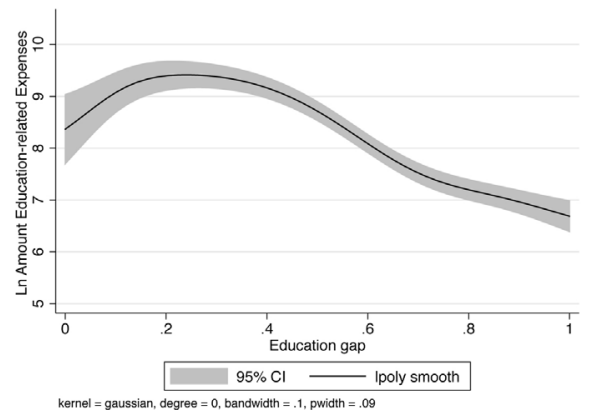

Fig. 7. Nonparametric relationship of education aspirations gap and education investment.

(a) Female gap, full sample

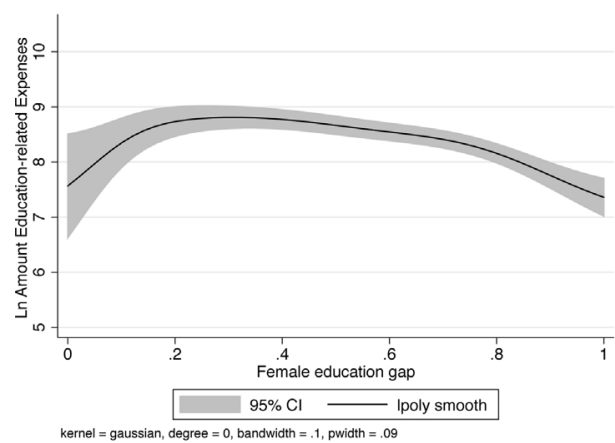

(c) Female gap, restricted sample

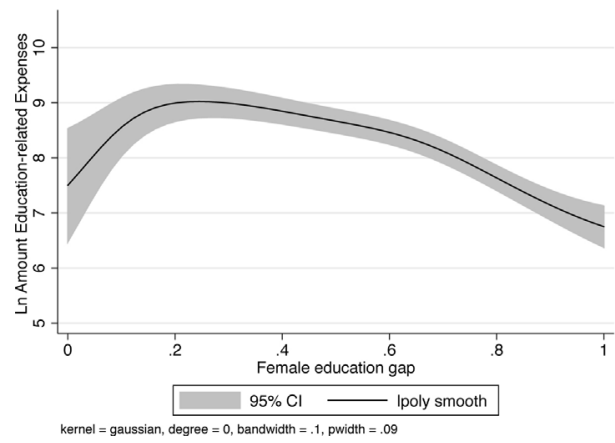

(b) Male gap, full sample

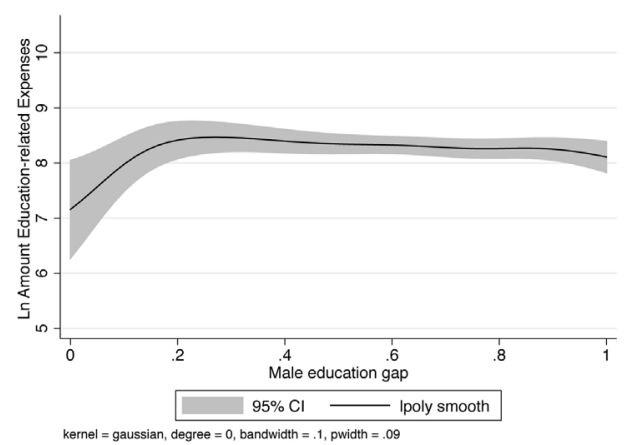

(d) Male gap, restricted sample

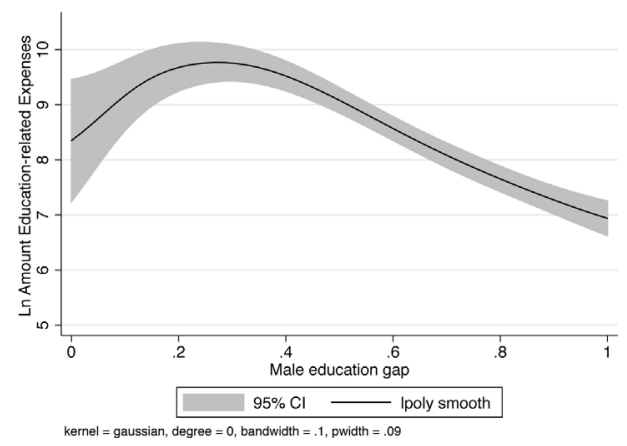

Fig. 8. Gender-disaggregated nonparametric relationship of education aspirations gap and education expenditures. 
Relationship between education aspirations gaps and education investment: Restricted sample

\begin{tabular}{|c|c|c|c|c|c|c|}
\hline & $\begin{array}{l}\text { (1) } \\
\text { Any Investment } \\
\text { All children }\end{array}$ & $\begin{array}{l}\text { (2) } \\
\text { Any Investment } \\
\text { Girls only }\end{array}$ & $\begin{array}{l}(3) \\
\text { Any Investment } \\
\text { Boys only }\end{array}$ & $\begin{array}{l}(4) \\
\text { Amt Spent } \\
\text { All children }\end{array}$ & $\begin{array}{l}\text { (5) } \\
\text { Amt Spent } \\
\text { Girls only }\end{array}$ & $\begin{array}{l}\text { (6) } \\
\text { Amt Spent } \\
\text { Boys only }\end{array}$ \\
\hline Education gap & $\begin{array}{l}0.57^{* *} \\
(0.23)\end{array}$ & & & $\begin{array}{l}5.95^{* *} \\
(2.34)\end{array}$ & & \\
\hline Education gap squared & $\begin{array}{l}-0.70^{* * *} \\
(0.21)\end{array}$ & & & $\begin{array}{l}-7.49^{* * *} \\
(2.16)\end{array}$ & & \\
\hline Female education gap & & $\begin{array}{l}0.40 \\
(0.53)\end{array}$ & & & $\begin{array}{l}3.53 \\
(5.52)\end{array}$ & \\
\hline Female education gap squared & & $\begin{array}{l}-0.49 \\
(0.45)\end{array}$ & & & $\begin{array}{l}-5.12 \\
(4.62)\end{array}$ & \\
\hline Male education gap & & & $\begin{array}{l}1.15^{* * *} \\
(0.41)\end{array}$ & & & $\begin{array}{l}10.9^{* * *} \\
(3.99)\end{array}$ \\
\hline Male education gap squared & & & $\begin{array}{l}-1.16^{* * *} \\
(0.36)\end{array}$ & & & $\begin{array}{l}-11.3^{* * *} \\
(3.68)\end{array}$ \\
\hline Current monthly income & $\begin{array}{l}0.0064^{*} \\
(0.0032)\end{array}$ & $\begin{array}{l}0.0073 \\
(0.0062)\end{array}$ & $\begin{array}{l}0.0025 \\
(0.0050)\end{array}$ & $\begin{array}{l}0.056^{*} \\
(0.033)\end{array}$ & $\begin{array}{l}0.082 \\
(0.066)\end{array}$ & $\begin{array}{l}-0.0016 \\
(0.046)\end{array}$ \\
\hline (mean) edu2 & $\begin{array}{l}0.0034 \\
(0.0046)\end{array}$ & $\begin{array}{l}-0.0035 \\
(0.0049)\end{array}$ & $\begin{array}{l}0.011 \\
(0.0082)\end{array}$ & $\begin{array}{l}0.13^{* * *} \\
(0.048)\end{array}$ & $\begin{array}{l}0.051 \\
(0.050)\end{array}$ & $\begin{array}{l}0.21^{* *} \\
(0.081)\end{array}$ \\
\hline Age (respondent) & $\begin{array}{l}-0.0054^{* * *} \\
(0.0020)\end{array}$ & $\begin{array}{l}-0.0083^{* *} \\
(0.0032)\end{array}$ & $\begin{array}{l}-0.0015 \\
(0.0028)\end{array}$ & $\begin{array}{l}-0.026 \\
(0.020)\end{array}$ & $\begin{array}{l}-0.057^{*} \\
(0.031)\end{array}$ & $\begin{array}{l}0.017 \\
(0.028)\end{array}$ \\
\hline Household has a migrant & $\begin{array}{l}-0.026 \\
(0.024)\end{array}$ & $\begin{array}{l}0.021 \\
(0.058)\end{array}$ & $\begin{array}{l}-0.042 \\
(0.036)\end{array}$ & $\begin{array}{l}0.047 \\
(0.24)\end{array}$ & $\begin{array}{l}0.37 \\
(0.55)\end{array}$ & $\begin{array}{l}-0.027 \\
(0.36)\end{array}$ \\
\hline Constant & $\begin{array}{l}0.91^{* * * *} \\
(0.14)\end{array}$ & $\begin{array}{l}1.06^{* * *} \\
(0.24)\end{array}$ & $\begin{array}{l}0.35^{*} \\
(0.19)\end{array}$ & $\begin{array}{l}6.93^{* * *} \\
(1.34)\end{array}$ & $\begin{array}{l}7.56^{* * * *} \\
(2.41)\end{array}$ & $\begin{array}{l}1.45 \\
(1.68)\end{array}$ \\
\hline Observations & 662 & 283 & 378 & 662 & 283 & 378 \\
\hline$R^{2}$ & 0.274 & 0.336 & 0.393 & 0.246 & 0.316 & 0.368 \\
\hline U-test Results: & & & & & & \\
\hline Turning Point & 0.412 & 0.414 & 0.496 & 0.397 & 0.344 & 0.483 \\
\hline Fieller 95\% Confidence Interval & {$[0.168,0.557]$} & {$[-\infty,+\infty]$} & {$[0.333,0.600]$} & {$[0.171,0.525]$} & {$[-\infty,+\infty]$} & {$[0.321,0.587]$} \\
\hline Sasabuchi $p$-value & 0.008 & 0.224 & 0.003 & 0.007 & 0.263 & 0.004 \\
\hline Slope at Min & 0.574 & 0.403 & 1.147 & 5.945 & 3.526 & 10.936 \\
\hline Slope at Max & -0.820 & -0.572 & -1.167 & -9.0333 & -6.722 & -11.693 \\
\hline
\end{tabular}

All specifications control for VDC fixed effects.

Cluster (VDC) robust standard errors in parentheses.

${ }^{*} p<0.1$.

*** $p<0.05$.

*** $p<0.01$.

\subsection{Estimation}

In Section 3 we presented a flexible model of aspirations formation (Eq. (5)) that accounts for an individual's position within her reference group. As stated previously, we expect aspirations to be inherently upward looking, so the empirical model must be flexible enough to allow an individual's aspirations to correlate differentially with the status of those "above" and "below" her. With these considerations in mind, we separately estimate the following equation for each aspirational dimension (income and education) using the three reference groups previously described: same tole, the social network within the tole that includes family, neighbors and friends, and the smaller plausibly exogenous social network of family and neighbors (but excluding friends). This model can be written as:

$$
a_{i v}=\alpha+\beta_{1} \bar{w}_{i v}+\beta_{2} \underline{w}_{i v}+\beta_{3} s_{i v}+\boldsymbol{x}_{\boldsymbol{i v}}^{\prime} \boldsymbol{\delta}+v_{d}+\varepsilon_{i v} .
$$

In Eq. (9), a represents individual $i$ 's aspirations in VDC $v$ for either income or children's education. We use $\bar{w}$ to denote the upward-looking window calculated as the average status of those "above" individual $i$, and $w$ to denote the downwardlooking window calculated as the average status of those "below" $i$. If aspirations are externally influenced but only upwardlooking, then $\beta_{1}>0$ and $\beta_{2}=0$. We presume that unobserved factors drive both one's own status and the average status of those in their reference group $(\bar{w}$ and $\underline{w}$ ), and therefore control for own status, $s$.

In all models of aspirations formation we control for a vector of covariates $\boldsymbol{x}$, which includes respondent age and education, and whether the household has a migrant. In the model of aspirations for children's education, we also include current income in the control vector $\boldsymbol{x}$ (current income is $s$ in the estimation of income aspirations formation). We control for the number of individuals above and below in the reference group because of the relationship between an individual's position within a reference group and the status of those above and below her, and to account for the fact some people by necessity had nobody above or below them.

Recall that in our social networks sample we exclude all individuals who reside outside the targeted tole in a VDC. When the reference group is the tole, all respondents within each tole share all of the the same reference individuals, so controlling for VDC (i.e., tole) fixed effects as we do in Section 2 is inappropriate. In the case where the reference group is 
the respondent-defined network there is some variation at the individual level, but still substantial overlap within each tole. Controlling for VDC fixed effects is therefore very conservative; potentially important variation between individuals across toles is lost in order to eliminate the influence of unobserved VDC-level variables. In our main results we therefore control for higher level district fixed effects $\left(v_{d}\right)$. We present results controlling for VDC-level fixed effects as a robustness check. Standard errors are always clustered at the VDC level.

We do not have exogenous variation in reference group membership or status, and therefore face several threats to identification. First, individuals may strategically create links because of their aspirations or goals. Someone who desires a higher income may choose to associate with high earners to gain information or business opportunities (Bala and Goyal, 2000). Or, individuals may misreport desires to be linked to someone as actual links (Comola and Fafchamps, 2014, 2017). Either of these phenomena could lead to biased estimates due to reverse causality; an individual's aspirations cause them to form a link, as opposed to (or in addition to) their links shaping their aspirations.

To address the problems of strategic link formation and wishful link reporting we use only reciprocated links (where both $i$ and $j$ claim to know one another). Whereas this approach eliminates desired links that are not reciprocated, it does not completely mitigate reverse causality incurred by strategically formed links that are reciprocated (perhaps due to mutual interest, among other factors). As an additional step to exclude stratgetic links, we consider a reference group that excludes friends, noting that a woman may choose her friends, but she does not choose her family or neighbors (in rural Nepal, moving is uncommon except for marriage) ${ }^{18}$

Second, the reflection problem (Manski, 1993) presents a challenge; it is difficult to determine if individual $i$ is influenced by individual $j$, or if they they behave similarly and achieve similar outcomes because they share characteristics, shocks, and circumstances. One distinction between our study and the situation described in Manski (1993) is that we examine how outcomes within $i$ 's network affect i's aspirations, whereas Manski (1993) presents a model of how behavior within $i$ 's network affects i's behavior. Clearly one's own status and aspirations are linked, and contextual factors or shared characteristics will influence both. By controlling for $i$ 's status, however, we can reduce the identification threat to factors that affect the status of those in $i$ 's network and $i$ 's aspirations conditional on $i$ 's own status.

For income aspirations, such a threat seems unlikely although not impossible. For example, suppose there is an idiosyncratic shock that affects the status of others in $i$ 's reference group (i.e., $\bar{w}$ and $\underline{w}$ ) but not $i$ 's own status. This shock could be negative (e.g., a disease that kills livestock) or positive (e.g., an NGO gives out cash or asset transfers). Although individual $i$ is not initially impacted by the shock, observing it may influence her aspirations for the future (she may believe her livestock will be harmed in the future, or she may anticipate a similar transfer). This would result in estimates of $\beta_{1}>0$ and $\beta_{2}>0$ in Eq. (9) above, but not the hypothesized result of $\beta_{1}>0$ and $\beta_{2}=0$, which is what we observe and describe below.

An additional identification threat for income aspirations stems from informal insurance mechanisms as described in Munshi and Rosenzweig (2009). Suppose wealthy individuals informally insure less wealthy individuals in their community or social network. Then expected future income could be higher for those with wealthier people in their reference group, which in turn raises their aspirations. If this were the case, we would observe $\beta_{1}>0$ and $\beta_{2}=0$ in the income regressions, but the mechanism would be quite different from what we have hypothesized. We cannot distinguish between these alternative explanations in the income aspirations regressions, and encourage future work in this area. However, we note that the insurance mechanism is unlikely to be relevant for the education regressions.

There are, however, other issues with estimating education aspirations as a function of children's education in the reference group. Here, it is relatively easy to see how shared circumstances could lead to finding $\beta_{1}>0$ and $\beta_{2}=0$. Suppose that in some areas the local school stops at grade eight and in other areas it continues to grade ten. For a cohort of women with young children, both $s$ and $\underline{w}$ are unlikely to be affected by the highest level of education offered locally, whereas $\bar{w}$ and $a$ are likely to be affected. Controlling for VDC fixed effects should mitigate this potential problem as educational infrastructure is shared at the VDC (or higher) level.

In spite of our efforts to mitigate bias, and the evidence that the hypothesized causal mechanism is at work, we interpret our findings with caution and refer to estimates as associations rather than causal effects. Research on this topic using experimental methods may be a fruitful area for future research.

\subsection{Formation of income aspirations}

Table 6 shows the results from estimating equation (9) where $a$ is income aspirations, $\bar{w}$ is the average income of those in individual $i$ 's reference group with higher income than $i$, and $\underline{w}$ is the average income of those in $i$ 's reference group with lower income. Because of long right tails in the distribution of income we log transform monetary values.

The first three columns each consider an alternative specification of the aspirations window. In column 1 , the reference group for the aspirations window includes all residents of the same tole. In columns 2 and 4 , the reference group includes members of $i$ 's broad social network including friends within the tole, while in columns 3 and 5 the reference group includes members of $i$ 's plausibly exogenous social network (excluding friends). Columns 1, 2, and 3 include district fixed effects, while columns 4 and 5 include VDC fixed effects.

\footnotetext{
18 There were many more of these types of links than expected in the data, suggesting respondents considered a fairly large geography when making this distinction. We also used links as defined by only family and obtained nearly identical results.
} 
Formation of income aspirations as a function of others' incomes

\begin{tabular}{|c|c|c|c|c|c|}
\hline & $\begin{array}{l}\text { (1) } \\
\text { Tole }\end{array}$ & $\begin{array}{c}(2) \\
\text { Links }\end{array}$ & $\begin{array}{c}(3) \\
\text { Ex links }\end{array}$ & $\begin{array}{c}(4) \\
\text { Links (FE) }\end{array}$ & $\begin{array}{c}(5) \\
\text { Ex links (FE) }\end{array}$ \\
\hline Avg. above (log Rs.) & $\begin{array}{c}0.051 \\
(0.197)\end{array}$ & $\begin{array}{l}0.141^{* *} \\
(0.064)\end{array}$ & $\begin{array}{l}0.114^{* *} \\
(0.055)\end{array}$ & $\begin{array}{c}0.084 \\
(0.063)\end{array}$ & $\begin{array}{l}0.044 \\
(0.058)\end{array}$ \\
\hline Avg. below (log Rs.) & $\begin{array}{c}0.018 \\
(0.071)\end{array}$ & $\begin{array}{l}-0.021 \\
(0.037)\end{array}$ & $\begin{array}{l}-0.019 \\
(0.035)\end{array}$ & $\begin{array}{l}-0.011 \\
(0.048)\end{array}$ & $\begin{array}{l}0.016 \\
(0.039)\end{array}$ \\
\hline Current income (log Rs.) & $\begin{array}{l}0.716^{\text {***** }} \\
(0.064)\end{array}$ & $\begin{array}{l}0.659^{* * *} \\
(0.046)\end{array}$ & $\begin{array}{l}0.664^{* * *} \\
(0.050)\end{array}$ & $\begin{array}{l}0.656^{* * * *} \\
(0.055)\end{array}$ & $\begin{array}{l}0.660 \text { **** } \\
(0.056)\end{array}$ \\
\hline Number of links above & $\begin{array}{c}0.046 \\
(0.042)\end{array}$ & $\begin{array}{l}-0.113 \\
(0.072)\end{array}$ & $\begin{array}{l}-0.125^{*} \\
(0.072)\end{array}$ & $\begin{array}{l}-0.031 \\
(0.085)\end{array}$ & $\begin{array}{l}0.034 \\
(0.100)\end{array}$ \\
\hline Number of links below & $\begin{array}{l}-0.008 \\
(0.040)\end{array}$ & $\begin{array}{l}-0.030 \\
(0.049)\end{array}$ & $\begin{array}{c}-0.088^{*} \\
(0.048)\end{array}$ & $\begin{array}{c}0.057 \\
(0.048)\end{array}$ & $\begin{array}{l}0.036 \\
(0.052)\end{array}$ \\
\hline Education (years) & $\begin{array}{c}0.032 \\
(0.038)\end{array}$ & $\begin{array}{c}0.028 \\
(0.037)\end{array}$ & $\begin{array}{c}0.028 \\
(0.036)\end{array}$ & $\begin{array}{c}0.012 \\
(0.039)\end{array}$ & $\begin{array}{l}0.013 \\
(0.039)\end{array}$ \\
\hline Age (years) & $\begin{array}{c}-0.034^{* * *} \\
(0.009)\end{array}$ & $\begin{array}{c}-0.034^{* * *} \\
(0.009)\end{array}$ & $\begin{array}{c}-0.035^{* * *} \\
(0.009)\end{array}$ & $\begin{array}{c}-0.030^{* * *} \\
(0.011)\end{array}$ & $\begin{array}{r}-0.031^{* * *} \\
(0.011)\end{array}$ \\
\hline Household has migrant & $\begin{array}{c}0.112 \\
(0.229)\end{array}$ & $\begin{array}{c}0.093 \\
(0.232)\end{array}$ & $\begin{array}{c}0.102 \\
(0.230)\end{array}$ & $\begin{array}{c}0.150 \\
(0.228)\end{array}$ & $\begin{array}{l}0.174 \\
(0.229)\end{array}$ \\
\hline Constant & $\begin{array}{c}2.874 \\
(2.239)\end{array}$ & $\begin{array}{l}3.339^{* * *} \\
(0.752)\end{array}$ & $\begin{array}{l}3.615^{* * *} \\
(0.680)\end{array}$ & $\begin{array}{l}4.753^{* * *} \\
(0.804)\end{array}$ & $\begin{array}{l}4.933^{* * *} \\
(0.706)\end{array}$ \\
\hline R-squared & 0.526 & 0.530 & 0.529 & 0.569 & 0.568 \\
\hline$N$ & 944 & 944 & 944 & 944 & 944 \\
\hline
\end{tabular}

Results of separate OLS regressions for each potential reference group.

District fixed effects included for models 1-3, VDC fixed effects included for models 4-5, results not shown.

Cluster (VDC) robust standard errors in parentheses.

${ }^{*} p<0.1$.

*** $p<0.05$.

${ }^{* * *} p<0.01$

When the reference group is the tole (column 1), we do not see a significant correlation between an individual's income aspirations and the income of those below and above her. The point estimate for the average income level of those above her is nearly three times as large as for those below her, and both are positive.

When we instead use individuals' reported links as the reference group (columns 2-3), we observe a positive and statistically significant correlation between an individual's income aspirations and the income of those above her. In column 2 , we see that a 100 percent increase in income among social contacts with higher incomes is associated with a 14 percent increase in income aspirations. We detect no significant correlation with those below, and the point estimates are very small. We find similar results when considering only exogenous network links. This pattern is consistent with the hypothesis that aspirations are upward looking. When we include VDC fixed effects, the point estimates for average income above are approximately halved and no longer statistically significant. As stated above, while including VDC fixed effects mitigates any bias due to unobserved factors common to all members of a tole, it also discards important inter-tole variation in network composition. While these extremely conservative estimates are not statistically significant, they do show a similar pattern to the results using district-level fixed effects.

\subsection{Formation of education aspirations}

Table 7 presents the education regressions for aspirations formation. Here, $\bar{w}$ refers to the average educational attainment of children (at the time of the survey) in individual $i$ 's reference group who have achieved higher education than $i$ 's children, while $\underline{w}$ refers to the average educational attainment of children in individual $i$ 's reference group exhibiting educational outcomes lower than i's children. The table format follows that of Table 6, where the first column employs the tole as the reference group, the second and fourth column use the respondent-defined social network as the reference group, and the third and fifth column use the social network excluding friends. Again, columns 1-3 include district fixed effects, while columns 4 and 5 include VDC fixed effects.

Similar to the results for income aspirations, we find that education aspirations are upward looking. The average education level of others' children with a higher level of education in the reference group is positively and significantly correlated with education aspirations. When we define the reference group as the tole, we find that each year of children's education above increases education aspirations by 0.44 years. When we use respondent-defined social links the estimates are much smaller, ranging from 0.09 to 0.22 . As was the case for income aspirations, there is no statistically significant correlation between education aspirations and the education level of those below, and the point estimates are small.

There are at least two possible explanations for why the estimate using the entire tole as the reference group is higher than estimates using respondent-defined social linkages. It could be that education aspirations are influenced more generally by those around them, as opposed to only by the people one knows personally. Because educational attainment is quite observable (at least relative to income), this may suggest that communication regarding educational possibilities is not 
Table 7

Formation of education aspirations as a function of others' children's education.

\begin{tabular}{|c|c|c|c|c|c|}
\hline & $\begin{array}{l}\text { (1) } \\
\text { Tole }\end{array}$ & $\begin{array}{c}(2) \\
\text { Links }\end{array}$ & $\begin{array}{c}(3) \\
\text { Ex links }\end{array}$ & $\begin{array}{c}(4) \\
\text { Links (FE) }\end{array}$ & $\begin{array}{c}(5) \\
\text { Ex links (FE) }\end{array}$ \\
\hline Avg. above & $\begin{array}{l}0.438^{* * *} \\
(0.089)\end{array}$ & $\begin{array}{l}0.224^{* * *} \\
(0.056)\end{array}$ & $\begin{array}{l}0.154^{* * *} \\
(0.055)\end{array}$ & $\begin{array}{l}0.134^{* *} \\
(0.061)\end{array}$ & $\begin{array}{l}0.093 \\
(0.058)\end{array}$ \\
\hline Avg. below & $\begin{array}{c}0.071 \\
(0.155)\end{array}$ & $\begin{array}{c}0.045 \\
(0.065)\end{array}$ & $\begin{array}{c}0.027 \\
(0.052)\end{array}$ & $\begin{array}{c}0.063 \\
(0.067)\end{array}$ & $\begin{array}{l}0.029 \\
(0.059)\end{array}$ \\
\hline Max child's education & $\begin{array}{c}0.031 \\
(0.152)\end{array}$ & $\begin{array}{l}-0.004 \\
(0.072)\end{array}$ & $\begin{array}{c}0.050 \\
(0.070)\end{array}$ & $\begin{array}{l}-0.055 \\
(0.081)\end{array}$ & $\begin{array}{l}0.001 \\
(0.082)\end{array}$ \\
\hline Own education (years) & $\begin{array}{l}0.223^{* * * *} \\
(0.032)\end{array}$ & $\begin{array}{l}0.254^{* * *} \\
(0.032)\end{array}$ & $\begin{array}{l}0.258^{* * *} \\
(0.033)\end{array}$ & $\begin{array}{l}0.187^{* * * *} \\
(0.039)\end{array}$ & $\begin{array}{l}0.188^{* * *} \\
\quad(0.039)\end{array}$ \\
\hline Number of links above & $\begin{array}{c}0.071 \\
(0.064)\end{array}$ & $\begin{array}{c}-0.194^{* *} \\
(0.081)\end{array}$ & $\begin{array}{c}-0.244^{* *} \\
(0.103)\end{array}$ & $\begin{array}{c}-0.188^{* *} \\
(0.075)\end{array}$ & $\begin{array}{r}-0.231^{* *} \\
(0.091)\end{array}$ \\
\hline Number of links below & $\begin{array}{l}-0.034 \\
(0.056)\end{array}$ & $\begin{array}{l}-0.022 \\
(0.089)\end{array}$ & $\begin{array}{l}-0.056 \\
(0.113)\end{array}$ & $\begin{array}{c}0.062 \\
(0.106)\end{array}$ & $\begin{array}{l}0.021 \\
(0.138)\end{array}$ \\
\hline Current income (log Rs.) & $\begin{array}{c}0.042 \\
(0.036)\end{array}$ & $\begin{array}{c}0.041 \\
(0.037)\end{array}$ & $\begin{array}{c}0.043 \\
(0.037)\end{array}$ & $\begin{array}{c}0.005 \\
(0.045)\end{array}$ & $\begin{array}{l}0.007 \\
(0.045)\end{array}$ \\
\hline Age (years) & $\begin{array}{c}-0.049^{* * * *} \\
(0.012)\end{array}$ & $\begin{array}{c}-0.050^{* * *} \\
(0.013)\end{array}$ & $\begin{array}{c}-0.048^{* * *} \\
(0.013)\end{array}$ & $\begin{array}{c}-0.051^{* * *} \\
(0.013)\end{array}$ & $\begin{array}{r}-0.051^{* * *} \\
(0.013)\end{array}$ \\
\hline Household has migrant & $\begin{array}{l}-0.045 \\
(0.246)\end{array}$ & $\begin{array}{l}-0.068 \\
(0.262)\end{array}$ & $\begin{array}{l}-0.079 \\
(0.256)\end{array}$ & $\begin{array}{c}0.084 \\
(0.254)\end{array}$ & $\begin{array}{l}0.079 \\
(0.250)\end{array}$ \\
\hline Constant & $\begin{array}{l}9.041^{* * * *} \\
(1.243)\end{array}$ & $\begin{array}{c}12.587^{* * * *} \\
(0.745)\end{array}$ & $\begin{array}{c}12.865^{* * *} \\
(0.709)\end{array}$ & $\begin{array}{c}16.077^{* * * *} \\
(0.741)\end{array}$ & $\begin{array}{l}16.146^{* * *} \\
(0.725)\end{array}$ \\
\hline R-squared & 0.215 & 0.198 & 0.195 & 0.282 & 0.280 \\
\hline$N$ & 730 & 730 & 730 & 730 & 730 \\
\hline
\end{tabular}

Results of separate OLS regressions for each potential reference group.

District fixed effects included for models 1-3, VDC fixed effects included for models 4-5, results not shown.

Cluster (VDC) robust standard errors in parentheses.

$* p<0.1$.

*** $\mathrm{p}<0.05$.

$\mathrm{p}<0.01$.

essential for the formation of education aspirations. Alternatively, this difference could be due to the reflection problem; common features of the tole such as school availability upwardly bias results. However, the significant coefficient estimates for reference group defined by the broader social network even when controlling for VDC fixed effects suggest the association between a mother's aspirations for her children's education and the level of education attained by the children of women in her reference group is not solely driven by common contextual factors.

In Tables C1 and C2 we report results disaggregated by gender. In these specifications we look separately at aspirations for sons' and daughters' education as a function of the education level of all other children in the reference group, irrespective of gender. We find similar results to those for all children, although they are generally stronger for boys.

\section{Concluding remarks}

This paper analyzes the complex relationship between aspirations and future-oriented behavior. We provide the first known direct empirical test of the widely cited model first introduced by Appadurai (2004) and Ray (2006) and formalized in Genicot and Ray (2017). Our empirical analysis reveals a convincing and robust inverted U-shaped relationship between aspirations and investment, as predicted by theory. This supports current thinking that behavioral constraints can indeed reinforce poverty, and interventions designed to alter aspirations may increase investment behavior, as other empirical work has shown.

Unlike much of the other empirical work in this area, however, this study finds that if aspirations are too large compared to current status they may result in failure and frustration. In a lecture on the importance of hope and aspirations, Duflo (2012) concludes that "goals should not be too lofty or hard to reach." Our results provide empirical evidence in support of this claim.

We also provide evidence that aspirations are in part socially formed. Through this analysis we confirm the importance of the hypothesized aspirations "window." If a program increases the status of those in an individual's reference group, or expands the reference group of a poor individual through increased exposure to individuals of higher status, then it is possible that aspirations will increase as a result. Several recent empirical papers confirm this logic. Macours and Vakis (2014) provide evidence from Nicaragua that a cash transfer program can increase aspirations, and that these effects are amplified when a community leader also receives a transfer. Bernard et al. (2014) provides evidence that a television documentary of "people from similar communities" can not only positively influence aspirations and behavior of viewers, but also improve education outcomes for those in viewers' social networks. Beaman et al. (2012) presents evidence that exposure to female role models increases the career aspirations and educational attainment of adolescent girls in India. This increase is likely not a result of direct social interaction (the role models considered are female public leaders), but is more likely a result of social observation. 
A better understanding of the social mechanisms through which aspirations form and influence behavior can inform the design of policies and interventions to alleviate internal constraints to investment. Furthermore, impact evaluations of such programs should consider spillovers through aspirational channels. Without doing so, they may not measure their full societal impact.

\section{Acknowledgements}

This research was supported by the USAID BASIS Assets and Markets Innovation Lab and the CGIAR Cereal Systems Initiative for South Asia. The authors thank Marc Bellemare, Michael Carter, Alain de Janvry, Kashi Kafle, Harounan Kazianga, Jason Kerwin, Travis Lybbert, Hope Michelson, Khushbu Mishra, Erica Myers, Elisabeth Sadoulet, Eve Sihra, David Spielman, Alex Winter-Nelson and participants at several seminars and workshops for helpful comments. We thank Savannah Noray, Giovanni Righi, Muna Sharma, Samyam Shrestha and Pranaya Sthapit for their excellent work as research assistants. All errors remain our own.

\section{Appendix A. Model of aspirations failure with aspirations exceeded by default}

If $\frac{\partial v_{1}}{\partial k}>\frac{\partial C}{\partial k} \mid k=\frac{a}{\rho}$ (as in Fig. A1a), then $k_{\text {high }}^{*}>k_{\text {low }}^{*}=\frac{a}{\rho}, N B\left(k_{\text {high }}^{*}\right)>N B\left(k_{\text {low }}^{*}\right)$, and $\frac{\partial k_{\text {high }}^{*}}{\partial a}=0$, i.e., aspirations do not affect investment. These conditions exist for aspirations below a unique threshold $\tilde{a}$, where $k_{\text {low }}^{*}=k_{\text {high }}^{*}=\frac{\tilde{a}}{\rho}$ as depicted in Fig. A1a. In Genicot and Ray's (2016) model there is no threshold equivalent to ã, as they assume that aspirations are always beyond some point where the marginal costs of investment exceed the marginal benefits. When we add this region to Fig. 3 we see a region over which aspirations do not affect investment at both low and high levels of aspirations (Fig. A2). This does not change the expected inverse-U empirical relationship between aspirations and investment.

(a)

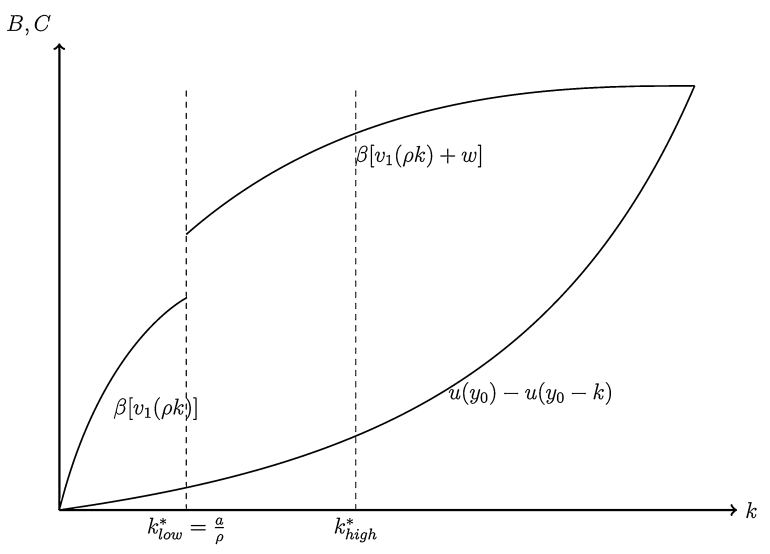

(b)

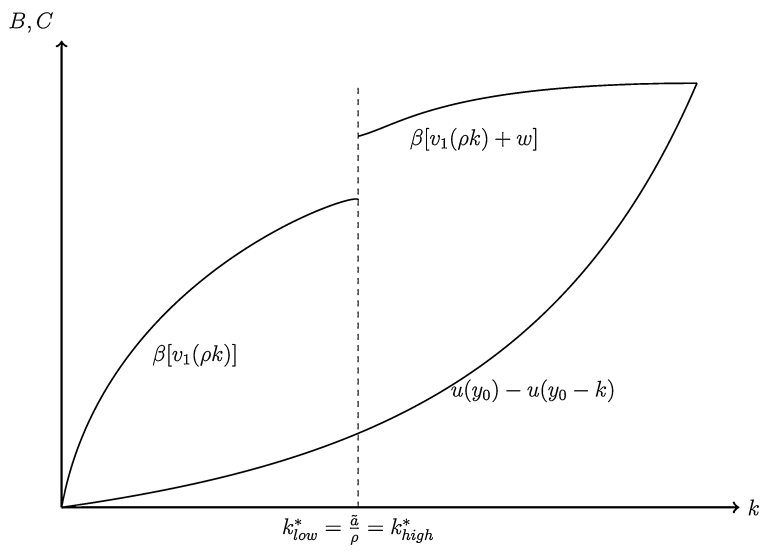

Fig. A1. Costs and benefits of investment with low aspirations.

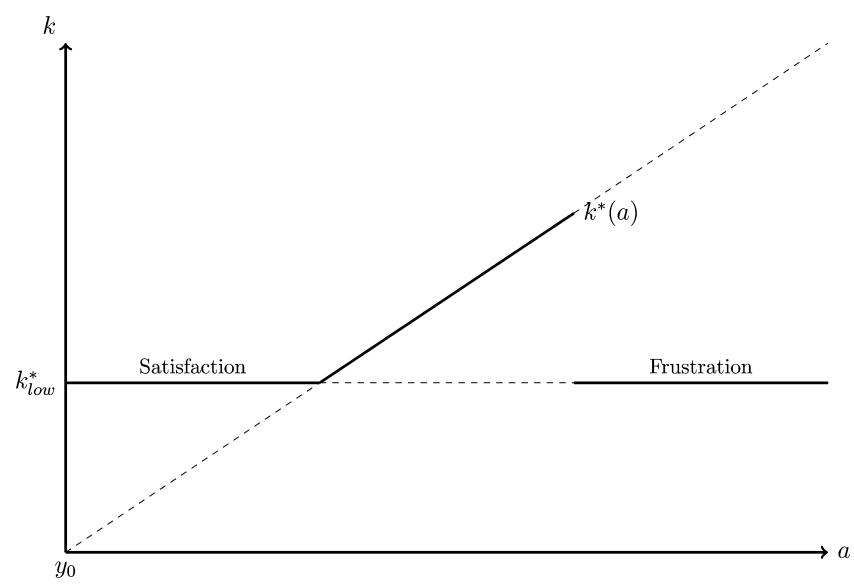

Fig. A2. Investment as a function of aspirations including when aspirations are met by default. 


\section{Appendix B. Comparative statics of $\hat{a}$}

Using the implicit function theorem we can find how changes in $\beta, y_{0}$, and $\rho$ affect the behavioral switching point $\hat{a}$. First, we set the indifference equation (4) equal to zero:

$$
I=\beta\left[v_{1}\left(\rho k_{l o w}^{*}\right)\right]+v_{0}\left(y_{0}-k_{l o w}^{*}\right)-\beta\left[v_{1}(\hat{a})+w\right]-v_{0}\left(y_{0}-\frac{\hat{a}}{\rho}\right) .
$$

First we derive $\frac{d \hat{a}}{d \beta}$ :

$$
\frac{d \hat{a}}{d \beta}=\frac{\frac{\partial I}{\partial \beta}}{\frac{\partial I}{\partial \hat{a}}}=\frac{-\left[v_{1}\left(\rho k_{l o w}^{*}\right)-v_{1}(\hat{a})-w\right]}{v_{0}^{\prime}\left(y-\frac{\hat{a}}{\rho}\right) \frac{1}{\rho}-\beta v_{1}^{\prime}(\hat{a})} .
$$

Because $w>0$ and $\hat{a}>\rho k_{l o w}^{*}$, the numerator of equation (11) is positive. The marginal benefit and marginal cost of investment are equal when $k=\frac{\tilde{a}}{\rho}$, i.e., $v_{0}^{\prime}\left(y-\frac{\tilde{a}}{\rho}\right) \frac{1}{\rho}=\beta v_{1}^{\prime}(\tilde{a})$. Because $\hat{a}>\tilde{a}$, the denominator of equation (11) must also be positive, therefore $\frac{d \hat{a}}{d \beta}>0$.

Next we derive $\frac{d \hat{a}}{d y_{0}}$ :

$$
\frac{d \hat{a}}{d y_{0}}=\frac{\frac{\partial I}{\partial y_{0}}}{\frac{\partial I}{\partial \hat{a}}}=\frac{-\left[v_{0}^{\prime}\left(y_{0}-k_{\text {low }}^{*}\right)-v_{0}^{\prime}\left(y_{0}-\frac{\hat{a}}{\rho}\right)\right]}{v_{0}^{\prime}\left(y-\frac{\hat{a}}{\rho}\right) \frac{1}{\rho}-\beta v_{1}^{\prime}(\hat{a})}
$$

Because $\frac{\hat{a}}{\rho}>k_{\text {low }}^{*}$, the numerator of equation (12) must be positive and $\frac{d \hat{a}}{d y_{0}}>0$.

Finally we derive $\frac{d \hat{a}}{d \rho}$ :

$$
\frac{d \hat{a}}{d \rho}=\frac{\frac{\partial I}{\partial \rho}}{\frac{\partial I}{\partial \hat{a}}}=\frac{-\left[\beta k_{\text {low }}^{*} v_{1}^{\prime}\left(\rho k_{\text {low }}\right)-\frac{\hat{a}}{\rho^{2}} v_{0}^{\prime}\left(y_{0}-\frac{\hat{a}}{\rho}\right)\right]}{v_{0}^{\prime}\left(y-\frac{\hat{a}}{\rho}\right) \frac{1}{\rho}-\beta v_{1}^{\prime}(\hat{a})} .
$$

Because $v_{0}^{\prime}\left(y-\frac{\hat{a}}{\rho}\right) \frac{1}{\rho}>\beta v_{1}^{\prime}(\hat{a})>0$, if $\beta \rho k_{\text {low }}^{*} v_{1}^{\prime}\left(\rho k_{\text {low }}\right)<\hat{a} v_{1}^{\prime}(\hat{a})$ then it also must be true that $\beta k_{\text {low }}^{*} v_{1}^{\prime}\left(\rho k_{\text {low }}\right)<\frac{\hat{a}}{\rho^{2}} v_{0}^{\prime}\left(y_{0}-\frac{\hat{a}}{\rho}\right)$. For most functional forms of $v$ (e.g., all of type $v=x^{\alpha}$ and $\left.v=\ln (x)\right), k_{l o w}^{*} v_{1}^{\prime}\left(\rho k_{l o w}\right) \leq \hat{a} v_{1}^{\prime}(\hat{a})$ because $\hat{a}>\rho k_{l o w}^{*}$. Therefore under reasonable assumptions $\beta \rho k_{\text {low }}^{*} v_{1}^{\prime}\left(\rho k_{\text {low }}\right)<\hat{a} v_{1}^{\prime}(\hat{a}), \beta k_{\text {low }}^{*} v_{1}^{\prime}\left(\rho k_{\text {low }}\right)<\frac{\hat{a}}{\rho^{2}} v_{0}^{\prime}\left(y_{0}-\frac{\hat{a}}{\rho}\right)$, and $\frac{d \hat{a}}{d \rho}>0$.

\section{Appendix C. Additional tables}

\begin{tabular}{|c|c|c|c|c|c|}
\hline & $\begin{array}{l}(1) \\
\text { Tole }\end{array}$ & $\begin{array}{c}(2) \\
\text { Links }\end{array}$ & $\begin{array}{c}(3) \\
\text { Ex links }\end{array}$ & $\begin{array}{c}(4) \\
\text { Links (FE) }\end{array}$ & $\begin{array}{c}(5) \\
\text { Ex links (FE) }\end{array}$ \\
\hline Boys' avg. above & $\begin{array}{l}0.546^{*+*} \\
(0.132)\end{array}$ & $\begin{array}{l}0.300 \\
(0.069)\end{array}$ & $\begin{array}{l}0.295^{* *} \\
(0.071)\end{array}$ & $\begin{array}{l}0.220 \\
(0.075)\end{array}$ & $\begin{array}{l}0.204 \\
(0.079)\end{array}$ \\
\hline Boys' avg. below & $\begin{array}{c}0.135 \\
(0.135)\end{array}$ & $\begin{array}{c}0.017 \\
(0.058)\end{array}$ & $\begin{array}{l}-0.017 \\
(0.051)\end{array}$ & $\begin{array}{c}0.007 \\
(0.064)\end{array}$ & $\begin{array}{r}-0.005 \\
(0.051)\end{array}$ \\
\hline Max boys' education & $\begin{array}{l}-0.067 \\
(0.077)\end{array}$ & $\begin{array}{c}0.019 \\
(0.072)\end{array}$ & $\begin{array}{c}0.026 \\
(0.066)\end{array}$ & $\begin{array}{l}-0.001 \\
(0.079)\end{array}$ & $\begin{array}{l}0.004 \\
(0.076)\end{array}$ \\
\hline Own education (years) & $\begin{array}{l}0.170^{*+1} \\
(0.046)\end{array}$ & $\begin{array}{l}0.205^{\circ *} \\
(0.050)\end{array}$ & $\begin{array}{l}0.208 \\
(0.048)\end{array}$ & $\begin{array}{l}0.131^{*} \\
(0.059)\end{array}$ & $\begin{array}{r}0.130 \\
(0.057)\end{array}$ \\
\hline Number of boys above & $\begin{array}{c}0.044 \\
(0.067)\end{array}$ & $\begin{array}{l}-0.126 \\
(0.082)\end{array}$ & $\begin{array}{c}-0.229 \\
(0.085)\end{array}$ & $\begin{array}{l}-0.086 \\
(0.077)\end{array}$ & $\begin{array}{r}-0.143^{\circ} \\
(0.079)\end{array}$ \\
\hline Number of boys links below & $\begin{array}{l}-0.004 \\
(0.059)\end{array}$ & $\begin{array}{c}0.031 \\
(0.079)\end{array}$ & $\begin{array}{c}0.013 \\
(0.087)\end{array}$ & $\begin{array}{c}0.111 \\
(0.098)\end{array}$ & $\begin{array}{l}0.130 \\
(0.102)\end{array}$ \\
\hline Current income (log Rs.) & $\begin{array}{c}0.072 \\
(0.045)\end{array}$ & $\begin{array}{c}0.069 \\
(0.047)\end{array}$ & $\begin{array}{c}0.075 \\
(0.048)\end{array}$ & $\begin{array}{c}0.042 \\
(0.058)\end{array}$ & $\begin{array}{l}0.048 \\
(0.059)\end{array}$ \\
\hline Age (years) & $\begin{array}{c}-0.090 \\
(0.021)\end{array}$ & $\begin{array}{c}-0.085 \\
(0.021)\end{array}$ & $\begin{array}{c}-0.084 \\
(0.022)\end{array}$ & $\begin{array}{c}-0.085 \\
(0.023)\end{array}$ & $\begin{array}{r}-0.086 \\
(0.023)\end{array}$ \\
\hline Household has migrant & $\begin{array}{c}0.409 \\
(0.312)\end{array}$ & $\begin{array}{c}0.407 \\
(0.344)\end{array}$ & $\begin{array}{c}0.395 \\
(0.334)\end{array}$ & $\begin{array}{l}0.643^{\prime} \\
(0.342)\end{array}$ & $\begin{array}{l}0.640^{+} \\
(0.331)\end{array}$ \\
\hline Constant & $\begin{array}{l}9.730 \\
(1.562)\end{array}$ & $\begin{array}{c}13.055 \\
(0.866)\end{array}$ & $\begin{array}{c}13.259 \\
(0.828)\end{array}$ & $\begin{array}{c}16.073 \\
(0.994)\end{array}$ & $\begin{array}{r}16.237 \\
(1.011)\end{array}$ \\
\hline R-squared & 0.196 & 0.175 & 0.177 & 0.270 & 0.271 \\
\hline$N$ & 568 & 568 & 568 & 568 & 568 \\
\hline
\end{tabular}

\section{Tables $\mathrm{C} 1$ and $\mathrm{C} 2$}

\section{Table C1}

Formation of education aspirations for boys as a function of other children's' education

Results of separate OLS regressions for each potential reference group.

District fixed effects included for models 1-3, VDC fixed effects included for models 4-5, results not shown.

Cluster (VDC) robust standard errors in parentheses.

${ }^{*} p<0.1$.

** $p<0.05$.

**** $p<0.01$. 
Table C2

Formation of education aspirations for girls as a function of other children's' education

\begin{tabular}{|c|c|c|c|c|c|}
\hline & $\begin{array}{l}(1) \\
\text { Tole }\end{array}$ & $\begin{array}{c}(2) \\
\text { Links }\end{array}$ & $\begin{array}{c}(3) \\
\text { Ex links }\end{array}$ & $\begin{array}{c}(4) \\
\text { Links (FE) }\end{array}$ & $\begin{array}{c}(5) \\
\text { Ex links (FE) }\end{array}$ \\
\hline Girls' avg. above & $\begin{array}{l}0.325^{* *} \\
(0.154)\end{array}$ & $\begin{array}{l}0.259^{* * * *} \\
(0.069)\end{array}$ & $\begin{array}{l}0.160^{* *} \\
(0.070)\end{array}$ & $\begin{array}{c}0.169^{*} \\
(0.099)\end{array}$ & $\begin{array}{l}0.057 \\
(0.090)\end{array}$ \\
\hline Girls' avg. below & $\begin{array}{l}-0.043 \\
(0.186)\end{array}$ & $\begin{array}{l}-0.136^{*} \\
(0.073)\end{array}$ & $\begin{array}{l}-0.062 \\
(0.061)\end{array}$ & $\begin{array}{l}-0.082 \\
(0.085)\end{array}$ & $\begin{array}{l}0.002 \\
(0.069)\end{array}$ \\
\hline Max girls's education & $\begin{array}{l}0.175^{* * *} \\
(0.070)\end{array}$ & $\begin{array}{l}0.170^{* * *} \\
(0.065)\end{array}$ & $\begin{array}{l}0.175^{* * *} \\
(0.063)\end{array}$ & $\begin{array}{l}0.167^{* *} \\
(0.070)\end{array}$ & $\begin{array}{l}0.173^{* *} \\
\quad(0.067)\end{array}$ \\
\hline Own education (years) & $\begin{array}{l}0.215^{* * *} \\
(0.038)\end{array}$ & $\begin{array}{l}0.223^{* * *} \\
(0.039)\end{array}$ & $\begin{array}{l}0.221^{* * * *} \\
(0.039)\end{array}$ & $\begin{array}{l}0.174^{* * * *} \\
(0.048)\end{array}$ & $\begin{array}{l}0.171^{* * *} \\
\quad(0.048)\end{array}$ \\
\hline Number of girls above & $\begin{array}{l}-0.027 \\
(0.072)\end{array}$ & $\begin{array}{c}-0.288^{* * *} \\
(0.109)\end{array}$ & $\begin{array}{c}-0.351^{* * * *} \\
(0.119)\end{array}$ & $\begin{array}{c}-0.211^{* * *} \\
(0.102)\end{array}$ & $\begin{array}{r}-0.235^{* *} \\
(0.109)\end{array}$ \\
\hline Number of girls links below & $\begin{array}{c}-0.088 \\
(0.069)\end{array}$ & $\begin{array}{c}-0.245^{* *} \\
(0.102)\end{array}$ & $\begin{array}{c}-0.298^{* *} \\
(0.137)\end{array}$ & $\begin{array}{l}-0.136 \\
(0.110)\end{array}$ & $\begin{array}{c}-0.149 \\
(0.152)\end{array}$ \\
\hline Current income (log Rs.) & $\begin{array}{c}0.029 \\
(0.049)\end{array}$ & $\begin{array}{c}0.024 \\
(0.049)\end{array}$ & $\begin{array}{c}0.024 \\
(0.051)\end{array}$ & $\begin{array}{l}-0.010 \\
(0.058)\end{array}$ & $\begin{aligned}-0.011 \\
(0.061)\end{aligned}$ \\
\hline Age (years) & $\begin{array}{c}-0.070^{* * *} \\
(0.019)\end{array}$ & $\begin{array}{c}-0.070^{* * * *} \\
(0.020)\end{array}$ & $\begin{array}{c}-0.067^{* * * *} \\
(0.020)\end{array}$ & $\begin{array}{c}-0.078^{* * * *} \\
(0.021)\end{array}$ & $\begin{array}{r}-0.077^{* * *} \\
(0.021)\end{array}$ \\
\hline Household has migrant & $\begin{array}{l}-0.215 \\
(0.316)\end{array}$ & $\begin{array}{l}-0.213 \\
(0.318)\end{array}$ & $\begin{array}{l}-0.222 \\
(0.313)\end{array}$ & $\begin{array}{l}-0.176 \\
(0.350)\end{array}$ & $\begin{array}{r}-0.166 \\
(0.349)\end{array}$ \\
\hline Constant & $\begin{array}{c}12.706^{* * *} \\
(1.329)\end{array}$ & $\begin{array}{c}14.066^{* * *} \\
(0.868)\end{array}$ & $\begin{array}{c}14.357^{* * * *} \\
(0.861)\end{array}$ & $\begin{array}{c}16.662^{* * *} \\
(1.133)\end{array}$ & $\begin{array}{r}17.143^{* * * *} \\
(1.105)\end{array}$ \\
\hline R-squared & 0.198 & 0.217 & 0.219 & 0.286 & 0.285 \\
\hline$N$ & 523 & 523 & 523 & 523 & 523 \\
\hline
\end{tabular}

Results of separate OLS regressions for each potential reference group.

District fixed effects included for models 1-3, VDC fixed effects included for models 4-5, results not shown.

Cluster (VDC) robust standard errors in parentheses.

${ }^{*} p<0.1$.

$p<0.05$.

**** $p<0.01$.

\section{References}

Allendorf, K., 2007. Do women's land rights promote empowerment and child health in Nepal? World Develop. 35, $1975-1988$.

Appadurai, A., 2004. The capacity to aspire: Culture and the terms of recognition. Culture and Public Action, pp. 59-84.

Ashraf, N., Karlan, D., Yin, W., 2006. Tying Odysseus to the Mast: Evidence from a Commitment Savings Product in the Philippines. Quar. J. Econ. 121, $635-672$.

Bala, V., Goyal, S., 2000. A noncooperative model of network formation. Econometrica 68, 1181-1229.

Bandiera, O., Rasul, I., 2006. Social networks and technology adoption in northern Mozambique. Econ. J. 116, 869-902.

Banerjee, A., Chandrasekhar, A., Duflo, E., Jackson, M., 2013. The diffusion of microfinance. Science, 341.

Beaman, L., Duflo, E., Pande, R., Topalova, P., 2012. Female leadership raises aspirations and educational attainment for girls: A policy experiment in India, Science 335, 582-586.

Bernard, T., Dercon, S., Orkin, K., Taffesse, A.S., 2014. The Future in Mind: Aspirations and Forward-Looking Behaviour in Rural Ethiopia. Centre for the Study of African Economies, University of Oxford, Working paper.

Bernard, T., Dercon, S., Taffesse, A.S., 2011. Beyond fatalism-an empirical exploration of self-efficacy and aspirations failure in Ethiopia.

Bernard, T., Taffesse, A., 2014. Aspirations: an approach to measurement with validation using Ethiopian data. J. Afr. Econ. 23, $189-224$.

Bertrand, M., Mullainathan, S., Shafir, E., 2004. A behavioral-economics view of poverty. Am. Econ. Rev. 94, 419-423.

Besley, T., Coate, S., Loury, G., 1993. The economics of rotating savings and credit associations. Am. Econ. Rev. 83, 792-810.

Bogliacino, F., Ortoleva, P., 2013. The Behavior of Others as a Reference Point. Columbia Business School Research Paper, pp. $13-55$.

Comola, M., Fafchamps, M., 2017. The missing transfers: Estimating mis-reporting in dyadic data. Econ. Develop. Cult. Change.

Comola, M., Fafchamps, M., 2014. Testing unilateral and bilateral link formation. Econ. J. 124, 954-976.

Conley, T.G., Udry, C.R., 2010. Learning about a new technology: Pineapple in Ghana. Am. Econ. Rev. 100, 35-69.

Dalton, P.S., Ghosal, S., Mani, A., 2016. Poverty and aspirations failure. Econ. J. 126, 165-188.

Deusenberry, J., 1949. Income, Saving and the Theory of Consumer Behavior. Harvard University Press, Cambridge, Mass.

Duflo, E., 2012. Lack of Hope and the Persistence of Poverty. Marshall Lecture Series.

Duflo, E., Kremer, M., Robinson, J., 2011. Nudging Farmers to Use Fertilizer: Theory and Experimental Evidence from Kenya. Am. Econ. Rev. 101, 2350-2390.

Fafchamps, M., Shilpi, F., 2008. Subjective welfare, isolation, and relative consumption. J. Develop. Econ. 86, 43-60.

Ferrer-i Carbonell, A., 2005. Income and well-being: an empirical analysis of the comparison income effect. J. Public Econ. 89, 997-1019.

Flory, J.A., 2012. Formal Savings Spillovers on Microenterprise Growth and Production Decisions Among Non-Savers in Villages: Evidence from a Field Experiment. In: Annual Meeting of the Agricultural and Applied Economics Association.

Genicot, G., Ray, D., 2017. Aspirations and inequality. Econometrica 85, 489-519.

Jack, W., Suri, T., 2011. Mobile money: the economics of M-PESA. National Bureau of Economic Research, Working paper.

Jensen, R., 2010. The (perceived) returns to education and the demand for schooling. Quar. J. Econ., 125.

Kahneman, D., Tversky, A., 1979. Prospect theory: an analysis of choice under risk. Econometrica 47, $263-291$.

Knight, J., Gunatilaka, R., 2012. Income, aspirations and the hedonic treadmill in a poor society. J. Econ. Behav. Org. 82, 67-81.

Laajaj, R., 2017. Endogenous time horizon and behavioral poverty trap: Theory and Evidence from Mozambique. J. Develop. Econ. 127, 187-208.

Lind, J.T., Mehlum, H., 2010. With or Without U? The Appropriate Test for a U-Shaped Relationship. Oxford Bull. Econ. Stat. $72,109-118$.

Lybbert, T.J., Wydick, B., 2016. Hope as Aspirations, Agency, and Pathways: Poverty Dynamics and Microfinance in Oaxaca, Mexico. National Bureau of

Economic Research, Working paper.

Lybbert, T.J., Wydick, B., Forthcoming. Poverty, Aspirations and the Economics of Hope. Econ. Develop. Cult. Change. 
Macours, K., Vakis, R., 2014. Changing Households' Investment Behaviour through Social Interactions with Local Leaders: evidence from a Randomised Transfer Programme. Econ. J. 124, 607-633.

Malapit, H., Kadiyala, S., Quisumbing, A.R., Cunningham, K., Tyagi, P., 2015. Women's empowerment mitigates the negative effects of low production diversity on maternal and child nutrition in Nepal. J. Develop. Stud. 51, 1097-1123.

Manski, C.F., 1993. Identification of endogenous social effects: The reflection problem. Rev. Econ. Stud. 60, $531-542$.

Manski, C.F., 2004. Measuring expectations. Econometrica 72, 1329-1376.

Mookherjee, D., Ray, D., Napel, S., 2010. Aspirations, segregation, and occupational choice. Journal of the European Economic Association 8, 139-168.

Mullainathan, S., Thaler, R.H., 2000. Behavioral economics. National Bureau of Economic Research, Working paper.

Munshi, K., Rosenzweig, M., 2009. Why is mobility in India so low? Social insurance, inequality, and growth. National Bureau of Economic Research, Working paper.

Nguyen, T., 2008. Information, role models and perceived returns to education: Experimental evidence from Madagascar, Unpublished.

Oxford English Dictionary, 2016. Oxford Living Dictionary.

Ray, D., 2006. Aspirations, poverty and economic change. Understanding Poverty, vol. 28. Oxford University Press, USA, pp. 409-421.

Ross, P.H., 2016. Aspirations and Human Capital Investment: Evidence from Indian Adolescents, Unpublished.

Rotter, J.B., 1966. Generalized expectancies for internal versus external control of reinforcement. Psychol. Monogr.: Gen. Appl., 80.

Sierneels, P., Dercon, S., 2014. Aspirations, Poverty and Education: Evidence from India, Unpublished.

Skoufias, E., Parker, S.W., Behrman, J.R., Pessino, C., 2001. Conditional Cash Transfers and Their Impact on Child Work and Schooling: Evidence from the PROGRESA Program in Mexico [with Comments]. Economía 2, 45-96.

Stutzer, A., 2004. The role of income aspirations in individual happiness. J. Econ. Behav. Org. 54, 89-109.

USAID, 2013. Nepal Country Profile.

World Bank, 2011. World Development Report 2012: Gender equality and development. World Bank, Washington DC. 
the amount an individual invests in the future depends on an individual's aspirations relative to their current status. If aspirations barely exceed current status, then the investment required to meet them is relatively low. This low investment is defined by Ray (2006) as an aspirations failure. As aspirations increase, failure is averted as optimal investment increases. But if aspirations are too large (relative to current status), the required investment becomes overly burdensome, investment is suspended, and aspirations also fail.

If internal constraints like aspirations inhibit economic behavior in a way that perpetuates poverty, then there is scope to design interventions that target internal constraints as well as external ones. Recent empirical papers on this topic have demonstrated how a variety of interventions can lengthen people's planning horizon (Laajaj, 2017), close the gender gap in aspirations for children's education and employment outcomes (Beaman et al., 2012), increase aspirations (Bernard et al., 2014; Lybbert and Wydick, 2016), and improve expectations and attitudes about the future (Macours and Vakis, 2014). These studies also estimate intervention impacts on future-oriented economic behavior, and thus provide a rich body of evidence that behavioral constraints limit investment, and that these constraints are mutable. In contrast, our study employs observational data on both aspirations and investment to empirically analyze the potentially complex and non-monotonic relationship described above.

It is also important to understand how aspirations are formed. The theoretical literature generally assumes that aspirations are influenced by observing neighbors and peers (Appadurai, 2004; Genicot and Ray, 2017). ${ }^{1}$ The empirical literature demonstrates that one's relative status (generally in terms of income) does impact their aspirations (Fafchamps and Shilpi, 2008; Ferrer-i-Carbonell, 2005; Knight and Gunatilaka, 2012; Stutzer, 2004). If aspirations are socially determined and affect behavior, there is scope for interventions that generate spillover effects by altering aspirations within a community. Indeed, several recent studies demonstrate the potential of aspiration-improving interventions to generate multiplier effects through social linkages (Macours and Vakis, 2014; Bernard et al., 2014).

In this paper we (1) use unique measures of aspirations for income and children's education to evaluate if and how aspirations contribute to future-oriented economic behavior, and (2) use detailed network data to examine social influences on aspirations. We find evidence supporting the hypothesized inverse- $U$ relationship between income aspirations and future oriented financial behavior. The probability of engaging in saving activities increases with income and (to a lesser extent) asset aspirations up to a point, but then falls as predicted by the model. We do, however, not see the opposite relationship between spending on temptation goods and aspirations. We also observe the hypothesized relationship between education aspirations and expenditures on education as predicted by theory. This inverse-U relationship is slightly stronger for girls than boys. In addition, we find that one's aspirations for income and children's education are associated with higher levels of observable wealth and children's education within her network, but uncorrelated with lower levels.

The paper proceeds as follows. In Sections 2 and 3 we discuss the relevant theoretical and empirical literature, presenting a theoretical model of aspirations failure (Section 2) and formation (Section 3) adapted from Genicot and Ray (2017). In Section 4 we describe the study setting and data. In Sections 5 and 6 we present our empirical approach and findings regarding aspirations failure and formation respectively. Section 7 concludes.

\section{Understanding aspirations failure}

Poor households often fail to make even small investments thought to have large returns in the long run, suggesting that they face constraints that prevent them from doing so. Many policies intended to increase investment among the poor focus on easing external constraints. Examples include programs and policies designed to increase savings through informal village banking systems such as ROSCAs (Besley et al., 1993), decrease transaction costs to access formal banking (Jack and Suri, 2011; Flory, 2012), improve information on the benefits of education (Nguyen, 2008; Jensen, 2010), and encourage investment in education using conditional cash transfer programs (Skoufias et al., 2001). However, despite the removal of external constraints through these kinds of programs, low levels of investment often persist.

Recent work recognizes that internal constraints, in addition to external ones, may hinder investment and other futureoriented behavior. A lack of the capacity to aspire and/or hope are examples of internal constraints identified as being critically important to investment and poverty dynamics. In a seminal contribution, anthropologist Arjun Appadurai (2004) argued that policies designed to strengthen the poor's capacity to aspire could "contest and alter the conditions of their poverty." Several recent theoretical papers explore such a relationship between aspirations, investment behavior, and poverty. Dalton et al. (2016), Genicot and Ray (2017), Bogliacino and Ortoleva (2013), and Lybbert and Wydick (in press) employ various assumptions as to how aspirations are formed and enter the utility function, yet all suggest low aspirations generate low levels of investment. In both Dalton et al. (2016) and Bogliacino and Ortoleva (2013), a critical "low" aspirations threshold exists above which investment grows with aspirations, and below which aspirations "fail" and optimal investment is low. Genicot and Ray (2017) also suggest that investment will be relatively low for low levels of aspirations, and subsequently grow with aspirations, but their model suggests a critical "high" aspirations threshold at which point aspirations also "fail" and investment plummets.

\footnotetext{
${ }^{1}$ According to Appadurai (2004), "Aspirations are never simply individual... They are always formed in interaction and in the thick of social life." Ray (2006) develops this concept further: "individual desires and standards of behavior are often defined by experience and observation; they don't exist in social isolation." Genicot and Ray (2017) demonstrate how socially driven aspirations influence inequality in society.
} 


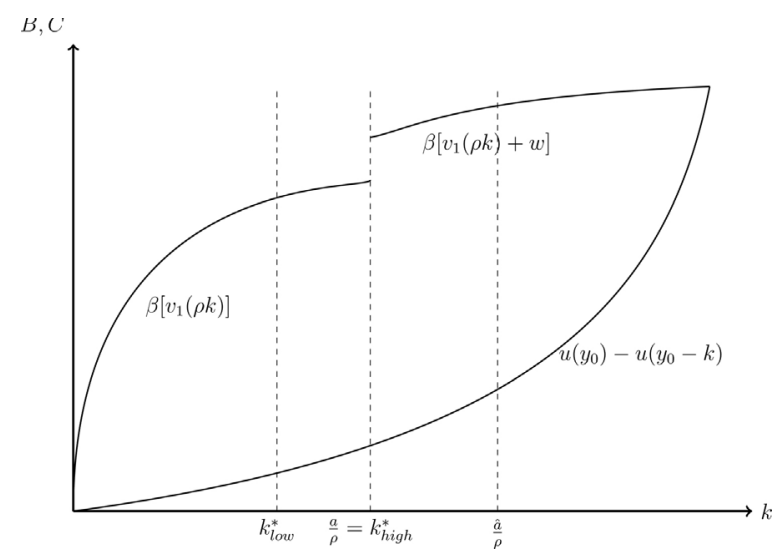

Fig. 1. Benefits and costs of investment with aspirations.

As explained in greater detail in the following section, the Genicot and Ray (2017) model predicts an inverse-U shaped relationship between aspirations and investment, a hypothesis that first appears in Appadurai (2004) and Ray (2006). In the next section we employ a version of the model presented in Genicot and Ray (2017), formalizing the intuition and providing necessary context for our empirical test of the aspirations failure theory. In Section 2.2 we review recent empirical literature related to the aspirations failure hypothesis.

\subsection{A model of aspirations failure}

To motivate our empirical analysis of aspirations failures, we employ the model presented in Genicot and Ray (2017) with minor adaptations. While their model is multi-generational, we suppose that an individual maximizes her own utility over two periods of her life, the present and the future. Starting with a wealth endowment of $y_{0}$, the individual can either consume $(c)$ or invest in the future $(k)$ so that $y_{0}=c+k$. She receives a return of $\rho$ on her investment so that she has income in the subsequent period $y_{1}=\rho k$.

The agent also has aspirations $a$, which for now are assumed to be exogenous. In the first period she derives utility only from consumption. In the second period she derives utility from income, and also from exceeding aspirations. This "bonus" utility from exceeding aspirations is written as $w$. Genicot and Ray (2017) treat $w$ as an increasing function of the amount by which aspirations are exceeded, starting at zero. We instead treat $w$ as a constant amount of utility gained if aspirations are met or exceeded, irrespective of by how much. We do this so that the marginal returns to consumption are not higher above the aspirations threshold than they are below, while maintaining a region of increasing marginal returns to investment where aspirations are met. In this way, our model is similar to models that treat aspirations as reference points using prospect theory (e.g., Bogliacino and Ortoleva, 2013). ${ }^{2}$

The agent maximizes the following 2-period utility function:

$$
u(c, k)=v_{0}(c)+\beta\left[v_{1}(\rho k)+w * I(\rho k \geq a)\right]
$$

where $\beta$ is a personal discount factor. We assume that $v_{0}$ and $v_{1}$ are smooth, increasing, and strictly concave.

When deciding how much to invest in the future, the agent compares the benefits and costs of investment. The costs of investment, in terms of forgone present consumption, are the same regardless of whether her aspirations are satisfied:

$$
C(k)=v_{0}\left(y_{0}\right)-v_{0}\left(y_{0}-k\right)
$$

Because $v_{0}^{\prime}(k)>0$ and $v_{0}^{\prime \prime}(k)<0$, it follows that $C^{\prime}(k)>0$ and $C^{\prime \prime}(k)>0$. To assess the benefits of investing, she must consider two scenarios: one where her aspirations are met (her aspirations are "satisfied", in the words of Genicot and Ray) and one where they are not (her aspirations are "frustrated"). This yields the following benefit function:

$$
B(k)= \begin{cases}\beta\left[v_{1}(\rho k)\right] & \text { if } \rho k<a(\text { frustrated) } \\ \beta\left[v_{1}(\rho k)+w\right] & \text { if } \rho k \geq a \text { (satisfied) }\end{cases}
$$

We depict the relationship between investment benefits and costs in Fig. 1. The individual will choose the level of investment $k^{*}$ that maximizes the net benefits of investment, $N B(k)=B(k)-C(k)$. As demonstrated in equation (3), there

\footnotetext{
2 The standard prospect theory model first established in Kahneman and Tversky (1979)) assumes a utility function that is convex up to the reference point. Following Genicot and Ray (2017) we do not assume convexity prior to the reference point, but unlike Genicot and Ray (2017) our model does accommodate loss aversion in the sense that there is a large jump in utility at the reference point. It can be shown that the key insights of the model hold if a more traditional prospect theory model such as the one presented in Bogliacino and Ortoleva (2013) were instead applied.
} 


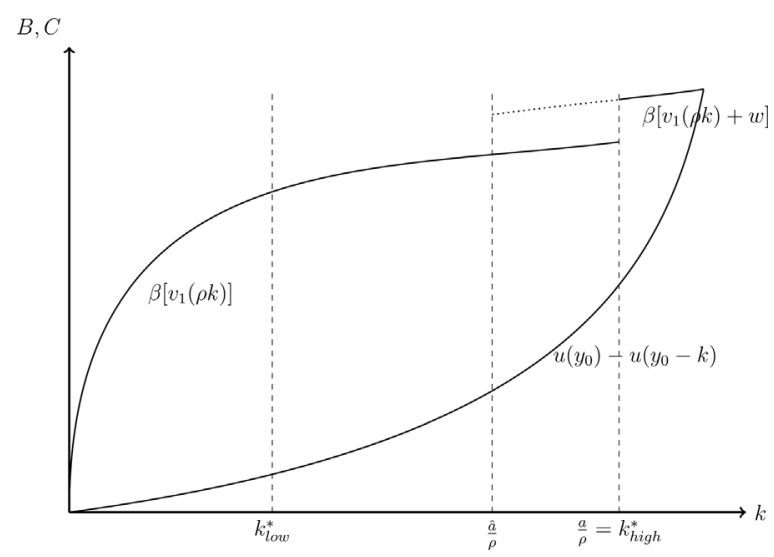

Fig. 2. Low investment when aspirations are above $\hat{a}$

exists a discontinuity in $B(k)$, and therefore in $N B$, where $k=\frac{a}{\rho}$. This discontinuity yields two local solutions: $k_{l o w}^{*}$ maximizes $N B$ to the left of $\frac{a}{\rho}$ and $k_{\text {high }}^{*}$ maximizes $N B$ at or to the right of $\frac{a}{\rho}$. From $k_{\text {low }}^{*}$ and $k_{\text {high }}^{*}$, the individual selects $k^{*}$ to maximize net benefits. For simplicity of exposition, we limit our use of the model to cases where $\frac{\partial v_{1}}{\partial k} \geq \frac{\partial C}{\partial k} \mid k=\frac{a}{\rho}$, which is the region where aspirations are not exceeded by default. In this case, $k_{\text {high }}^{*}=\frac{\alpha}{\rho}>k_{\text {low }}^{*}$. For completeness, we examine the case where $\frac{\partial v_{1}}{\partial k}<\frac{\partial C}{\partial k} \mid k=\frac{a}{\rho}$ in Appendix A.

As indicated by Genicot and Ray (2017), there is some unique threshold level of aspirations $\hat{a}$, depicted in Figs. 1 and 2 , at which the individual is indifferent between selecting $k_{\text {high }}^{*}$ to satisfy her aspirations and selecting $k_{\text {low }}^{*}$ in frustration. If $a<\hat{a}, k_{\text {high }}^{*}$ is the optimal choice as in Fig. 1, and aspirations are satisfied. If $a>\hat{a}, k_{\text {low }}^{*}$ is the optimal choice as in Fig. 2, and aspirations are frustrated.

The relationship between $a, k_{\text {low }}^{*}, k_{\text {high }}^{*}$, and $k^{*}$ is depicted in Fig. 3. When aspirations are very low they are easily satisfied by setting $k^{*}=k_{\text {high }}^{*}$ at levels not much higher than $k_{\text {low }}^{*}$. As aspirations increase, so does $k^{*}$ up until some threshold level $\hat{a}$. Beyond $\hat{a}$, the cost of achieving aspirations will outweigh the benefits and the individual will become frustrated, setting $k^{*}=k_{\text {low }}^{*}$. Recall that at $\hat{a}, N B\left(k_{\text {low }}^{*}\right)=N B\left(k_{\text {high }}^{*}\right)$, i.e., the individual is indifferent between satisfying her aspirations or not. This indifference holds if:

$$
\beta\left[v_{1}\left(\rho k_{\text {low }}^{*}\right)\right]+v_{0}\left(y_{0}-k_{\text {low }}^{*}\right)=\beta\left[v_{1}(\hat{a})+w\right]+v_{0}\left(y_{0}-\frac{\hat{a}}{\rho}\right) .
$$

From this equation it is clear that the behavioral threshold $\hat{a}$ depends on the agent's initial endowment, discount factor, the rate of return on investment, and individual characteristics that enter the utility function. Using the implicit function theorem, we find that $\frac{\partial \hat{a}}{\partial \beta}>0, \frac{\partial \hat{a}}{\partial y_{0}}>0$, and $\frac{\partial \hat{a}}{\partial \rho}>0$ (calculations in Appendix B). In other words, individuals who are more

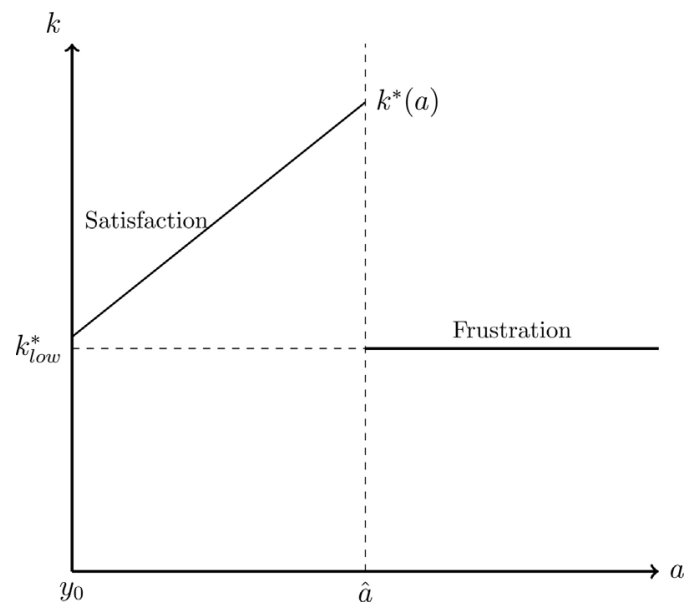

Fig. 3. Investment as a function of aspirations. 
patient, initially better off, and have a higher rate of return on investment are more likely to choose $k_{\text {high }}^{*}$ over $k_{\text {low }}^{*}$ for a given level of aspirations $a$.

Note that differences between individuals' levels for $\hat{a}$ are distinct from differences in aspirations. In Section 3 we will discuss how aspirations form. What is important here is the relationship between $a$ and $\hat{a}$ : If $a>\hat{a}$, the individual will invest $k_{\text {low }}^{*}$, and if $a<\hat{a}$ she will invest $k_{\text {high }}^{*}$ (at $a=\hat{a}$ she is indifferent). Empirically, if $\hat{a}$ were similar for each individual in the sample it might be possible to estimate the relationship depicted in Fig. 3. But because â depends on individual characteristics, this is unlikely to be the case. If $\hat{a}$ varies among individuals, empirical analysis is likely to yield something resembling an inverted-U relationship between aspirations and investment.

To understand why this is true, consider the following thought exercise: At any level of $\hat{a}$ some proportion of individuals exhibit $a<\hat{a}$ and invest $k_{\text {high }}^{*}$, and the rest exhibit $a>\hat{a}$ and invest $k_{\text {low }}^{*}$. As $a$ increases, more of the population will invest $k_{l o w}^{*}$, resulting in a downward sloping relationship between $a$ and $k$ but no precipitous drop. This will be true for both discrete and continuous measures of future oriented behavior.

We use a simple simulation exercise to demonstrate this point. For the exercise, we assume $k_{\text {high }}=a$ and $k_{\text {low }}=1$. To fix ideas, we first set $\hat{a}$ equal to 50 . Fig. $4 \mathrm{a}$ presents the investment policy function under these parameters for individuals with aspirations varying between 0 and 100 with a behavioral switching point at $\hat{a}=50$. In our first simulation, for each possible level of aspirations $a$, we consider a sample of 100 individuals with values of $a$ taken from a random normal distribution with a mean of 50 and a standard deviation of 25. In the second simulation, for each possible level of aspirations $a$, we consider a sample of 100 individuals with values of $\hat{a}$ randomly drawn from a uniform distribution from 0 to 100 . The aggregate relationships between aspirations and average (or expected) investment are presented in Fig. $4 \mathrm{~b}$ (normally distributed $\hat{a}$ ) and Fig. 4c (uniformly distributed $\hat{a}$ ). Regardless of our assumptions about the distribution of $\hat{a}$, theory predicts a clear inverse-U relationship between aspirations and average investment.

In earlier work, Ray (2006) supposes that it is not aspirations per se, but the difference between the aspired-to outcome and current status that matters for investment. This difference has been articulated as an "aspirations gap" (Ray, 2006) and an "aspirations ratio" (Genicot and Ray, 2017). The aspirations gap, $g$, is the percent difference between an individual's realized level or status of some outcome, $s$, and their aspired-to level, $a$; i.e. $g=\frac{a-s}{a}$. Because an individual should aspire to be at least as well off in the future as they are in the present, $g$ must be positive and between zero and one. In our empirical analysis that follows, we test for the hypothesized inverted-U shape between the aspirations gap and observed investment. ${ }^{3}$ Using the gap for empirical applications, as opposed to simply aspirations or the the difference between aspirations and current status, facilitates meaningful comparisons across individuals with different current status levels.

\subsection{Empirical evidence of aspirations failure}

Several recent papers suggest that future-oriented behavior can be improved by increasing aspirations. Macours and Vakis (2014) present evidence from a randomized cash transfer program suggesting that improved aspirations led to increased investment in Nicaragua. Laajaj (2017) describes a particular type of aspirations failure as the inability to think about a future of bleak prospects, resulting in a lack of investment. Using a randomized control trial, he shows that a positive shock in the form of agro-input subsidies lengthens poor farmers' planning horizons in Mozambique. Bernard et al. (2011) find evidence of aspirations failure in the fatalism exhibited by Ethiopian farmers, and show that this failure is correlated with negatively future-oriented economic behavior. Bernard et al. (2014) and (Lybbert and Wydick, 2016) find short inspirational documentary films increase aspirations, and in some instances increase investment, in Ethiopia and Mexico, respectively. Beaman et al. (2012) exploit a randomized policy experiment in India that reserved a certain number of village leadership roles for women to demonstrate how educational investment in girls increases when aspirations increase.

While these empirical analyses demonstrate the effectiveness of interventions designed to encourage future-oriented behavior by alleviating internal constraints, they are not designed to estimate the non-monotonic relationship between aspirations and investment described in the theoretical literature. Besides the analysis presented here, we are aware of only two working papers that explicitly test the hypothesized inverse-U hypothesis between aspirations and future-oriented behavior. Ross (2016) and Sierneels and Dercon (2014) both proceed from the same body of theoretical work that we consider here and examine a related set of outcomes: the relationship between parents' aspirations for children's education and educational attainment. Both papers provide some support for the inverse-U hypothesis between education aspirations and educational attainment.

Despite these similarities, this paper differs from those two papers in several important ways. First, we explore the links between aspirations and investment (which may lead to an outcome) and not aspirations and the outcome itself, resulting in a more direct test of the theory. Second, in addition to testing an investment response to the aspirations gap with respect to education, we offer further evidence of the inverted-U with respect to aspirations for income and corresponding

\footnotetext{
${ }^{3}$ The aspirations ratio, $r$, is the current level or status of the outcome divided by their aspirations; i.e. $r=\frac{s}{a}=1-g$. Fig. 3 can be easily altered to accommodate the inverse aspirations ratio $\left(r^{-1}\right)$ by dividing the values on both the $\mathrm{x}$-and $\mathrm{y}$-axis by $s$, such that the value on the $\mathrm{y}$-axis becomes percent of current level invested. Because $r^{-1}$ and $g$ move in the same direction with respect to $a$, we would expect to see the same relationship between $a$ and $k$ as we do between $r^{-1}$ and $k$, and similarly between $g$ and $k$.
} 


\section{(a) Individual}

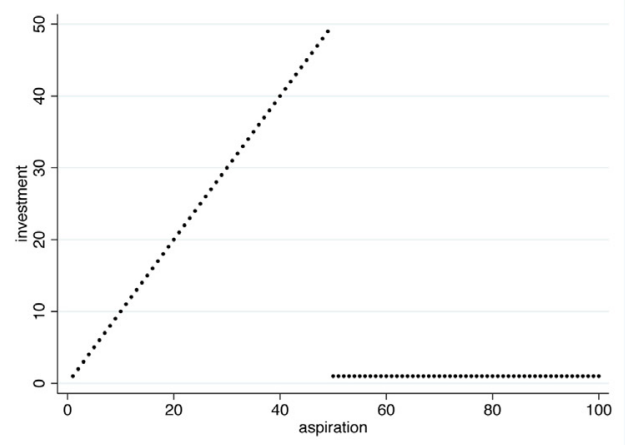

(b) Aggregate behavior (normal distribution)

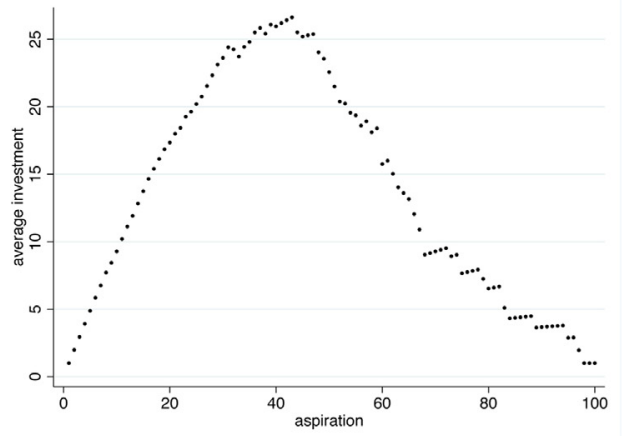

(c) Aggregate behavior (uniform distribution)

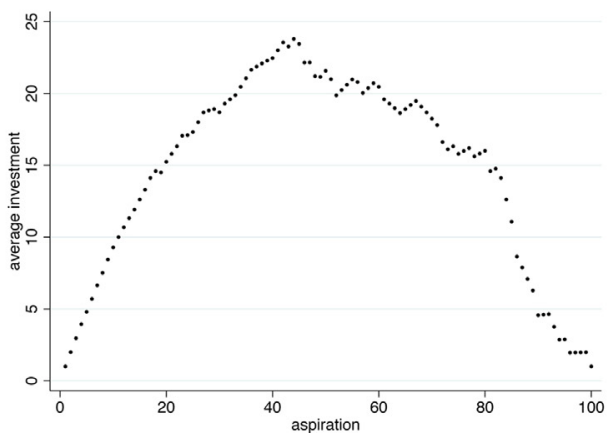

Fig. 4. Model Implications on Individual and Aggregate Behavior.

investments. Third, we offer a complimentary analysis of the social component for aspirations formation, which we develop in the following section.

\section{Understanding aspirations formation}

In his seminal work, Ray (2006), suggests that people "draw [their] aspirations from the lives, achievements, and ideals of those who exist in [their] aspirations window." In other words, an individual's aspirations are formed socially. ${ }^{4}$ In particular, Ray posits that it is the "similar" or "attainable" people who exist in an individual's "cognitive neighborhood" that frame one's aspirations.

${ }^{4}$ The theoretical model presented by Dalton et al. (2016) focuses on the internal drivers of aspirations, but represents an exception in the theoretical literature which more often considers external forces. 
If aspirations are formed externally or socially, then aspiration-based spillovers of development interventions may influence non-beneficiary investment (either positively or negatively) through aspirational channels. Some evidence of positive spillovers exists. Bernard and Taffesse (2014) find that showing aspirational videos (depicting a pathway to a better future) to Ethiopian farmers increased investment in education not only for those who viewed the videos, but also for peers in their social network. ${ }^{5}$ Macours and Vakis (2014) find that the impact of receiving a productive investment package is stronger, in terms of positive attitudes and happiness, when community leaders also receive the package. They conclude that having a village leader receive the package improves other recipients' capacity to inspire. These studies provide evidence that aspirations are, at least in part, formed from external influences.

The literature on subjective well-being also contains substantial evidence that aspirations are socially influenced. Several papers examining the importance of relative status to happiness demonstrate a social aspect of aspirations formation. Stutzer (2004) finds that average community income increases individuals' income aspirations in Switzerland, and that these heightened aspirations decrease happiness. In a similar study, Knight and Gunatilaka (2012) find that in rural China, income aspirations are pushed upward by both own current income and reference group income. Neither of these papers directly capture income aspirations, but proxy for them using the minimum income level on which the respondent deems adequate to get by. While not explicitly dealing with aspirations, Ferrer-i-Carbonell (2005) finds subjective well-being decreases with reference group income in Germany, and Fafchamps and Shilpi (2008) find that the probability individuals considers their own household consumption adequate decreases with the total consumption of households in their reference group in Nepal.

The papers mentioned in the previous paragraph all assume that aspirations are a combination of internal factors (the individual's current status and past experience) and external ones (the status of people in their reference group). Accordingly, Genicot and Ray (2017) suggest that aspirations formation can be modeled as:

$$
a=(1-\gamma) y_{0}+\gamma \Psi\left(y_{0}, F\right)
$$

In Eq. (5), $\gamma$ is the weight one places on their position relative to others, $F$ represents the distribution of the outcome within their reference group, and $\Psi$ is a function by which an individual's position in the reference distribution affects their aspirations. The composition of an individual's reference group is an empirical question, and may depend heavily on context. Most of the papers mentioned at the beginning of this section assume the reference group was determined at least in part geographically. Ferrer-i-Carbonell (2005) use people of similar age and education level living in the same region. Knight and Gunatilaka (2012) and Fafchamps and Shilpi (2008) use the village as the reference group. In a second empirical model, Fafchamps and Shilpi (2008) use the district of birth as the reference group for migrants. In this paper we test reference groups based on geography (neighborhood) and social network as defined by the individual.

The specification in Eq. (5) is agnostic with respect to how $F$ and $y_{0}$ enter the aspirations formation function $\Psi$, and Genicot and Ray (2017) put forth three possibilities. First, the social component of an individual's aspirations for an outcome could simply be the maximum level of that outcome in her reference group. Second, it could be the average level of the outcome in her reference group. This has been the most common assumption in the existing empirical literature (Fafchamps and Shilpi, 2008; Knight and Gunatilaka, 2012; Stutzer, 2004). Third, it could be the average outcome of individuals in her reference group with a higher level of the outcome. This possibility is based on the Deusenberry (1949) hypothesis, and has been demonstrated empirically by Ferrer-i-Carbonell (2005). In the empirical section of this paper, we test a model that is flexible enough to allow for either the second or third possibility.

\section{Context and data}

Aspirations failure and formation have mostly evaded empirical analysis for two reasons: First, aspirations are not easily observable, difficult to measure, and rarely captured in household surveys. Second, using reference groups based on observable data such as geography or religion may present a very rough representation of social connectivity. Social network data can provide a more accurate representation, but is seldom collected in standard surveys. This paper takes advantage of a unique household dataset that includes respondents' aspirations and detailed social networks data. In the following subsection we describe the study setting and the overall survey instrument. Because the aspirations data and social networks data are both critical and unique to our analysis, we describe both in greater detail in sections 4.2 and 4.3 respectively.

\subsection{Data from rural Nepal}

Between June and September 2014 we collected data from nearly 3300 rural women eligible to participate in an asset transfer program across three regions of Nepal. ${ }^{6}$ Nepal is the poorest country in South Asia and the 13th poorest country in the world. Nepal has made significant strides towards poverty alleviation in recent years, yet poverty persists, especially

\footnotetext{
${ }^{5}$ Bernard et al. (2014) find increases in aspirations among viewers but not their peers, potentially suggesting the indirect effects may be due to non-viewers following the behavior of their peers who watched the videos rather than having their own aspirations improved.

${ }^{6}$ In addition to serving as the dataset used in this paper, the data serves as baseline data for an impact evaluation of the asset transfer program.
} 
in the countryside; 55 percent of Nepalese survive on less than $\$ 1.25$ a day, and that number climbs sharply in the rural mountain and hill districts where more than 70 percent of people rely on agriculture for their livelihoods (USAID, 2013).

There are several reasons why a focus on women's aspirations in Nepal is important. The condition of women, and their empowerment relative to men, is a development priority, as evidenced by the third Millennium Development Goal and more recently, the World Bank 2012 World Development Report (World Bank, 2011). Recent studies from Nepal demonstrate that greater female control over income (Malapit et al., 2015) and assets (Allendorf, 2007) is correlated with better maternal and child nutrition in Nepal.

Data used for this study are from the baseline survey of an RCT conducted in conjunction with an NGO. Because the survey was conducted prior to any intervention associated with the RCT, it can largely be ignored here. However, the stratified sampling required for the RCT has implications for the dataset, particularly the social network data. The sample includes 45 treatment village development committees (VDCs) and 15 control VDCs spread across 7 districts. ${ }^{7}$ In treatment and control VDCs we sampled 20-25 women selected by the NGO to potentially receive benefits as part of the RCT. These women were selected based on geography only. Essentially, the NGO identified all women living in a neighborhood (called a tole) within a ward, and all of these women $(N=945)$ were included in the sample. In addition, we randomly sampled 15 women living in the same ward outside the targeted tole. In treatment wards only, we randomly selected an additional 10 women each from two other wards in the same VDC. Our full sample size is therefore 3280 women.

Data collection took place in two phases. First, a team administered an extensive household survey including questions about income, asset ownership and control, financial decisions, education, health and nutrition, food security, women's empowerment, and aspirations. In what follows, income is yearly individual income, as reported by the respondent. Asset value is the total value of land and housing belonging to the household. ${ }^{8}$ At this first interview, enumerators took photographs of respondents to be compiled into community photo directories containing all sampled individuals within a VDC.

In the second phase of data collection, these photo directories were used to collect social networks data for all women in targeted treatment wards, including those inside and outside the targeted targeted tole. In the analysis involving social networks data, we only consider women residing in targeted toles for two reasons. First, connectivity is highest within these groups; 21 percent of possible connections are realized links where individual $i$ and individual $j$ both claim each other, whereas only five percent of possible connections are realized links if one or both women reside outside the targeted tole. Second, we sampled 100 percent of women in these toles. As a result, the probability that a link within the tole is observed in our sample is one, whereas it is considerably lower for links beyond the targeted tole. This holds for links between women $i$ residing within the targeted tole and women $j$ outside the targeted tole, as well as for links between women $i$ outside the targeted tole to women $j$ outside the targeted tole. In other words, for each observed link to a woman outside the targeted tole, individual $i$ likely has several others not captured in the data. Limiting the sample to the 45 targeted toles thus yields a complete social network within these toles and a total network sample size of 944 women.

Table 1 contains descriptive statistics for the full sample and the subsample for whom we have network data. The table is organized into three panels: (A) basic demographic and economic variables, (B) investment behavior, and (C) aspirations. Mean respondent age is approximately 40 years. On average respondents had 2.76 years of formal education, but median years of education is zero. The women chosen for the study are generally poor (although some are considerably better off than others). Average personal yearly income was around 60,000 NPR (approximately 600 USD) ${ }^{9}$ and respondents estimated their household land and home to be worth 1.4 million NPR, but there is substantial variance. Note that this data was collected one year prior to a devastating earthquake that destroyed the homes and assets of many of the households in our sample. Economic migration to urban areas and foreign countries (typically Gulf states) is very common in Nepal. In our sample, 60 percent of households had an outgoing migrant.

Unfortunately, the survey did not directly capture investment. We use savings behavior, spending on temptation goods, and annual education-related expenditures as indicators of future-oriented behavior and investment. To measure savings, we consider whether the respondent is in a savings group, whether she or any member of the household put any money into savings in the prior month, and how much the household saved in the previous month. Notice that income data is available for the individual, while savings behavior - excluding membership in a savings group - was collected at the household level. Savings for future expenditures and/or investment is quite common: 42 percent of respondents are in a savings group, which exist in nearly every VDC in rural Nepal, and 54 percent of households saved at least some money in the month leading up to the survey. On average, the amount saved was 1,500 NPR (15 USD). Only 23 percent of respondents indicate they have any input into how much money is put into savings, something we will control for in the analysis to follow. Despite having very little education themselves, women in the sample invest substantially in their children's education. On average, women with at least one child under the age of 15 spent 9,000 NPR (90 USD) per child in the year before the survey.

An alternative to investment is to spend money on non-productive temptation goods. We use expenditures on tobacco, cigarettes and alcohol as an alternative non-investment good. Approximately 60 percent of households in our sample

\footnotetext{
7 There are 75 districts in Nepal, each containing on average 42 VDCs. Each VDC is a cluster of 9 wards, and wards contain 100 households on average (although this varies considerably).

${ }^{8}$ While pre-testing the survey, this was determined to be the most important indicator of a household's asset base.

${ }_{9}$ At the time of the study the exchange rate was roughly 100 NPR to 1 USD.
} 
Table 1

Sample descriptive statistics

\begin{tabular}{|c|c|c|}
\hline Variable & Full sample & Network sample \\
\hline & $(\mathrm{N}=3280)$ & $(\mathrm{N}=944)$ \\
\hline \multicolumn{3}{|l|}{ Panel A: Basic characteristics. } \\
\hline \multirow[t]{2}{*}{ Age } & 40.53 & 40.41 \\
\hline & $(13.98)$ & $(14.02)$ \\
\hline \multirow[t]{2}{*}{ Years of education } & 2.76 & 2.76 \\
\hline & $(4.35)$ & $(4.35)$ \\
\hline \multirow[t]{2}{*}{ Max child's years of education } & 7.19 & 7.18 \\
\hline & $(4.35)$ & $(4.27)$ \\
\hline \multirow[t]{2}{*}{ Max boy's years of education } & 5.99 & 6.03 \\
\hline & $(4.72)$ & $(4.66)$ \\
\hline \multirow[t]{2}{*}{ Max girl's years of education } & 3.79 & 3.63 \\
\hline & $(4.28)$ & $(4.13)$ \\
\hline \multirow[t]{2}{*}{ Current personal income (NPR/year) } & 59,689 & 66,043 \\
\hline & $(189,398)$ & $(264,186)$ \\
\hline \multirow[t]{2}{*}{ Respondent reports no income } & 0.32 & 0.31 \\
\hline & $(0.47)$ & $(0.46)$ \\
\hline \multirow[t]{2}{*}{ Current value of household land and home (NPR) } & $1,410,821$ & 985,453 \\
\hline & $(6,079,916)$ & $(2,923,084)$ \\
\hline \multirow[t]{2}{*}{ Household has a migrant } & 0.62 & 0.62 \\
\hline & $(0.49)$ & $(0.48)$ \\
\hline \multicolumn{3}{|l|}{ Panel B: Saving and investment } \\
\hline \multirow[t]{2}{*}{ Respondent controls savings } & 0.24 & 0.24 \\
\hline & $(0.42)$ & $(0.42)$ \\
\hline \multirow[t]{2}{*}{ Membership in a savings group } & 0.42 & 0.44 \\
\hline & $(0.49)$ & $(0.50)$ \\
\hline \multirow[t]{2}{*}{ Saved money last month } & 0.54 & 0.57 \\
\hline & $(0.50)$ & $(0.50)$ \\
\hline \multirow[t]{2}{*}{ Amount saved last month (NPR) } & 1,536 & 1,494 \\
\hline & $(30,781)$ & $(26,335)$ \\
\hline \multirow[t]{2}{*}{ Temptation goods spending last month (NPR) } & 878 & 861 \\
\hline & $(2,641)$ & $(2,087)$ \\
\hline \multirow[t]{2}{*}{ Any education spending } & 0.83 & 0.83 \\
\hline & $(0.38)$ & $(0.38)$ \\
\hline \multirow[t]{2}{*}{ Education spending last year (NPR) } & 21,145 & 17,151 \\
\hline & $(68,845)$ & $(34,600)$ \\
\hline \multicolumn{3}{|l|}{ Panel C: Aspirations } \\
\hline \multirow[t]{2}{*}{ Aspired personal income (NPR/year) } & 153,064 & 129,005 \\
\hline & $(1,043,751)$ & $(507,166)$ \\
\hline \multirow[t]{2}{*}{ Aspired land and home value (NPR) } & $3,185,397$ & $2,755,110$ \\
\hline & $(16,813,091)$ & $(19,487,914)$ \\
\hline \multirow[t]{2}{*}{ Aspired years of education for children } & 14.05 & 13.73 \\
\hline & $(3.85)$ & $(4.06)$ \\
\hline \multirow[t]{2}{*}{ Aspired years of education for boys } & 14.07 & 13.78 \\
\hline & $(4.13)$ & $(4.43)$ \\
\hline \multirow[t]{2}{*}{ Aspired years of education for girls } & 13.47 & 13.14 \\
\hline & $(4.39)$ & $(4.66)$ \\
\hline
\end{tabular}

Standard deviations in parentheses. 100 NPR equals approximately 1 USD.

purchased some tobacco, cigarettes and/or alcohol in the month prior to being surveyed. Average monthly expenditures in this category is approximately 900 NPR (9 USD).

\subsection{Measuring aspirations}

As noted by Bernard and Taffesse (2014), economists have recently measured aspirations using mostly ad-hoc indicators, with little consistency across studies. Stutzer (2004) and Knight and Gunatilaka (2012) use the minimum level of income a respondent said would be adequate to proxy for aspirations. While this indicator is in the money metric, it does not capture the outer bound of what someone thinks is possible. Other studies use attitudes about the future thought to be linked to aspirations: Macours and Vakis (2014) use a depression scale; Bernard et al. (2011) use two simple measures of locus of control and self-efficacy based on Rotter (1966); and Laajaj (2017) uses planning horizon for future expenditures.

Each of the proxy variables used in the above studies are distinct from aspirations in the model presented in section 2. Beaman et al. (2012) consider an arguably more direct approach toward measuring aspirations by asking parents about the desired educational attainment for their children, desired age of marriage for children, preferred occupation of children at the age of 25 , and whether the parent wished for a female child to become a village leader. Building on this more direct approach, Bernard and Taffesse (2014) propose a novel instrument constructed by asking directly about aspirations across multiple dimensions, where each dimension is given a weight by the respondent so an aggregate index can be created. 
Our analysis uses two components of the Bernard and Taffesse (2014) aspirations index: aspirations over personal income and children's education. We also collected data on the third and fourth components employed in the Bernard and Taffesse (2014) index - wealth and social status - but do not employ them here. We use income aspirations rather than asset aspirations because we believe income is a better measure of financially-related aspirations. ${ }^{10}$ While we could construct and use the composite index itself, the decision to use aspirational dimensions rather than an aggregate index reflects our desire to explicitly test the theoretical model presented in Sections 2 and 3. First, we are testing a hypothesis linking aspirations in a specific dimension to investment outcomes in that same dimension. There are clear investment-related behaviors linked to income and education aspirations, whereas for status aspirations, there is no direct way to observe investment in status. Second, we expect the formation of aspirations to vary across dimensions.

For both income and education aspirations, we ask four questions. Following Manski's (2004) suggestions for measuring expectations, the first two questions are intended to help respondents delineate a realistic range before stating their own current status and their aspirations. The third question records the personal status for that dimension. The fourth question is interpreted as the individual's aspiration.

Following Bernard and Taffesse (2014), the questions related to income aspirations are: (1) "What is the maximum level of income that a person in your community might expect to earn in a year?" (2) "What is the minimum level of income that a person in your community might expect to earn in a year?" (3) "What is your present personal level of income?" and (4) "What level of yearly income do you personally think you might be able to achieve in the future?" Aspirations for children's education are measured similarly, replacing income with "level of education for your children" so the fourth question eliciting aspirations becomes, "What level of education would you like your children to achieve?" Notice that this question asks generally about all children. If the respondent has different aspirations for different children, it is up to the respondent to interpret and answer the question however they deem suitable. In particular, we might expect aspirations to differ by gender of the child. For this reason the survey also asked about aspirations separately for boys and girls. Rather than ask about children's current education level (which is child-specific and depends on the age of children in the household), the module asked about the education of the respondent in the third question of the series.

One concern is that our measurement of aspirations is potentially conditioned by agency or self efficacy, which are closely related to expectations. The difference between aspirations and expectations is nuanced. An aspiration is defined as, "a hope or ambition to achieve something," whereas an expectation is defined as, "a strong belief that something will happen or be the case" (Oxford English Dictionary, 2016). The questions we use to capture aspirations, based on Bernard and Taffesse (2014) and adapted to the local context, are written to capture the outer edge of what is possible, rather than the most likely outcome. The choice of wording resulted from extensive discussion with the Nepali enumeration team. In Ethiopia, Bernard and Taffesse (2014) use the term "wish," as in "what level of income do you wish to achieve?" In Nepali, the words for "wish" or "hope" are quite strong. Our understanding is that even the simple phrase "like to" evokes a tendency to think wishfully and even completely unrealistically - about money. We determined that this wording was too strong in Nepali and would yield unrealistic figures. Instead, for income and asset aspirations, we ask what the woman might be able to achieve. Unlike amounts of money, the level of education children can achieve is inherently bounded, so we were advised by the Nepali enumeration team to ask what the woman would like her children to achieve.

The responses to these questions suggest respondents were stating their aspired outcomes rather than their expected ones, as they were much higher than their current levels. On average, respondents aspired for a yearly personal income of approximately 150,000 NPR (1500 USD) or 2.5 times their current income. Similarly, respondents aspired for wealth equal to approximately 3 million NPR (30,000 USD), twice the current value of home and landholdings. While few women in our sample have any formal schooling, the average aspired education for their children is much higher than their own educational experience (Table 1, panel C). Among women with a child under the age of 15 irrespective of whether the child is enrolled currently, mean aspired education for children generally is 14 years, and 90 percent of women aspired to at least 10 years of education for their children. Aspirations are lower on average by about half a school year (13.4) for girls than they are for boys (14).

Fig. 5a and $\mathrm{c}$ plot the distribution of income aspirations (top coded at the 98th percentile) and education aspirations. Fig. 5a demonstrates particularly high variance, even after top coding. The aspirations gap, i.e. aspirations relative to current status $\left(g=\frac{a-s}{a}\right)$, is a useful concept empirically because it limits the range of possible values and allows for more meaningful comparisons across individuals. Note that $g$ will be one if a household has zero income and any nonzero level of aspirations. In order to avoid this mechanical relationship and distinguish someone with $s=0$ and high aspirations from someone with $s=0$ and low aspirations, we convert zero entries for $s$ and $a$ to one prior to constructing the gap. After making this transformation, Fig. $5 b$ and $d$ plot the distribution of the income aspirations gap and the education aspirations gap.

\footnotetext{
${ }^{10}$ Essentially, the asset measure requires a more complicated internal calculation involving a stream of income and decisions regarding savings and expenditures. Furthermore, asset aspirations are defined as the "value of home and land," which is an incomplete measure of total assets or wealth. Our results are qualitatively similar using either measure, although employing asset aspirations results in substantially less precision.
} 
(a) Income aspirations

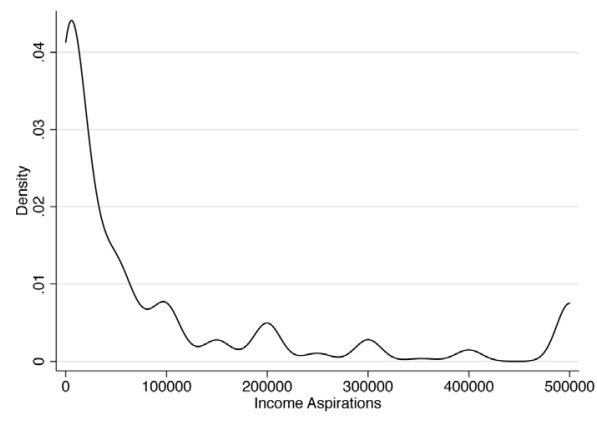

(c) Education aspirations

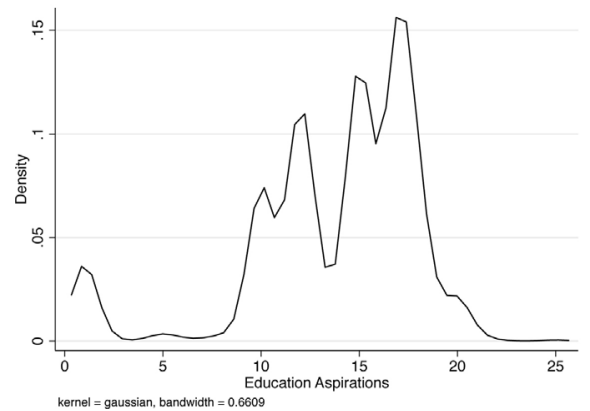

(b) Income aspirations gap

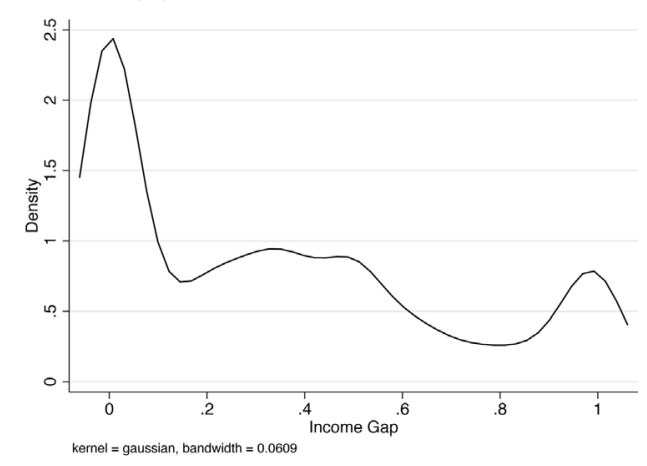

(d) Education aspirations gap

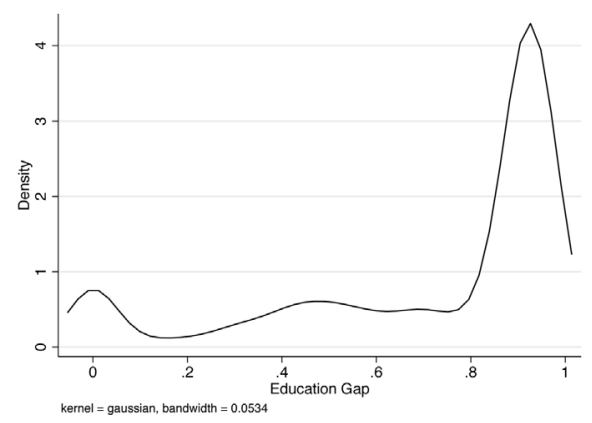

Fig. 5. Distributions of aspirations and aspirations gaps.

\subsection{Constructing the aspirations window}

In Section 3 we discussed possibilities for how the status of others in one's reference group, the aspirations "window," guide aspirations formation. Defining the relevant reference group is challenging, particularly if that reference group is not determined by easily observable characteristics like geography, religion or caste. We first consider a reference group for which data is typically available: all residents within a certain geographical boundary. Specifically, we consider all women residing within the same tole, which is like a neighborhood. We then define the reference group using social network data within the tole.

In the past decade or so, a host of studies have used detailed social network data to examine the role of peercommunication on technology diffusion (Bandiera and Rasul, 2006; Banerjee et al., 2013; Conley and Udry, 2010, and others), and in at least one case to study spillover effects of an intervention targeting aspirations (Bernard et al., 2014). We capture social linkages by showing respondents a community photo directory, and asking each respondent to identify any individuals whom she knows, and then specify the relationship; i.e., whether each known individual is a close family member, a relative, a neighbor, a friend, an acquaintance, or a familiar face. For our analysis we ignore links identified as an "acquaintance" or a "familiar face."

A common issue with dyadic network data is misreporting and/or asymmetrical reporting where individual $i$ claims individual $j$ as a network link, but $j$ does not claim $i$ (Comola and Fafchamps, 2014, 2017). For this study, we are particularly concerned with individuals citing those they aspire to be linked to rather than those they are actually linked to, as these aspirational links may be related to their aspirations for income and children's education. We therefore consider individuals $i$ and $j$ to be linked only if each cites the other as a link. ${ }^{11}$ Individual $i$ 's social network is thus composed of all individuals within the targeted tole whom $i$ knows and claim to know $i$ reciprocally.

Once the relevant reference group has been defined, the aspirations window captures the distribution of observable outcomes within it. Because the relevant observable outcomes are likely to vary across aspirational dimensions, the window will be defined separately for each dimension. For income aspirations, we consider the income of others in the potential window. For education aspirations, we consider the education attained by others' children. Selecting a single variable to define children's education outcomes for a household with multiple children is complicated, especially when most children

\footnotetext{
11 We require $i$ and $j$ to each cite the other as any type of link under consideration (family, relative, friend, or neighbor); we do not require them to claim
} the same type of link as there may be considerable overlap among link types. 
Descriptive statistics on potential aspirations window variables

\begin{tabular}{|c|c|c|c|}
\hline Variable & Same tole & Links & Ex links \\
\hline \multicolumn{4}{|l|}{ Panel A: Income window for all women, $N=944$} \\
\hline \multirow[t]{2}{*}{ Average income in window (NPR) } & 65,762 & 67,843 & 65,176 \\
\hline & $(105,954)$ & $(203,771)$ & $(223,806)$ \\
\hline \multirow[t]{2}{*}{ Average income above (NPR) } & 184,750 & 139,958 & 118,273 \\
\hline & $(425,269)$ & $(425,503)$ & $(343,722)$ \\
\hline \multirow[t]{2}{*}{ Average income below (NPR) } & 12,809 & 25,427 & 29,903 \\
\hline & $(26,311)$ & $(116,419)$ & $(155,205)$ \\
\hline \multicolumn{4}{|c|}{ Panel B: Children's education window (child 15 years old or younger), $N=731$} \\
\hline \multirow[t]{2}{*}{ Average max years child's education in window } & 7.07 & 7.05 & 7.01 \\
\hline & $(1.94)$ & $(3.27)$ & $(3.51)$ \\
\hline \multirow[t]{2}{*}{ Average max children's education above } & 10.38 & 9.22 & 8.90 \\
\hline & $(2.60)$ & $(3.42)$ & $(3.60)$ \\
\hline \multirow[t]{2}{*}{ Average max children's below } & 3.53 & 4.54 & 4.71 \\
\hline & $(2.68)$ & $(3.56)$ & (3.67) \\
\hline
\end{tabular}

Standard deviations in parentheses. 100 NPR equals approximately 1 USD.

have not yet finished their schooling. Since aspirations are forward-looking, we consider the maximum level of education attained by any child in each reference household, whether or not schooling is complete.

Finally, we define the window for each possible reference group using two separate components: the (mean) level of outcomes in one's reference group that are higher than one's own status, and the (mean) level of outcomes in one's reference group that are lower. Following Ferrer-i-Carbonell (2005), this disaggregation accommodates estimation of "upwardlooking" aspirations as hypothesized by Deusenberry (1949). For ease of exposition, we refer to a woman with a higher income (or higher education achievement by children) as being "above," and a woman with the same or lower income (or lower educational achievement by children) as "below." If individual $i$ does not have anyone in her reference group above/below her, that value is replaced with her own current level of the outcome.

Table 2 presents descriptive statistics of the aspirations windows using the various reference groups. Average annual income in the reference groups is near the sample average of 65,000 NPR (650 USD) shown in Table 1. Average income among those above is between 118,000-184,000 NPR (1180 USD-1840 USD); the average asset value for those below is between 13,000-29,000 NPR (130 - 290 USD). For education aspirations windows, we limit the sample to women with at least one child age 15 or under. Likewise, in the gender-disaggregated analysis, we limit the sample to women with a son (daughter) age 15 or under. For households with at least one child age 15 or under, the highest level of education attained by any child in the household, whether or not they have completed their schooling, is seven years on average. The average maximum education level obtained by any child is approximately 10 years for those above and between four years for those below.

\section{Aspirations failure in Nepal}

In this section we empirically test for the theoretical relationship described in Section 2 . We first describe our empirical approach in Section 5.1. We then present evidence of an inverse-U relationship between income aspirations and futureoriented savings and investment behavior (Section 5.2), and between educational aspirations and educational expenditures (Section 5.3).

\subsection{Testing for aspirations failure}

The theoretical model developed in Section 2.1 predicts an inverse-U relationship between aspirations and investment. In the analysis that follows we consider two approaches to test for this non-monotonic relationship across two different aspirational dimensions: income and education. For each dimension we estimate the following linear regression model of investment on the aspirations gap, $g$, for individual $i$ from $\operatorname{VDC} v$, where $g$ enters the right hand side of the equation as a quadratic term:

$$
k_{i v}=\alpha+\beta_{1} g_{i v}+\beta_{2} g_{i v}^{2}+\beta_{3} s_{i v}+\beta_{4} d_{i v}+\boldsymbol{x}_{i v}^{\prime} \boldsymbol{\delta}+v_{v}+\varepsilon_{i v} .
$$

Current status $s$ is a component of the aspirations gap, yet it is essential to control for $s$ on its own for two reasons. First, current status is likely to be correlated with future-oriented behavior through non-aspirational channels (when you have more or earn more you can save more). Second, the behavioral switching point $\hat{a}$, which determines at what point the aspirations gap becomes large enough to cause aspirations failure, is increasing in one's current status.

We also control for $d$, a dummy variable equal to one if the individual's current status (before converting zeros to ones) for a given dimension is zero. This is important because of the way the gap is constructed. Even though we convert zeros to ones for anyone with $s=0$, households with zero current status are clustered at either one end of the aspirations gap spectrum or the other. Specifically, those with zero aspirations and zero current status have $g=0$ and those with non-zero 
Table 3

Relationship between income aspirations gaps and financial decisions.

\begin{tabular}{|c|c|c|c|c|}
\hline & $\begin{array}{l}\text { (1) } \\
\text { Savings group }\end{array}$ & $\begin{array}{l}\text { (2) } \\
\text { Saved last month }\end{array}$ & $\begin{array}{l}\text { (3) } \\
\text { Amt Saved }\end{array}$ & $\begin{array}{l}(4) \\
\text { Amt Temp Spending }\end{array}$ \\
\hline Income aspirations gap & $\begin{array}{l}0.33^{* *} \\
(0.13)\end{array}$ & $\begin{array}{l}0.26^{* *} \\
(0.10)\end{array}$ & $\begin{array}{l}1.28^{* *} \\
(0.60)\end{array}$ & $\begin{array}{l}-0.11 \\
(0.68)\end{array}$ \\
\hline Income gap squared & $\begin{array}{l}-0.34^{* *} \\
(0.13)\end{array}$ & $\begin{array}{l}-0.25^{* *} \\
(0.11)\end{array}$ & $\begin{array}{l}-1.16^{*} \\
(0.63)\end{array}$ & $\begin{array}{l}0.20 \\
(0.73)\end{array}$ \\
\hline Zero income & $\begin{array}{l}0.18^{* *} \\
(0.088)\end{array}$ & $\begin{array}{l}0.054 \\
(0.081)\end{array}$ & $\begin{array}{l}0.98^{* *} \\
(0.45)\end{array}$ & $\begin{array}{l}0.22 \\
(0.60)\end{array}$ \\
\hline Current monthly income & $\begin{array}{l}0.028^{* * *} \\
(0.0085)\end{array}$ & $\begin{array}{l}0.015^{*} \\
(0.0077)\end{array}$ & $\begin{array}{l}0.16^{* * *} \\
(0.045)\end{array}$ & $\begin{array}{l}0.00014 \\
(0.059)\end{array}$ \\
\hline Years of education (respondent) & $\begin{array}{l}0.0063^{* *} \\
(0.0027)\end{array}$ & $\begin{array}{l}0.0036 \\
(0.0027)\end{array}$ & $\begin{array}{l}0.051^{* * *} \\
(0.016)\end{array}$ & $\begin{array}{l}-0.11^{* * * *} \\
(0.020)\end{array}$ \\
\hline Age (respondent) & $\begin{array}{l}-0.0012^{*} \\
(0.00070)\end{array}$ & $\begin{array}{l}-0.0030^{* * *} \\
(0.00080)\end{array}$ & $\begin{array}{l}-0.017^{* * *} \\
(0.0043)\end{array}$ & $\begin{array}{l}-0.010^{*} \\
(0.0058)\end{array}$ \\
\hline Household has a migrant & $\begin{array}{l}0.051^{* * *} \\
(0.019)\end{array}$ & $\begin{array}{l}0.045^{* *} \\
(0.017)\end{array}$ & $\begin{array}{l}0.31^{* * *} \\
(0.093)\end{array}$ & $\begin{array}{l}-0.33^{* *} \\
(0.13)\end{array}$ \\
\hline Respondent controls savings & $\begin{array}{l}0.049 \\
(0.034)\end{array}$ & $\begin{array}{l}0.15^{* * *} \\
(0.031)\end{array}$ & $\begin{array}{l}0.99^{* * *} \\
(0.17)\end{array}$ & $\begin{array}{l}0.25 \\
(0.16)\end{array}$ \\
\hline Constant & $\begin{array}{l}0.23^{* *} \\
(0.088)\end{array}$ & $\begin{array}{l}0.47^{* * *} \\
(0.092)\end{array}$ & $\begin{array}{l}0.82 \\
(0.51)\end{array}$ & $\begin{array}{l}3.83^{* * *} \\
(0.67)\end{array}$ \\
\hline $\begin{array}{l}\text { Observations } \\
R^{2}\end{array}$ & $\begin{array}{l}3277 \\
0.127\end{array}$ & $\begin{array}{l}3277 \\
0.159\end{array}$ & $\begin{array}{l}3277 \\
0.195\end{array}$ & $\begin{array}{l}3277 \\
0.099\end{array}$ \\
\hline U-test Results: & & & & \\
\hline Turning Point & 0.498 & 0.522 & 0.552 & 0.269 \\
\hline Fieller $95 \%$ Confidence Interval & {$[0.40,0.72]$} & {$[0.40,0.94]$} & {$[-\infty,+\infty]$} & {$[-\infty,+\infty]$} \\
\hline Sasabuchi $p$-value & 0.013 & 0.023 & 0.066 & 0.437 \\
\hline Slope at Min & 0.335 & 0.258 & 1.283 & -0.108 \\
\hline Slope at Max & -0.337 & -0.236 & -1.042 & 0.295 \\
\hline
\end{tabular}

All specifications control for VDC fixed effects.

Cluster (VDC) robust standard errors in parentheses

${ }^{*} p<0.1$.

${ }^{* *} p<0.05$.

${ }^{* * *} p<0.01$.

aspirations have $g$ near one. These zero status households are likely to have low investment levels for reasons other than aspirations, potentially even after controlling for status linearly in equation (6). The inclusion of $d$ ensures our results are not driven entirely by these low status individuals' at either end of the aspirations gap range. ${ }^{12}$ Finally, we control for a vector of covariates $\boldsymbol{x}$, and VDC fixed effects $\left(v_{v}\right)$. We estimate equation (6) using OLS for continuous and dichotomous outcomes; for the latter, results are robust to the problt specification.

Given equation (6), and the fact that $g$ is constrained to be between zero and one, an inverse-U shape requires that the slope of the curve is positive when $g=0$ (i.e., $\beta_{1}>0$ ), and negative when $g=1$ (i.e., $\beta_{1}+2 \beta_{2}<0$ ), with one extreme turning point in between. To test for an inverse-U shape, we employ Lind and Mehlum's (2010) test for an inverse-U shape. We report the results from this test, including the Sasabuchi $p$-value, the estimated slope at $g=0$ and $g=1$, the estimated turning point, and the 95 percent Fieller confidence interval for the turning point.

The regression strategy outlined in equation (6) provides a useful first step approach, however, the hypothesized inverted$\mathrm{U}$ relationship may be better captured using semi-parametric techniques. For our second approach we estimate the partially linear model described by:

$$
k_{i v}=\alpha+f(g)+\beta s_{i v}+\boldsymbol{x}_{\boldsymbol{i v}}^{\prime} \boldsymbol{\delta}+v_{v}+\varepsilon_{i v} .
$$

The only difference between equations (6) and (7) is in how the gap enters the estimation. In equation (6) we assumed the quadratic relationship. Equation (7) provides a more flexible alternative for modeling the nonlinear relationship between $g$ and $k$.

\subsection{Evidence of aspirations failure for income}

Table 3 reports estimation results for equation (6) for income aspirations, where in columns $1-3 k$ is savings, an indicator of future-oriented investment behavior. Column 1 uses a dependent variable equal to one if the individual is a member of a savings group, column 2 uses a dependent variable equal to one if the individual reported any savings in the past month,

12 Note also that $g=0$ whenever $a=s=0$ (zero income with no aspirations for income/wealth) or $a=s>0$ (aspirations are satisfied by current income/wealth). In both cases we expect low investment, as captured by our hypothesis. 
(a) Savings group membership

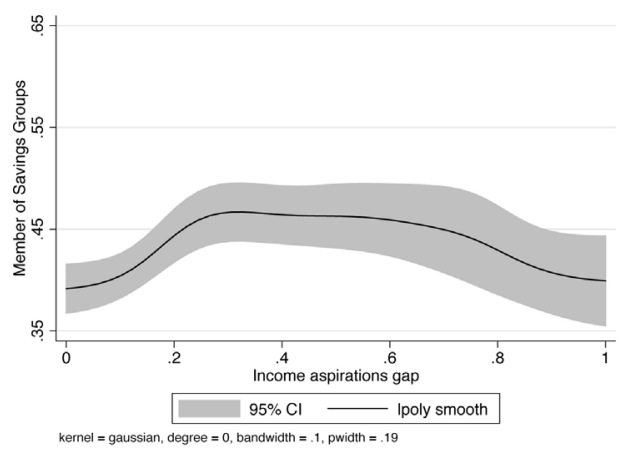

(c) Amount savings

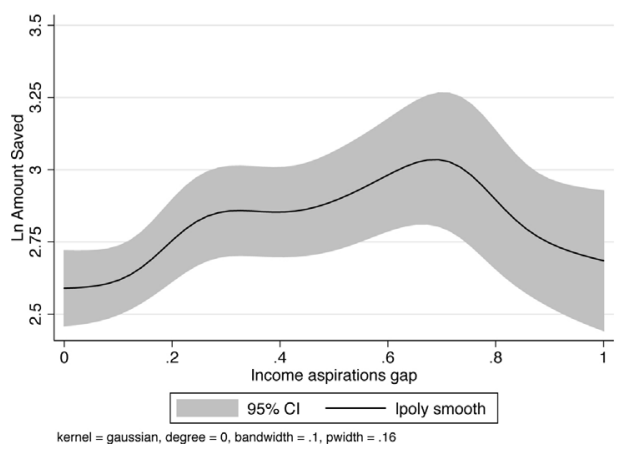

(b) Any savings

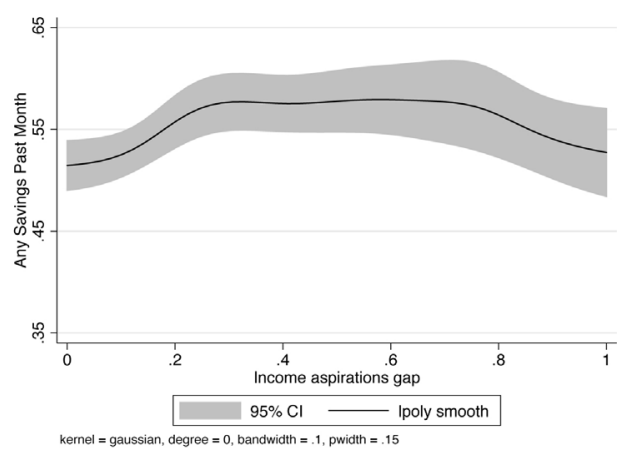

(d) Spending on temptation goods

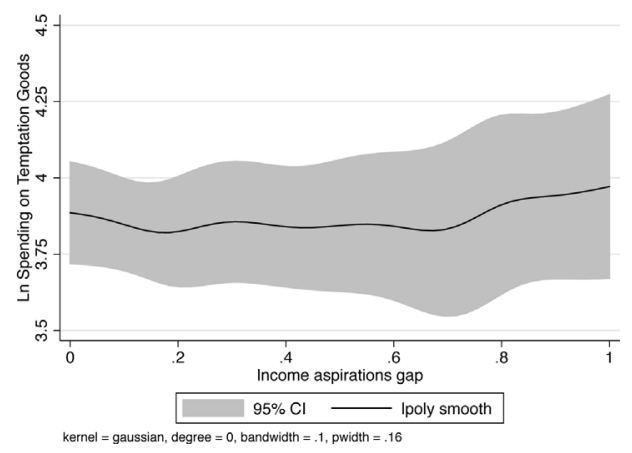

Fig. 6. Nonparametric relationship of income aspirations gaps and financial decisions.

and column 3 considers the $(\mathrm{ln})$ amount saved in the previous month as the dependent variable. ${ }^{13}$ In each regression we control separately for current income, or "status" and include a dummy variable for individuals with zero income. ${ }^{14}$ We also control for the respondent's education and age, if the household has a migrant, if the respondent has input into the savings decision, and VDC fixed effects. Standard errors are clustered at the VDC level.

The results presented in columns 1-3 show the income aspirations gap is indeed positively correlated with savings. Aspiring for income levels that are higher than one's current income is associated with a higher likelihood that one is a member of a savings group and/or actively saves for the future. As predicted by theory, there is also strong evidence that the relationship between the income-aspirations gap and savings is an inverse-U. The coefficient $\beta_{2}$ estimating the relationship between $g^{2}$ and $k$ is negative, as expected. Results from Lind and Mehlum's (2010) test for an inverse-U shape yield a plausible turning point (around $g=0.5$ ), appropriately signed slopes at 0 and 1 , and a highly significant $p$-value.

Another indicator of future-oriented behavior, or lack thereof, is spending on non-productive temptation goods (tobacco, cigarettes and alcohol). The idea is that such spending crowds out savings or investment in productive activities. If that's true, in a regression of temptation spending on aspiration gaps, rather than an inverse- $U$ relationship, we now expect a regular-U relationship. However, the fourth column of Table 3 provides no strong evidence of a $U$ relationship between the income aspirations gap and expenditures on temptation goods. The signs of the estimated coefficients for the quadratic are what we would expect, but the coefficients are far from statistically significant. Results from Lind and Mehlum's (2010) test for a regular-U shape again suggest a plausible turning point (around $g=0.3$ ), appropriately signed slopes at 0 and 1 , but an insignificant p-value.

As outlined in Section 5.1, we also employ semi-parametric techniques to test for an inverse-U relationship between income aspirations and savings-related financial decisions, and a normal-U relationship between income aspirations and temptation goods. In Fig. 6a-d we present the nonparametric component of estimating Eq. (7). The approach follows that taken in the linear model; we consider the same three savings outcome variables alongside spending on temptation goods. The results from the semi-parametric approach are strongly indicative of an inverse-U relationship between income

\footnotetext{
${ }^{13}$ We use the $\ln (X+1)$ transformation for monetary variables to account for long right tails and zero values. All results are robust using the inverse hyperbolic sine transformation.

1431 percent of households report zero income.
} 
aspirations and savings. Alternatively, in Fig. $6 \mathrm{~d}$ we see no discernable evidence of the hypothesized regular-U relationship between the income aspirations gap and spending on temptation goods.

\subsection{Evidence of aspirations failure for education}

In this section we explore the relationship between the education aspirations gap and education-related expenditures in the past year. The expenditures we consider include transportation costs to attend school, school tuition, school uniforms, and school supplies. The data includes education aspirations for all children and disaggregated by gender, allowing for gender-disaggregated analysis. However, for the analysis of education aspirations failure, several challenges exist, and the empirical approach is not as straightforward as it is in Section 5.2.

Defining the education aspirations gap is considerably more difficult than defining the income aspirations gaps. Our data on educational aspirations are for all of the respondent's children, i.e., one aspiration for all of her children (but only her own children, and not other children in the household). However, educational status, achievement and aspirations can be unique for each child. To address this challenge as best we can, we define the education aspirations gap as the difference between the woman's stated aspired level of education for her children and the current education level of her most educated child.

A second challenge is that the education aspirations gap may not pertain to the exact same group of children as education spending. Education expenditures are expressed as the sum of all household education-related expenditures, and may also include expenditures for children that are not the respondent's (e.g., grandchildren, younger siblings, nephews and nieces). Household education spending likely increases with the number of children in the household, and educational aspirations are likely correlated with the number of children in the household (with the theoretical direction of correlation uncertain). For households with multiple children, there is nothing we can do to parse out spending on a particular child, or even the respondent's own children. To deal with this problem as best as we can, we control for the total number of children in the household using a series of dummy variables as explained below.

One solution to these challenges is to limit the sample to households with an only child. This ensures the education expenditures and aspirations are related to the same child. ${ }^{15}$ The tradeoff to this approach is twofold. First, 662 households have an only child; this much smaller sample size will diminish power. This tradeoff is especially stark for the genderdisaggregated analysis where data is available for only 283 single-daughter households and 378 single-son households. ${ }^{16}$ Second, the results can only be interpreted for the restricted sample, that is, households with an only child. In what follows, we will report results from both the full and restricted (one child) samples.

A final challenge in estimating education aspirations is how to account for current educational status $s$, and especially $s=0$. Educational expenditures are explicitly linked to having at least one child in school. Consider two children of similar age. One is in school (positive investment), and one is not (zero investment). Conditional on age we are interested in the educational investment decision, which is a combination of sending children to school and (conditional on going to school) expenditures. If we control for $s=0$ (no child has attended, or is attending, school), then we control for households who are choosing to not invest in education - but this is an important component of the relationship we're interested in. Educational aspirations also likely increase with a child's age, conditional on enrollment. To address each of these issues we control for the age of all children in the household (and simultaneously the number of children) using a vector $\boldsymbol{a}$ of age dummy variables, that take on a value of 1 if the household has a child of a particular age. In doing so, we control for the exogenous part of educational status (child's age), but not the endogenous part (child's enrollment). With these changes, Eq. (6) adapted to education becomes:

$$
k_{i v}=\alpha+\beta_{1} g_{i v}+\beta_{2} g_{i v}^{2}+\boldsymbol{a}_{\boldsymbol{i v}}^{\prime} \boldsymbol{\gamma}+\boldsymbol{x}_{\boldsymbol{i v}}^{\prime} \boldsymbol{\delta}+v_{v}+\varepsilon_{i v}
$$

Table 4 reports the results of estimating equation (8) for educational aspirations and investment using the full sample. The dependent variable takes two forms: columns 1-3 employ a dummy variable if expenditures are positive (i.e., any investment $)^{17}$, and columns 4-6 consider the (ln) amount spent on education-related expenses in the previous year. The table reports the estimated relationship for the full sample (columns 1 and 4), girls only (columns 2 and 5), and boys only (columns 3 and 6). All specifications control for household income, respondent age and education, if the households has a migrant, and VDC fixed effects. As in the previous section, we report results from Lind and Mehlum's (2010) test. Table 5 reports the same specifications using the restricted sample (households with an only child).

The results presented in Table 4 provide strong evidence of an inverse-U relationship between the education-aspirations gap and investment in children's education, both on aggregate and for boys and girls separately. Across all specifications, the estimated coefficients suggest that a quadratic relationship between $g_{i v}$ and $k_{i v}$ provides a better approximation than a linear one. Results from Lind and Mehlum's (2010) test for an inverse-U shape suggest plausible turning points (0.41 to 0.57 ), appropriately signed slopes at 0 and 1 , and a highly significant $p$-value. The results are quite robust to using only the

\footnotetext{
${ }^{15}$ It is still possible that aspirations are expressed for an unobserved child not living with the household, or for child yet to be born. We think these are both unlikely possibilities.

16 One child is of unknown gender.

17 These results are also robust to probit specification.
} 
Relationship between education aspirations gaps and education investment: Full sample

\begin{tabular}{|c|c|c|c|c|c|c|}
\hline & $\begin{array}{l}\text { (1) } \\
\text { Any Investment } \\
\text { All children }\end{array}$ & $\begin{array}{l}(2) \\
\text { Any Investment } \\
\text { Girls only }\end{array}$ & $\begin{array}{l}(3) \\
\text { Any Investment } \\
\text { Boys only }\end{array}$ & $\begin{array}{l}(4) \\
\text { Amt Spent } \\
\text { All children }\end{array}$ & $\begin{array}{l}\text { (5) } \\
\text { Amt Spent } \\
\text { Girls only }\end{array}$ & $\begin{array}{l}(6) \\
\text { Amt Spent } \\
\text { Boys only }\end{array}$ \\
\hline Education gap & $\begin{array}{l}0.25^{*} \\
(0.14)\end{array}$ & & & $\begin{array}{l}3.50^{* * *} \\
(1.29)\end{array}$ & & \\
\hline Education gap squared & $\begin{array}{l}-0.29^{* *} \\
(0.13)\end{array}$ & & & $\begin{array}{l}-4.30^{* * *} \\
(1.20)\end{array}$ & & \\
\hline Female education gap & & $\begin{array}{l}0.51^{* * *} \\
(0.15)\end{array}$ & & & $\begin{array}{l}5.62^{* * *} \\
(1.51)\end{array}$ & \\
\hline Female education gap squared & & $\begin{array}{l}-0.51^{* * *} \\
(0.13)\end{array}$ & & & $\begin{array}{l}-6.13^{* * *} \\
(1.26)\end{array}$ & \\
\hline Male education gap & & & $\begin{array}{l}0.40^{* *} \\
(0.18)\end{array}$ & & & $\begin{array}{l}3.80^{* *} \\
(1.83)\end{array}$ \\
\hline Male education gap squared & & & $\begin{array}{l}-0.36^{* *} \\
(0.15)\end{array}$ & & & $\begin{array}{l}-3.34^{* *} \\
(1.51)\end{array}$ \\
\hline Current monthly income & $\begin{array}{l}0.0039^{* * *} \\
(0.0013)\end{array}$ & $\begin{array}{l}0.0042^{* *} \\
(0.0016)\end{array}$ & $\begin{array}{l}0.0037^{* *} \\
(0.0015)\end{array}$ & $\begin{array}{l}0.053^{* * *} \\
(0.012)\end{array}$ & $\begin{array}{l}0.065^{* * *} \\
(0.016)\end{array}$ & $\begin{array}{l}0.051^{* * *} \\
(0.013)\end{array}$ \\
\hline (mean) edu2 & $\begin{array}{l}0.0014 \\
(0.0019)\end{array}$ & $\begin{array}{l}-0.00091 \\
(0.0021)\end{array}$ & $\begin{array}{l}0.0024 \\
(0.0023)\end{array}$ & $\begin{array}{l}0.11^{* * *} \\
(0.020)\end{array}$ & $\begin{array}{l}0.077^{* * *} \\
(0.021)\end{array}$ & $\begin{array}{l}0.12^{* * *} \\
(0.024)\end{array}$ \\
\hline Age (respondent) & $\begin{array}{l}-0.0049^{* * *} \\
(0.0011)\end{array}$ & $\begin{array}{l}-0.0061^{* * *} \\
(0.0013)\end{array}$ & $\begin{array}{l}-0.0027^{* *} \\
(0.0011)\end{array}$ & $\begin{array}{l}-0.037^{* * *} \\
(0.011)\end{array}$ & $\begin{array}{l}-0.054^{* * *} \\
(0.013)\end{array}$ & $\begin{array}{l}-0.014 \\
(0.011)\end{array}$ \\
\hline Household has a migrant & $\begin{array}{l}-0.0072 \\
(0.012)\end{array}$ & $\begin{array}{l}-0.0059 \\
(0.016)\end{array}$ & $\begin{array}{l}-0.0096 \\
(0.013)\end{array}$ & $\begin{array}{l}0.097 \\
(0.13)\end{array}$ & $\begin{array}{l}0.095 \\
(0.17)\end{array}$ & $\begin{array}{l}0.036 \\
(0.15)\end{array}$ \\
\hline Constant & $\begin{array}{l}1.05^{* * *} \\
(0.070)\end{array}$ & $\begin{array}{l}0.95^{* * *} \\
(0.082)\end{array}$ & $\begin{array}{l}0.81^{* * *} \\
(0.074)\end{array}$ & $\begin{array}{l}8.46^{* * * *} \\
(0.69)\end{array}$ & $\begin{array}{l}8.19^{* * * *} \\
(0.85)\end{array}$ & $\begin{array}{l}6.99^{* * *} \\
(0.70)\end{array}$ \\
\hline Observations & 1924 & 1316 & 1470 & 1924 & 1316 & 1470 \\
\hline$R^{2}$ & 0.152 & 0.169 & 0.164 & 0.181 & 0.213 & 0.194 \\
\hline U-test Results: & & & & & & \\
\hline Turning Point & 0.435 & 0.502 & 0.561 & 0.407 & 0.486 & 0.569 \\
\hline Fieller 95\% Confidence Interval & {$[0.178,0.658]$} & {$[0.375,0.600]$} & {$[0.234,0.732]$} & {$[0.212,0.517]$} & {$[0.337,0.535]$} & {$[0.140,0.848]$} \\
\hline Sasabuchi $p$-value & 0.033 & 0.001 & 0.016 & 0.004 & 0.000 & 0.021 \\
\hline Slope at Min & 0.253 & 0.514 & 0.404 & 3.502 & 5.618 & 3.800 \\
\hline Slope at Max & -0.330 & -0.509 & -0.316 & -5.093 & -6.634 & -2.877 \\
\hline
\end{tabular}

All specifications control for VDC fixed effects.

Cluster (VDC) robust standard errors in parentheses.

${ }^{*} p<0.1$.

** $p<0.05$

*** $p<0.01$.

restricted sample, as shown in Table 5. The main exception is that the gender-disaggregated results for females, although qualitatively similar, are no longer statistically significant.

We conduct semi-parametric regressions for the relationship between education aspirations and education spending similar to Section 5.2. The nonlinear relationship between education aspirations and education-related expenses are shown in Figs. 7 and 8. First, Fig. 7a and b shows the results for all children using any education expenses and the logged amount spent, respectively. An inverse-U relationship is apparent. The subsequent two Figs. (7c and $7 \mathrm{~d}$ ) replicate the first two figures using only the restricted sample; the results are robust.

Fig. 8 presents the gender-disaggregated results using logged expenditures as the dependent variable. Fig. 8a shows the results using one's educational aspirations for daughters, while Fig. 8b shows the same results using aspirations for sons. Both show a strong inverse-U relationship. These results are robust to including only the restricted sample, as shown in Fig. $8 \mathrm{c}$ and $\mathrm{d}$, but there are some differences. The full sample results show similar investment for boys and girls for those with a small to moderate aspirations gap (around 0.5), but as the gap becomes large investment for girls diminishes whereas for boys it does not. The restricted sample results reveal similar investment for boys and girls when the mother has a small or large aspirations gap, but investment by those with a moderate aspirations gap is higher for boys. These results combined suggest that a "failure" of educational investment is more likely to occur for girls than for boys. When aspirations are moderate, larger investments are made in boys education compared to girls education. When aspirations are either too large or too small, girls are more likely to be affected by lower investment.

\section{Aspirations formation in Nepal}

In this section we investigate the formation of aspirations. We first describe our basic empirical specification (Section 6.1), and then present our analysis of social influences on aspirations for income (Section 6.2) and children's education (Section $6.3)$. 
(a) Any investment, full sample

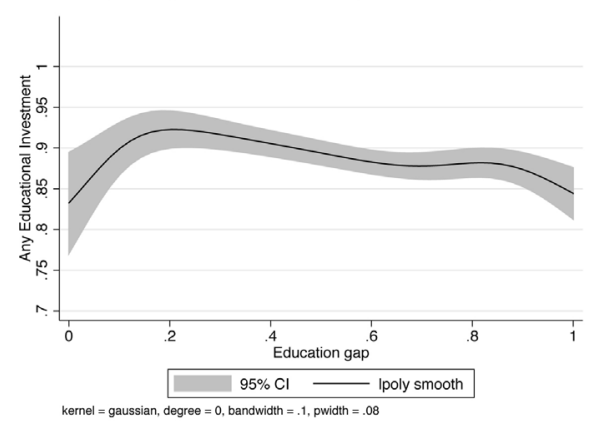

(c) Any investment, restricted sample

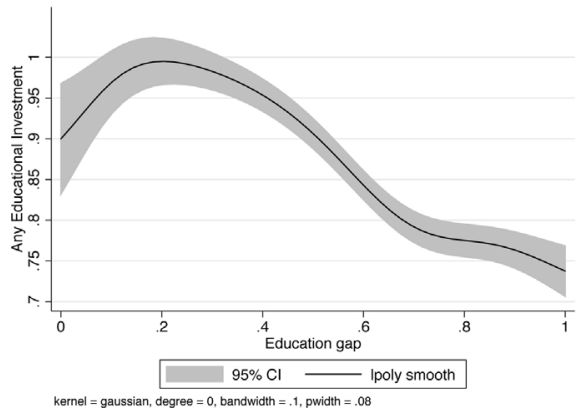

(b) Education expenditures, full sample

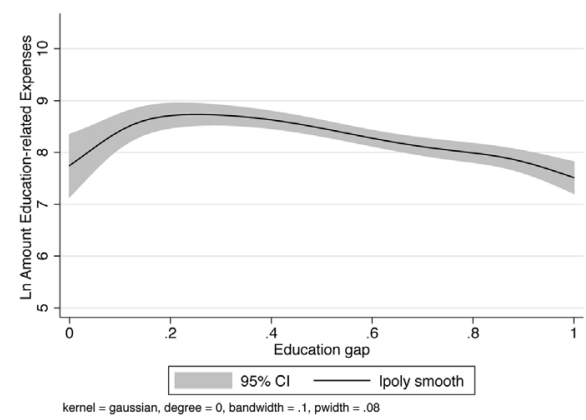

(d) Education expenditures, restricted sample

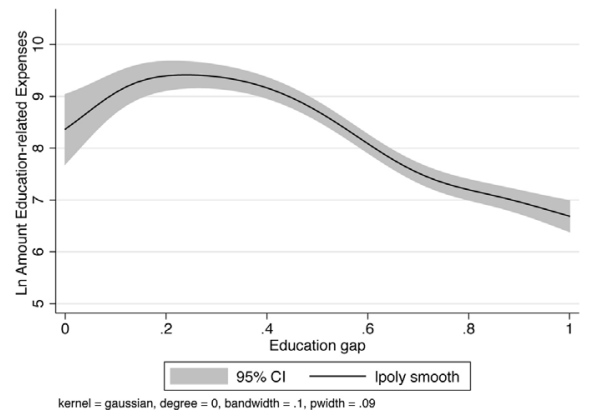

Fig. 7. Nonparametric relationship of education aspirations gap and education investment.

(a) Female gap, full sample

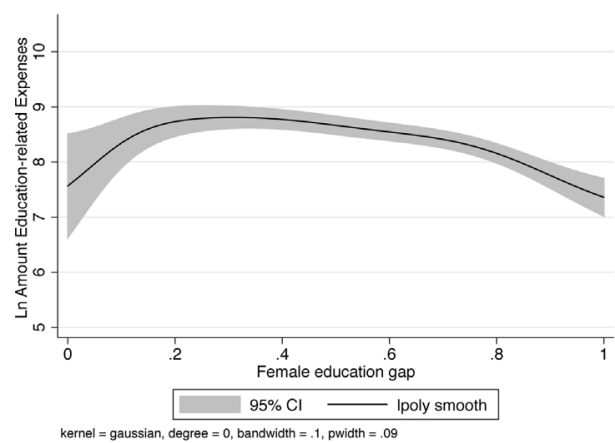

(c) Female gap, restricted sample

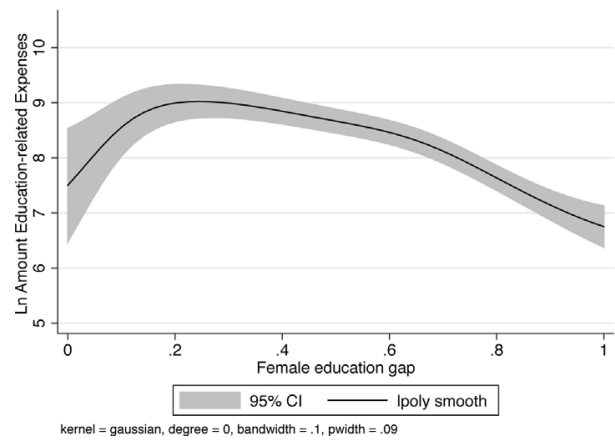

(b) Male gap, full sample

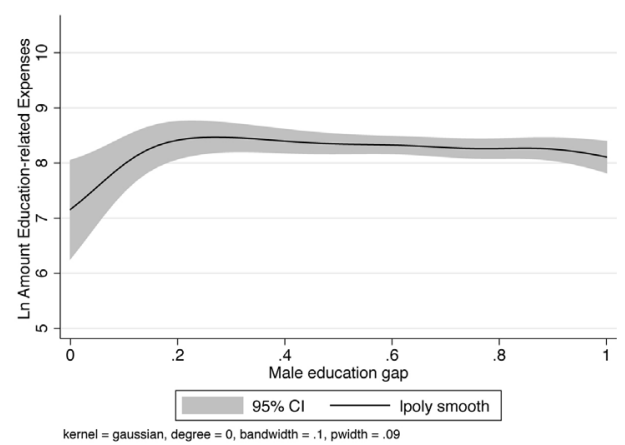

(d) Male gap, restricted sample

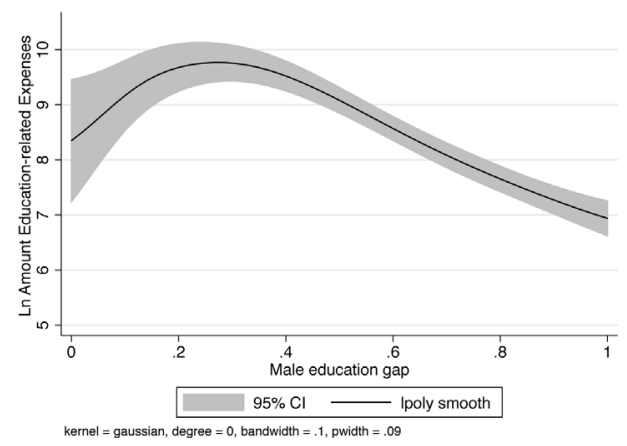

Fig. 8. Gender-disaggregated nonparametric relationship of education aspirations gap and education expenditures. 
Relationship between education aspirations gaps and education investment: Restricted sample

\begin{tabular}{|c|c|c|c|c|c|c|}
\hline & $\begin{array}{l}\text { (1) } \\
\text { Any Investment } \\
\text { All children }\end{array}$ & $\begin{array}{l}\text { (2) } \\
\text { Any Investment } \\
\text { Girls only }\end{array}$ & $\begin{array}{l}\text { (3) } \\
\text { Any Investment } \\
\text { Boys only }\end{array}$ & $\begin{array}{l}(4) \\
\text { Amt Spent } \\
\text { All children }\end{array}$ & $\begin{array}{l}\text { (5) } \\
\text { Amt Spent } \\
\text { Girls only }\end{array}$ & $\begin{array}{l}(6) \\
\text { Amt Spent } \\
\text { Boys only }\end{array}$ \\
\hline Education gap & $\begin{array}{l}0.57^{* *} \\
(0.23)\end{array}$ & & & $\begin{array}{l}5.95^{* *} \\
(2.34)\end{array}$ & & \\
\hline Education gap squared & $\begin{array}{l}-0.70^{* * *} \\
(0.21)\end{array}$ & & & $\begin{array}{l}-7.49^{* * *} \\
(2.16)\end{array}$ & & \\
\hline Female education gap & & $\begin{array}{l}0.40 \\
(0.53)\end{array}$ & & & $\begin{array}{l}3.53 \\
(5.52)\end{array}$ & \\
\hline Female education gap squared & & $\begin{array}{l}-0.49 \\
(0.45)\end{array}$ & & & $\begin{array}{l}-5.12 \\
(4.62)\end{array}$ & \\
\hline Male education gap & & & $\begin{array}{l}1.15^{* * *} \\
(0.41)\end{array}$ & & & $\begin{array}{l}10.9^{* * *} \\
(3.99)\end{array}$ \\
\hline Male education gap squared & & & $\begin{array}{l}-1.16^{* * *} \\
(0.36)\end{array}$ & & & $\begin{array}{l}-11.3^{* * *} \\
(3.68)\end{array}$ \\
\hline Current monthly income & $\begin{array}{l}0.0064^{*} \\
(0.0032)\end{array}$ & $\begin{array}{l}0.0073 \\
(0.0062)\end{array}$ & $\begin{array}{l}0.0025 \\
(0.0050)\end{array}$ & $\begin{array}{l}0.056^{*} \\
(0.033)\end{array}$ & $\begin{array}{l}0.082 \\
(0.066)\end{array}$ & $\begin{array}{l}-0.0016 \\
(0.046)\end{array}$ \\
\hline (mean) edu2 & $\begin{array}{l}0.0034 \\
(0.0046)\end{array}$ & $\begin{array}{l}-0.0035 \\
(0.0049)\end{array}$ & $\begin{array}{l}0.011 \\
(0.0082)\end{array}$ & $\begin{array}{l}0.13^{* * *} \\
(0.048)\end{array}$ & $\begin{array}{l}0.051 \\
(0.050)\end{array}$ & $\begin{array}{l}0.21^{* *} \\
(0.081)\end{array}$ \\
\hline Age (respondent) & $\begin{array}{l}-0.0054^{* * *} \\
(0.0020)\end{array}$ & $\begin{array}{l}-0.0083^{* *} \\
(0.0032)\end{array}$ & $\begin{array}{l}-0.0015 \\
(0.0028)\end{array}$ & $\begin{array}{l}-0.026 \\
(0.020)\end{array}$ & $\begin{array}{l}-0.057^{*} \\
(0.031)\end{array}$ & $\begin{array}{l}0.017 \\
(0.028)\end{array}$ \\
\hline Household has a migrant & $\begin{array}{l}-0.026 \\
(0.024)\end{array}$ & $\begin{array}{l}0.021 \\
(0.058)\end{array}$ & $\begin{array}{l}-0.042 \\
(0.036)\end{array}$ & $\begin{array}{l}0.047 \\
(0.24)\end{array}$ & $\begin{array}{l}0.37 \\
(0.55)\end{array}$ & $\begin{array}{l}-0.027 \\
(0.36)\end{array}$ \\
\hline Constant & $\begin{array}{l}0.91^{* * *} \\
(0.14)\end{array}$ & $\begin{array}{l}1.06^{* * *} \\
(0.24)\end{array}$ & $\begin{array}{l}0.35^{*} \\
(0.19)\end{array}$ & $\begin{array}{l}6.93^{* * *} \\
(1.34)\end{array}$ & $\begin{array}{l}7.56^{* * *} \\
(2.41)\end{array}$ & $\begin{array}{l}1.45 \\
(1.68)\end{array}$ \\
\hline Observations & 662 & 283 & 378 & 662 & 283 & 378 \\
\hline$R^{2}$ & 0.274 & 0.336 & 0.393 & 0.246 & 0.316 & 0.368 \\
\hline U-test Results: & & & & & & \\
\hline Turning Point & 0.412 & 0.414 & 0.496 & 0.397 & 0.344 & 0.483 \\
\hline Fieller 95\% Confidence Interval & {$[0.168,0.557]$} & {$[-\infty,+\infty]$} & {$[0.333,0.600]$} & {$[0.171,0.525]$} & {$[-\infty,+\infty]$} & {$[0.321,0.587]$} \\
\hline Sasabuchi $p$-value & 0.008 & 0.224 & 0.003 & 0.007 & 0.263 & 0.004 \\
\hline Slope at Min & 0.574 & 0.403 & 1.147 & 5.945 & 3.526 & 10.936 \\
\hline Slope at Max & -0.820 & -0.572 & -1.167 & -9.0333 & -6.722 & -11.693 \\
\hline
\end{tabular}

All specifications control for VDC fixed effects.

Cluster (VDC) robust standard errors in parentheses.

${ }^{*} p<0.1$.

** $p<0.05$

**** $p<0.01$.

\subsection{Estimation}

In Section 3 we presented a flexible model of aspirations formation (Eq. (5)) that accounts for an individual's position within her reference group. As stated previously, we expect aspirations to be inherently upward looking, so the empirical model must be flexible enough to allow an individual's aspirations to correlate differentially with the status of those "above" and "below" her. With these considerations in mind, we separately estimate the following equation for each aspirational dimension (income and education) using the three reference groups previously described: same tole, the social network within the tole that includes family, neighbors and friends, and the smaller plausibly exogenous social network of family and neighbors (but excluding friends). This model can be written as:

$$
a_{i v}=\alpha+\beta_{1} \bar{w}_{i v}+\beta_{2} \underline{w}_{i v}+\beta_{3} s_{i v}+\boldsymbol{x}_{\boldsymbol{i v}}^{\prime} \boldsymbol{\delta}+v_{d}+\varepsilon_{i v} .
$$

In Eq. (9), $a$ represents individual $i$ 's aspirations in VDC $v$ for either income or children's education. We use $\bar{w}$ to denote the upward-looking window calculated as the average status of those "above" individual $i$, and $\underline{w}$ to denote the downwardlooking window calculated as the average status of those "below" $i$. If aspirations are externally influenced but only upwardlooking, then $\beta_{1}>0$ and $\beta_{2}=0$. We presume that unobserved factors drive both one's own status and the average status of those in their reference group $(\bar{w}$ and $\underline{w})$, and therefore control for own status, $s$.

In all models of aspirations formation we control for a vector of covariates $\boldsymbol{x}$, which includes respondent age and education, and whether the household has a migrant. In the model of aspirations for children's education, we also include current income in the control vector $\boldsymbol{x}$ (current income is $s$ in the estimation of income aspirations formation). We control for the number of individuals above and below in the reference group because of the relationship between an individual's position within a reference group and the status of those above and below her, and to account for the fact some people by necessity had nobody above or below them.

Recall that in our social networks sample we exclude all individuals who reside outside the targeted tole in a VDC. When the reference group is the tole, all respondents within each tole share all of the the same reference individuals, so controlling for VDC (i.e., tole) fixed effects as we do in Section 2 is inappropriate. In the case where the reference group is 
the respondent-defined network there is some variation at the individual level, but still substantial overlap within each tole. Controlling for VDC fixed effects is therefore very conservative; potentially important variation between individuals across toles is lost in order to eliminate the influence of unobserved VDC-level variables. In our main results we therefore control for higher level district fixed effects $\left(v_{d}\right)$. We present results controlling for VDC-level fixed effects as a robustness check. Standard errors are always clustered at the VDC level.

We do not have exogenous variation in reference group membership or status, and therefore face several threats to identification. First, individuals may strategically create links because of their aspirations or goals. Someone who desires a higher income may choose to associate with high earners to gain information or business opportunities (Bala and Goyal, 2000). Or, individuals may misreport desires to be linked to someone as actual links (Comola and Fafchamps, 2014, 2017). Either of these phenomena could lead to biased estimates due to reverse causality; an individual's aspirations cause them to form a link, as opposed to (or in addition to) their links shaping their aspirations.

To address the problems of strategic link formation and wishful link reporting we use only reciprocated links (where both $i$ and $j$ claim to know one another). Whereas this approach eliminates desired links that are not reciprocated, it does not completely mitigate reverse causality incurred by strategically formed links that are reciprocated (perhaps due to mutual interest, among other factors). As an additional step to exclude stratgetic links, we consider a reference group that excludes friends, noting that a woman may choose her friends, but she does not choose her family or neighbors (in rural Nepal, moving is uncommon except for marriage) ${ }^{18}$

Second, the reflection problem (Manski, 1993) presents a challenge; it is difficult to determine if individual $i$ is influenced by individual $j$, or if they they behave similarly and achieve similar outcomes because they share characteristics, shocks, and circumstances. One distinction between our study and the situation described in Manski (1993) is that we examine how outcomes within $i$ 's network affect $i$ 's aspirations, whereas Manski (1993) presents a model of how behavior within $i$ 's network affects i's behavior. Clearly one's own status and aspirations are linked, and contextual factors or shared characteristics will influence both. By controlling for $i$ 's status, however, we can reduce the identification threat to factors that affect the status of those in $i$ 's network and $i$ 's aspirations conditional on $i$ 's own status.

For income aspirations, such a threat seems unlikely although not impossible. For example, suppose there is an idiosyncratic shock that affects the status of others in $i$ 's reference group (i.e., $\bar{w}$ and $\underline{w}$ ) but not $i$ 's own status. This shock could be negative (e.g., a disease that kills livestock) or positive (e.g., an NGO gives out cash or asset transfers). Although individual $i$ is not initially impacted by the shock, observing it may influence her aspirations for the future (she may believe her livestock will be harmed in the future, or she may anticipate a similar transfer). This would result in estimates of $\beta_{1}>0$ and $\beta_{2}>0$ in Eq. (9) above, but not the hypothesized result of $\beta_{1}>0$ and $\beta_{2}=0$, which is what we observe and describe below.

An additional identification threat for income aspirations stems from informal insurance mechanisms as described in Munshi and Rosenzweig (2009). Suppose wealthy individuals informally insure less wealthy individuals in their community or social network. Then expected future income could be higher for those with wealthier people in their reference group, which in turn raises their aspirations. If this were the case, we would observe $\beta_{1}>0$ and $\beta_{2}=0$ in the income regressions, but the mechanism would be quite different from what we have hypothesized. We cannot distinguish between these alternative explanations in the income aspirations regressions, and encourage future work in this area. However, we note that the insurance mechanism is unlikely to be relevant for the education regressions.

There are, however, other issues with estimating education aspirations as a function of children's education in the reference group. Here, it is relatively easy to see how shared circumstances could lead to finding $\beta_{1}>0$ and $\beta_{2}=0$. Suppose that in some areas the local school stops at grade eight and in other areas it continues to grade ten. For a cohort of women with young children, both $s$ and $\underline{w}$ are unlikely to be affected by the highest level of education offered locally, whereas $\bar{w}$ and $a$ are likely to be affected. Controlling for VDC fixed effects should mitigate this potential problem as educational infrastructure is shared at the VDC (or higher) level.

In spite of our efforts to mitigate bias, and the evidence that the hypothesized causal mechanism is at work, we interpret our findings with caution and refer to estimates as associations rather than causal effects. Research on this topic using experimental methods may be a fruitful area for future research.

\subsection{Formation of income aspirations}

Table 6 shows the results from estimating equation (9) where $a$ is income aspirations, $\bar{w}$ is the average income of those in individual $i$ 's reference group with higher income than $i$, and $\underline{w}$ is the average income of those in $i$ 's reference group with lower income. Because of long right tails in the distribution of income we log transform monetary values.

The first three columns each consider an alternative specification of the aspirations window. In column 1 , the reference group for the aspirations window includes all residents of the same tole. In columns 2 and 4, the reference group includes members of $i$ 's broad social network including friends within the tole, while in columns 3 and 5 the reference group includes members of $i$ 's plausibly exogenous social network (excluding friends). Columns 1, 2, and 3 include district fixed effects, while columns 4 and 5 include VDC fixed effects.

\footnotetext{
18 There were many more of these types of links than expected in the data, suggesting respondents considered a fairly large geography when making this distinction. We also used links as defined by only family and obtained nearly identical results.
} 
Formation of income aspirations as a function of others' incomes

\begin{tabular}{|c|c|c|c|c|c|}
\hline & $\begin{array}{l}(1) \\
\text { Tole }\end{array}$ & $\begin{array}{c}(2) \\
\text { Links }\end{array}$ & $\begin{array}{c}(3) \\
\text { Ex links }\end{array}$ & $\begin{array}{c}(4) \\
\text { Links (FE) }\end{array}$ & $\begin{array}{c}(5) \\
\text { Ex links (FE) }\end{array}$ \\
\hline Avg. above (log Rs.) & $\begin{array}{c}0.051 \\
(0.197)\end{array}$ & $\begin{array}{l}0.141^{* *} \\
(0.064)\end{array}$ & $\begin{array}{l}0.114^{* *} \\
(0.055)\end{array}$ & $\begin{array}{c}0.084 \\
(0.063)\end{array}$ & $\begin{array}{l}0.044 \\
(0.058)\end{array}$ \\
\hline Avg. below (log Rs.) & $\begin{array}{c}0.018 \\
(0.071)\end{array}$ & $\begin{array}{l}-0.021 \\
(0.037)\end{array}$ & $\begin{array}{l}-0.019 \\
(0.035)\end{array}$ & $\begin{array}{l}-0.011 \\
(0.048)\end{array}$ & $\begin{array}{l}0.016 \\
(0.039)\end{array}$ \\
\hline Current income (log Rs.) & $\begin{array}{l}0.716^{* * *} \\
(0.064)\end{array}$ & $\begin{array}{l}0.659^{* * * *} \\
(0.046)\end{array}$ & $\begin{array}{l}0.664^{* * * *} \\
(0.050)\end{array}$ & $\begin{array}{l}0.656^{* * *} \\
(0.055)\end{array}$ & $\begin{array}{l}0.660^{* * *} \\
(0.056)\end{array}$ \\
\hline Number of links above & $\begin{array}{c}0.046 \\
(0.042)\end{array}$ & $\begin{array}{l}-0.113 \\
(0.072)\end{array}$ & $\begin{array}{l}-0.125^{*} \\
(0.072)\end{array}$ & $\begin{array}{l}-0.031 \\
(0.085)\end{array}$ & $\begin{array}{l}0.034 \\
(0.100)\end{array}$ \\
\hline Number of links below & $\begin{array}{l}-0.008 \\
(0.040)\end{array}$ & $\begin{array}{l}-0.030 \\
(0.049)\end{array}$ & $\begin{array}{l}-0.088^{*} \\
(0.048)\end{array}$ & $\begin{array}{c}0.057 \\
(0.048)\end{array}$ & $\begin{array}{l}0.036 \\
(0.052)\end{array}$ \\
\hline Education (years) & $\begin{array}{c}0.032 \\
(0.038)\end{array}$ & $\begin{array}{c}0.028 \\
(0.037)\end{array}$ & $\begin{array}{c}0.028 \\
(0.036)\end{array}$ & $\begin{array}{c}0.012 \\
(0.039)\end{array}$ & $\begin{array}{l}0.013 \\
(0.039)\end{array}$ \\
\hline Age (years) & $\begin{array}{c}-0.034^{* * *} \\
(0.009)\end{array}$ & $\begin{array}{c}-0.034^{* * *} \\
(0.009)\end{array}$ & $\begin{array}{c}-0.035^{* * *} \\
(0.009)\end{array}$ & $\begin{array}{c}-0.030^{* * * *} \\
(0.011)\end{array}$ & $\begin{array}{r}-0.031^{* * *} \\
(0.011)\end{array}$ \\
\hline Household has migrant & $\begin{array}{c}0.112 \\
(0.229)\end{array}$ & $\begin{array}{c}0.093 \\
(0.232)\end{array}$ & $\begin{array}{c}0.102 \\
(0.230)\end{array}$ & $\begin{array}{c}0.150 \\
(0.228)\end{array}$ & $\begin{array}{l}0.174 \\
(0.229)\end{array}$ \\
\hline Constant & $\begin{array}{c}2.874 \\
(2.239)\end{array}$ & $\begin{array}{l}3.339^{* * *} \\
(0.752)\end{array}$ & $\begin{array}{l}3.615^{* * *} \\
(0.680)\end{array}$ & $\begin{array}{l}4.753^{* * *} \\
(0.804)\end{array}$ & $\begin{array}{l}4.933^{* * *} \\
(0.706)\end{array}$ \\
\hline R-squared & 0.526 & 0.530 & 0.529 & 0.569 & 0.568 \\
\hline$N$ & 944 & 944 & 944 & 944 & 944 \\
\hline
\end{tabular}

Results of separate OLS regressions for each potential reference group.

District fixed effects included for models 1-3, VDC fixed effects included for models 4-5, results not shown.

Cluster (VDC) robust standard errors in parentheses.

${ }^{*} p<0.1$.

** $p<0.05$

${ }^{* * *} p<0.01$

When the reference group is the tole (column 1), we do not see a significant correlation between an individual's income aspirations and the income of those below and above her. The point estimate for the average income level of those above her is nearly three times as large as for those below her, and both are positive.

When we instead use individuals' reported links as the reference group (columns 2-3), we observe a positive and statistically significant correlation between an individual's income aspirations and the income of those above her. In column 2 , we see that a 100 percent increase in income among social contacts with higher incomes is associated with a 14 percent increase in income aspirations. We detect no significant correlation with those below, and the point estimates are very small. We find similar results when considering only exogenous network links. This pattern is consistent with the hypothesis that aspirations are upward looking. When we include VDC fixed effects, the point estimates for average income above are approximately halved and no longer statistically significant. As stated above, while including VDC fixed effects mitigates any bias due to unobserved factors common to all members of a tole, it also discards important inter-tole variation in network composition. While these extremely conservative estimates are not statistically significant, they do show a similar pattern to the results using district-level fixed effects.

\subsection{Formation of education aspirations}

Table 7 presents the education regressions for aspirations formation. Here, $\bar{w}$ refers to the average educational attainment of children (at the time of the survey) in individual $i$ 's reference group who have achieved higher education than $i$ 's children, while $\underline{w}$ refers to the average educational attainment of children in individual $i$ 's reference group exhibiting educational outcomes lower than i's children. The table format follows that of Table 6 , where the first column employs the tole as the reference group, the second and fourth column use the respondent-defined social network as the reference group, and the third and fifth column use the social network excluding friends. Again, columns 1-3 include district fixed effects, while columns 4 and 5 include VDC fixed effects.

Similar to the results for income aspirations, we find that education aspirations are upward looking. The average education level of others' children with a higher level of education in the reference group is positively and significantly correlated with education aspirations. When we define the reference group as the tole, we find that each year of children's education above increases education aspirations by 0.44 years. When we use respondent-defined social links the estimates are much smaller, ranging from 0.09 to 0.22 . As was the case for income aspirations, there is no statistically significant correlation between education aspirations and the education level of those below, and the point estimates are small.

There are at least two possible explanations for why the estimate using the entire tole as the reference group is higher than estimates using respondent-defined social linkages. It could be that education aspirations are influenced more generally by those around them, as opposed to only by the people one knows personally. Because educational attainment is quite observable (at least relative to income), this may suggest that communication regarding educational possibilities is not 
Table 7

Formation of education aspirations as a function of others' children's education.

\begin{tabular}{|c|c|c|c|c|c|}
\hline & $\begin{array}{l}(1) \\
\text { Tole }\end{array}$ & $\begin{array}{l}(2) \\
\text { Links }\end{array}$ & $\begin{array}{c}(3) \\
\text { Ex links }\end{array}$ & $\begin{array}{c}(4) \\
\text { Links (FE) }\end{array}$ & $\begin{array}{c}(5) \\
\text { Ex links (FE) }\end{array}$ \\
\hline Avg. above & $\begin{array}{l}0.438^{* * *} \\
(0.089)\end{array}$ & $\begin{array}{l}0.224^{* * *} \\
(0.056)\end{array}$ & $\begin{array}{l}0.154^{* * *} \\
(0.055)\end{array}$ & $\begin{array}{l}0.134^{* *} \\
(0.061)\end{array}$ & $\begin{array}{l}0.093 \\
(0.058)\end{array}$ \\
\hline Avg. below & $\begin{array}{c}0.071 \\
(0.155)\end{array}$ & $\begin{array}{c}0.045 \\
(0.065)\end{array}$ & $\begin{array}{c}0.027 \\
(0.052)\end{array}$ & $\begin{array}{c}0.063 \\
(0.067)\end{array}$ & $\begin{array}{l}0.029 \\
(0.059)\end{array}$ \\
\hline Max child's education & $\begin{array}{c}0.031 \\
(0.152)\end{array}$ & $\begin{array}{l}-0.004 \\
(0.072)\end{array}$ & $\begin{array}{c}0.050 \\
(0.070)\end{array}$ & $\begin{array}{l}-0.055 \\
(0.081)\end{array}$ & $\begin{array}{l}0.001 \\
(0.082)\end{array}$ \\
\hline Own education (years) & $\begin{array}{l}0.223^{* * *} \\
(0.032)\end{array}$ & $\begin{array}{l}0.254^{* * *} \\
(0.032)\end{array}$ & $\begin{array}{l}0.258^{* * *} \\
(0.033)\end{array}$ & $\begin{array}{l}0.187^{* * *} \\
(0.039)\end{array}$ & $\begin{array}{l}0.188^{* * *} \\
(0.039)\end{array}$ \\
\hline Number of links above & $\begin{array}{c}0.071 \\
(0.064)\end{array}$ & $\begin{array}{c}-0.194^{* *} \\
(0.081)\end{array}$ & $\begin{array}{c}-0.244^{* *} \\
(0.103)\end{array}$ & $\begin{array}{c}-0.188^{* *} \\
(0.075)\end{array}$ & $\begin{array}{r}-0.231^{* *} \\
(0.091)\end{array}$ \\
\hline Number of links below & $\begin{array}{l}-0.034 \\
(0.056)\end{array}$ & $\begin{array}{l}-0.022 \\
(0.089)\end{array}$ & $\begin{array}{l}-0.056 \\
(0.113)\end{array}$ & $\begin{array}{c}0.062 \\
(0.106)\end{array}$ & $\begin{array}{l}0.021 \\
(0.138)\end{array}$ \\
\hline Current income (log Rs.) & $\begin{array}{c}0.042 \\
(0.036)\end{array}$ & $\begin{array}{c}0.041 \\
(0.037)\end{array}$ & $\begin{array}{c}0.043 \\
(0.037)\end{array}$ & $\begin{array}{c}0.005 \\
(0.045)\end{array}$ & $\begin{array}{l}0.007 \\
(0.045)\end{array}$ \\
\hline Age (years) & $\begin{array}{c}-0.049^{* * *} \\
(0.012)\end{array}$ & $\begin{array}{c}-0.050^{* * *} \\
(0.013)\end{array}$ & $\begin{array}{c}-0.048^{* * *} \\
(0.013)\end{array}$ & $\begin{array}{c}-0.051^{* * *} \\
(0.013)\end{array}$ & $\begin{array}{r}-0.051^{* * *} \\
(0.013)\end{array}$ \\
\hline Household has migrant & $\begin{array}{l}-0.045 \\
(0.246)\end{array}$ & $\begin{array}{l}-0.068 \\
(0.262)\end{array}$ & $\begin{array}{l}-0.079 \\
(0.256)\end{array}$ & $\begin{array}{c}0.084 \\
(0.254)\end{array}$ & $\begin{array}{l}0.079 \\
(0.250)\end{array}$ \\
\hline Constant & $\begin{array}{l}9.041^{* * *} \\
(1.243)\end{array}$ & $\begin{array}{c}12.587^{* * *} \\
(0.745)\end{array}$ & $\begin{array}{c}12.865^{* * *} \\
(0.709)\end{array}$ & $\begin{array}{c}16.077^{* * * *} \\
(0.741)\end{array}$ & $\begin{array}{l}16.146^{* * *} \\
(0.725)\end{array}$ \\
\hline R-squared & 0.215 & 0.198 & 0.195 & 0.282 & 0.280 \\
\hline$N$ & 730 & 730 & 730 & 730 & 730 \\
\hline
\end{tabular}

Results of separate OLS regressions for each potential reference group.

District fixed effects included for models 1-3, VDC fixed effects included for models 4-5, results not shown.

Cluster (VDC) robust standard errors in parentheses.

${ }^{*} p<0.1$.

*** $\mathrm{p}<0.05$.

$\mathrm{p}<0.01$.

essential for the formation of education aspirations. Alternatively, this difference could be due to the reflection problem; common features of the tole such as school availability upwardly bias results. However, the significant coefficient estimates for reference group defined by the broader social network even when controlling for VDC fixed effects suggest the association between a mother's aspirations for her children's education and the level of education attained by the children of women in her reference group is not solely driven by common contextual factors.

In Tables C1 and C2 we report results disaggregated by gender. In these specifications we look separately at aspirations for sons' and daughters' education as a function of the education level of all other children in the reference group, irrespective of gender. We find similar results to those for all children, although they are generally stronger for boys.

\section{Concluding remarks}

This paper analyzes the complex relationship between aspirations and future-oriented behavior. We provide the first known direct empirical test of the widely cited model first introduced by Appadurai (2004) and Ray (2006) and formalized in Genicot and Ray (2017). Our empirical analysis reveals a convincing and robust inverted U-shaped relationship between aspirations and investment, as predicted by theory. This supports current thinking that behavioral constraints can indeed reinforce poverty, and interventions designed to alter aspirations may increase investment behavior, as other empirical work has shown.

Unlike much of the other empirical work in this area, however, this study finds that if aspirations are too large compared to current status they may result in failure and frustration. In a lecture on the importance of hope and aspirations, Duflo (2012) concludes that "goals should not be too lofty or hard to reach." Our results provide empirical evidence in support of this claim.

We also provide evidence that aspirations are in part socially formed. Through this analysis we confirm the importance of the hypothesized aspirations "window." If a program increases the status of those in an individual's reference group, or expands the reference group of a poor individual through increased exposure to individuals of higher status, then it is possible that aspirations will increase as a result. Several recent empirical papers confirm this logic. Macours and Vakis (2014) provide evidence from Nicaragua that a cash transfer program can increase aspirations, and that these effects are amplified when a community leader also receives a transfer. Bernard et al. (2014) provides evidence that a television documentary of "people from similar communities" can not only positively influence aspirations and behavior of viewers, but also improve education outcomes for those in viewers' social networks. Beaman et al. (2012) presents evidence that exposure to female role models increases the career aspirations and educational attainment of adolescent girls in India. This increase is likely not a result of direct social interaction (the role models considered are female public leaders), but is more likely a result of social observation. 
A better understanding of the social mechanisms through which aspirations form and influence behavior can inform the design of policies and interventions to alleviate internal constraints to investment. Furthermore, impact evaluations of such programs should consider spillovers through aspirational channels. Without doing so, they may not measure their full societal impact.

\section{Acknowledgements}

This research was supported by the USAID BASIS Assets and Markets Innovation Lab and the CGIAR Cereal Systems Initiative for South Asia. The authors thank Marc Bellemare, Michael Carter, Alain de Janvry, Kashi Kafle, Harounan Kazianga, Jason Kerwin, Travis Lybbert, Hope Michelson, Khushbu Mishra, Erica Myers, Elisabeth Sadoulet, Eve Sihra, David Spielman, Alex Winter-Nelson and participants at several seminars and workshops for helpful comments. We thank Savannah Noray, Giovanni Righi, Muna Sharma, Samyam Shrestha and Pranaya Sthapit for their excellent work as research assistants. All errors remain our own.

\section{Appendix A. Model of aspirations failure with aspirations exceeded by default}

If $\frac{\partial v_{1}}{\partial k}>\frac{\partial C}{\partial k} \mid k=\frac{a}{\rho}$ (as in Fig. A1a), then $k_{\text {high }}^{*}>k_{\text {low }}^{*}=\frac{a}{\rho}, N B\left(k_{\text {high }}^{*}\right)>N B\left(k_{\text {low }}^{*}\right)$, and $\frac{\partial k_{\text {high }}^{*}}{\partial a}=0$, i.e., aspirations do not affect investment. These conditions exist for aspirations below a unique threshold $\tilde{a}$, where $k_{\text {low }}^{*}=k_{\text {high }}^{*}=\frac{\tilde{a}}{\rho}$ as depicted in Fig. A1a. In Genicot and Ray's (2016) model there is no threshold equivalent to $\tilde{a}$, as they assume that aspirations are always beyond some point where the marginal costs of investment exceed the marginal benefits. When we add this region to Fig. 3 we see a region over which aspirations do not affect investment at both low and high levels of aspirations (Fig. A2). This does not change the expected inverse-U empirical relationship between aspirations and investment.

(a)

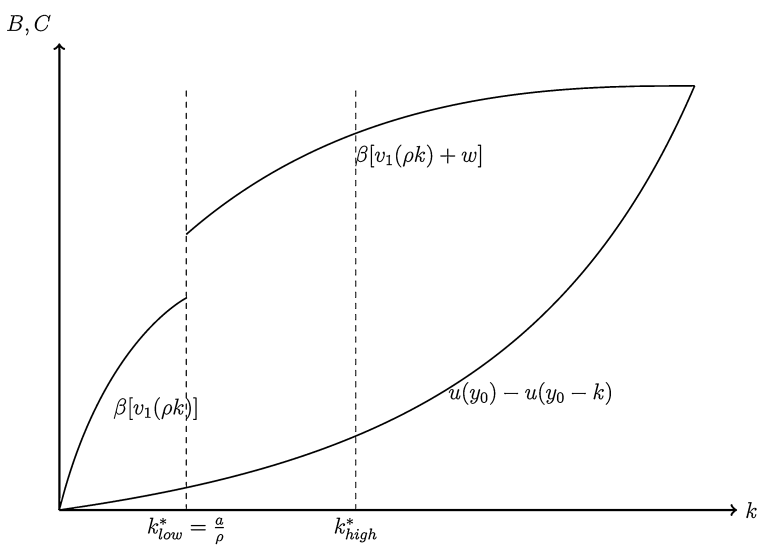

(b)

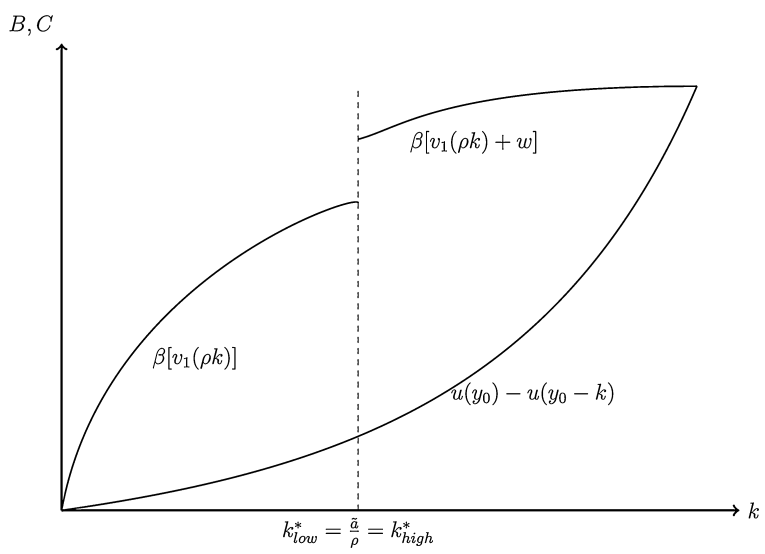

Fig. A1. Costs and benefits of investment with low aspirations.

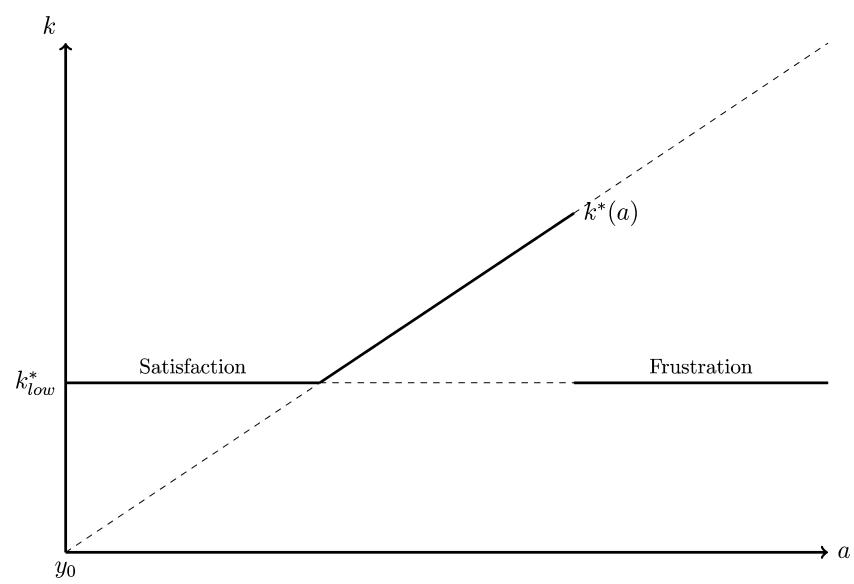

Fig. A2. Investment as a function of aspirations including when aspirations are met by default 


\section{Appendix B. Comparative statics of $\hat{a}$}

Using the implicit function theorem we can find how changes in $\beta, y_{0}$, and $\rho$ affect the behavioral switching point $\hat{a}$. First, we set the indifference equation (4) equal to zero:

$$
I=\beta\left[v_{1}\left(\rho k_{l o w}^{*}\right)\right]+v_{0}\left(y_{0}-k_{l o w}^{*}\right)-\beta\left[v_{1}(\hat{a})+w\right]-v_{0}\left(y_{0}-\frac{\hat{a}}{\rho}\right) .
$$

First we derive $\frac{d \hat{a}}{d \beta}$ :

$$
\frac{d \hat{a}}{d \beta}=\frac{\frac{\partial I}{\partial \beta}}{\frac{\partial I}{\partial \hat{a}}}=\frac{-\left[v_{1}\left(\rho k_{l o w}^{*}\right)-v_{1}(\hat{a})-w\right]}{v_{0}^{\prime}\left(y-\frac{\hat{a}}{\rho}\right) \frac{1}{\rho}-\beta v_{1}^{\prime}(\hat{a})} .
$$

Because $w>0$ and $\hat{a}>\rho k_{l o w}^{*}$, the numerator of equation (11) is positive. The marginal benefit and marginal cost of investment are equal when $k=\frac{\tilde{a}}{\rho}$, i.e., $v_{0}^{\prime}\left(y-\frac{\tilde{a}}{\rho}\right) \frac{1}{\rho}=\beta v_{1}^{\prime}(\tilde{a})$. Because $\hat{a}>\tilde{a}$, the denominator of equation (11) must also be positive, therefore $\frac{d \hat{a}}{d \beta}>0$.

Next we derive $\frac{d \hat{a}}{d y_{0}}$ :

$$
\frac{d \hat{a}}{d y_{0}}=\frac{\frac{\partial I}{\partial y_{0}}}{\frac{\partial I}{\partial \hat{a}}}=\frac{-\left[v_{0}^{\prime}\left(y_{0}-k_{l o w}^{*}\right)-v_{0}^{\prime}\left(y_{0}-\frac{\hat{a}}{\rho}\right)\right]}{v_{0}^{\prime}\left(y-\frac{\hat{a}}{\rho}\right) \frac{1}{\rho}-\beta v_{1}^{\prime}(\hat{a})}
$$

Because $\frac{\hat{a}}{\rho}>k_{\text {low }}^{*}$, the numerator of equation (12) must be positive and $\frac{d \hat{a}}{d y_{0}}>0$.

Finally we derive $\frac{d \hat{a}}{d \rho}$ :

$$
\frac{d \hat{a}}{d \rho}=\frac{\frac{\partial I}{\partial \rho}}{\frac{\partial I}{\partial \hat{a}}}=\frac{-\left[\beta k_{l o w}^{*} v_{1}^{\prime}\left(\rho k_{l o w}\right)-\frac{\hat{a}}{\rho^{2}} v_{0}^{\prime}\left(y_{0}-\frac{\hat{a}}{\rho}\right)\right]}{v_{0}^{\prime}\left(y-\frac{\hat{a}}{\rho}\right) \frac{1}{\rho}-\beta v_{1}^{\prime}(\hat{a})} .
$$

Because $v_{0}^{\prime}\left(y-\frac{\hat{a}}{\rho}\right) \frac{1}{\rho}>\beta v_{1}^{\prime}(\hat{a})>0$, if $\beta \rho k_{l o w}^{*} v_{1}^{\prime}\left(\rho k_{l o w}\right)<\hat{a} v_{1}^{\prime}(\hat{a})$ then it also must be true that $\beta k_{\text {low }}^{*} v_{1}^{\prime}\left(\rho k_{l o w}\right)<\frac{\hat{a}}{\rho^{2}} v_{0}^{\prime}\left(y_{0}-\frac{\hat{a}}{\rho}\right)$. For most functional forms of $v$ (e.g., all of type $v=\chi^{\alpha}$ and $\left.v=\ln (x)\right), k_{\text {low }}^{*} v_{1}^{\prime}\left(\rho k_{\text {low }}\right) \leq \hat{a} v_{1}^{\prime}(\hat{a})$ because $\hat{a}>\rho k_{l o w}^{*}$. Therefore under reasonable assumptions $\beta \rho k_{\text {low }}^{*} v_{1}^{\prime}\left(\rho k_{\text {low }}\right)<\hat{a} v_{1}^{\prime}(\hat{a}), \beta k_{\text {low }}^{*} v_{1}^{\prime}\left(\rho k_{\text {low }}\right)<\frac{\hat{a}}{\rho^{2}} v_{0}^{\prime}\left(y_{0}-\frac{\hat{a}}{\rho}\right)$, and $\frac{d \hat{a}}{d \rho}>0$.

\section{Appendix C. Additional tables}

\begin{tabular}{|c|c|c|c|c|c|}
\hline & $\begin{array}{l}(1) \\
\text { Tole }\end{array}$ & $\begin{array}{c}(2) \\
\text { Links }\end{array}$ & $\begin{array}{c}(3) \\
\text { Ex links }\end{array}$ & $\begin{array}{c}(4) \\
\text { Links (FE) }\end{array}$ & $\begin{array}{c}(5) \\
\text { Ex links (FE) }\end{array}$ \\
\hline Boys' avg. above & $\begin{array}{l}0.546^{* *+} \\
(0.132)\end{array}$ & $\begin{array}{l}0.300 * \\
(0.069)\end{array}$ & $\begin{array}{l}0.295^{* *} \\
(0.071)\end{array}$ & $\begin{array}{l}0.220^{* * *} \\
(0.075)\end{array}$ & $\begin{array}{l}0.204^{* *} \\
(0.079)\end{array}$ \\
\hline Boys' avg. below & $\begin{array}{c}0.135 \\
(0.135)\end{array}$ & $\begin{array}{c}0.017 \\
(0.058)\end{array}$ & $\begin{array}{l}-0.017 \\
(0.051)\end{array}$ & $\begin{array}{c}0.007 \\
(0.064)\end{array}$ & $\begin{array}{r}-0.005 \\
(0.051)\end{array}$ \\
\hline Max boys' education & $\begin{array}{l}-0.067 \\
(0.077)\end{array}$ & $\begin{array}{c}0.019 \\
(0.072)\end{array}$ & $\begin{array}{c}0.026 \\
(0.066)\end{array}$ & $\begin{array}{l}-0.001 \\
(0.079)\end{array}$ & $\begin{array}{l}0.004 \\
(0.076)\end{array}$ \\
\hline Own education (years) & $\begin{array}{l}0.170^{*+1} \\
(0.046)\end{array}$ & $\begin{array}{l}0.205^{*+3} \\
(0.050)\end{array}$ & $\begin{array}{l}0.208^{* * *} \\
(0.048)\end{array}$ & $\begin{array}{l}0.131^{* *} \\
(0.059)\end{array}$ & $\begin{array}{l}0.130^{*+1} \\
(0.057)\end{array}$ \\
\hline Number of boys above & $\begin{array}{c}0.044 \\
(0.067)\end{array}$ & $\begin{array}{l}-0.126 \\
(0.082)\end{array}$ & $\begin{array}{c}-0.229^{* * *} \\
(0.085)\end{array}$ & $\begin{array}{l}-0.086 \\
(0.077)\end{array}$ & $\begin{array}{r}-0.143^{*} \\
(0.079)\end{array}$ \\
\hline Number of boys links below & $\begin{array}{l}-0.004 \\
(0.059)\end{array}$ & $\begin{array}{c}0.031 \\
(0.079)\end{array}$ & $\begin{array}{c}0.013 \\
(0.087)\end{array}$ & $\begin{array}{c}0.111 \\
(0.098)\end{array}$ & $\begin{array}{l}0.130 \\
(0.102)\end{array}$ \\
\hline Current income (log Rs.) & $\begin{array}{c}0.072 \\
(0.045)\end{array}$ & $\begin{array}{c}0.069 \\
(0.047)\end{array}$ & $\begin{array}{c}0.075 \\
(0.048)\end{array}$ & $\begin{array}{c}0.042 \\
(0.058)\end{array}$ & $\begin{array}{l}0.048 \\
(0.059)\end{array}$ \\
\hline Age (years) & $\begin{array}{c}-0.090 \\
(0.021)\end{array}$ & $\begin{array}{c}-0.085 \\
(0.021)\end{array}$ & $\begin{array}{c}-0.084 \\
(0.022)\end{array}$ & $\begin{array}{c}-0.085 \\
(0.023)\end{array}$ & $\begin{array}{r}-0.086^{*} \\
(0.023)\end{array}$ \\
\hline Household has migrant & $\begin{array}{c}0.409 \\
(0.312)\end{array}$ & $\begin{array}{c}0.407 \\
(0.344)\end{array}$ & $\begin{array}{c}0.395 \\
(0.334)\end{array}$ & $\begin{array}{l}0.643^{+} \\
(0.342)\end{array}$ & $\begin{array}{l}0.640^{\circ} \\
(0.331)\end{array}$ \\
\hline Constant & $\begin{array}{l}9.730 \\
(1.562)\end{array}$ & $\begin{array}{c}13.055^{* 2 *} \\
(0.866)\end{array}$ & $\begin{array}{c}13.259^{* * *} \\
(0.828)\end{array}$ & $\begin{array}{c}16.073^{* *+1} \\
(0.994)\end{array}$ & $\begin{array}{r}16.237^{* 1+2} \\
(1.011)\end{array}$ \\
\hline R-squared & 0.196 & 0.175 & 0.177 & 0.270 & 0.271 \\
\hline & 568 & 568 & & 568 & \\
\hline
\end{tabular}

\section{Tables $\mathrm{C} 1$ and $\mathrm{C} 2$}

\section{Table C1}

Formation of education aspirations for boys as a function of other children's' education

Results of separate OLS regressions for each potential reference group.

District fixed effects included for models 1-3, VDC fixed effects included for models 4-5, results not shown.

Cluster (VDC) robust standard errors in parentheses.

${ }^{*} p<0.1$.

${ }^{* *} p<0.05$.

${ }^{* * *} p<0.01$. 
Table C2

Formation of education aspirations for girls as a function of other children's' education

\begin{tabular}{|c|c|c|c|c|c|}
\hline & $\begin{array}{l}(1) \\
\text { Tole }\end{array}$ & $\begin{array}{c}(2) \\
\text { Links }\end{array}$ & $\begin{array}{c}(3) \\
\text { Ex links }\end{array}$ & $\begin{array}{c}(4) \\
\text { Links (FE) }\end{array}$ & $\begin{array}{c}(5) \\
\text { Ex links (FE) }\end{array}$ \\
\hline Girls' avg. above & $\begin{array}{l}0.325^{* *} \\
(0.154)\end{array}$ & $\begin{array}{l}0.259^{* * *} \\
(0.069)\end{array}$ & $\begin{array}{l}0.160^{* *} \\
(0.070)\end{array}$ & $\begin{array}{c}0.169^{*} \\
(0.099)\end{array}$ & $\begin{array}{l}0.057 \\
(0.090)\end{array}$ \\
\hline Girls' avg. below & $\begin{array}{l}-0.043 \\
(0.186)\end{array}$ & $\begin{array}{l}-0.136^{*} \\
(0.073)\end{array}$ & $\begin{array}{l}-0.062 \\
(0.061)\end{array}$ & $\begin{array}{l}-0.082 \\
(0.085)\end{array}$ & $\begin{array}{l}0.002 \\
(0.069)\end{array}$ \\
\hline Max girls's education & $\begin{array}{l}0.175^{* *} \\
(0.070)\end{array}$ & $\begin{array}{l}0.170^{* *} \\
(0.065)\end{array}$ & $\begin{array}{l}0.175^{* * *} \\
(0.063)\end{array}$ & $\begin{array}{l}0.167^{* *} \\
(0.070)\end{array}$ & $\begin{array}{l}0.173^{* *} \\
(0.067)\end{array}$ \\
\hline Own education (years) & $\begin{array}{l}0.215^{* * *} \\
(0.038)\end{array}$ & $\begin{array}{l}0.223^{* * *} \\
(0.039)\end{array}$ & $\begin{array}{l}0.221^{* * *} \\
(0.039)\end{array}$ & $\begin{array}{l}0.174^{* * *} \\
(0.048)\end{array}$ & $\begin{array}{l}0.171^{* * *} \\
(0.048)\end{array}$ \\
\hline Number of girls above & $\begin{array}{l}-0.027 \\
(0.072)\end{array}$ & $\begin{array}{c}-0.288^{* *} \\
(0.109)\end{array}$ & $\begin{array}{c}-0.351^{* * * *} \\
(0.119)\end{array}$ & $\begin{array}{c}-0.211^{* *} \\
(0.102)\end{array}$ & $\begin{array}{r}-0.235^{* *} \\
(0.109)\end{array}$ \\
\hline Number of girls links below & $\begin{array}{l}-0.088 \\
(0.069)\end{array}$ & $\begin{array}{c}-0.245^{* *} \\
(0.102)\end{array}$ & $\begin{array}{c}-0.298^{* *} \\
(0.137)\end{array}$ & $\begin{array}{l}-0.136 \\
(0.110)\end{array}$ & $\begin{array}{l}-0.149 \\
(0.152)\end{array}$ \\
\hline Current income (log Rs.) & $\begin{array}{c}0.029 \\
(0.049)\end{array}$ & $\begin{array}{c}0.024 \\
(0.049)\end{array}$ & $\begin{array}{c}0.024 \\
(0.051)\end{array}$ & $\begin{array}{l}-0.010 \\
(0.058)\end{array}$ & $\begin{array}{l}-0.011 \\
(0.061)\end{array}$ \\
\hline Age (years) & $\begin{array}{c}-0.070^{* * *} \\
(0.019)\end{array}$ & $\begin{array}{c}-0.070^{* * *} \\
(0.020)\end{array}$ & $\begin{array}{c}-0.067^{* * *} \\
(0.020)\end{array}$ & $\begin{array}{c}-0.078^{* * *} \\
(0.021)\end{array}$ & $\begin{array}{r}-0.077^{* * *} \\
(0.021)\end{array}$ \\
\hline Household has migrant & $\begin{array}{l}-0.215 \\
(0.316)\end{array}$ & $\begin{array}{l}-0.213 \\
(0.318)\end{array}$ & $\begin{array}{l}-0.222 \\
(0.313)\end{array}$ & $\begin{array}{l}-0.176 \\
(0.350)\end{array}$ & $\begin{array}{r}-0.166 \\
(0.349)\end{array}$ \\
\hline Constant & $\begin{array}{c}12.706^{* * *} \\
(1.329)\end{array}$ & $\begin{array}{c}14.066^{* * *} \\
(0.868)\end{array}$ & $\begin{array}{c}14.357^{* * *} \\
(0.861)\end{array}$ & $\begin{array}{c}16.662^{* * *} \\
(1.133)\end{array}$ & $\begin{array}{r}17.143^{* * *} \\
(1.105)\end{array}$ \\
\hline R-squared & 0.198 & 0.217 & 0.219 & 0.286 & 0.285 \\
\hline$N$ & 523 & 523 & 523 & 523 & 523 \\
\hline
\end{tabular}

Results of separate OLS regressions for each potential reference group.

District fixed effects included for models 1-3, VDC fixed effects included for models 4-5, results not shown.

Cluster (VDC) robust standard errors in parentheses.

${ }^{*} p<0.1$.

*** $p<0.05$.

**** $p<0.01$

\section{References}

Allendorf, K., 2007. Do women's land rights promote empowerment and child health in Nepal? World Develop. $35,1975-1988$.

Appadurai, A., 2004. The capacity to aspire: Culture and the terms of recognition. Culture and Public Action, pp. 59-84.

Ashraf, N., Karlan, D., Yin, W., 2006. Tying Odysseus to the Mast: Evidence from a Commitment Savings Product in the Philippines. Quar. J. Econ. 121, 635-672.

Bala, V., Goyal, S., 2000. A noncooperative model of network formation. Econometrica 68, 1181-1229.

Bandiera, O., Rasul, I., 2006. Social networks and technology adoption in northern Mozambique. Econ. J. 116, 869-902.

Banerjee, A., Chandrasekhar, A., Duflo, E., Jackson, M., 2013. The diffusion of microfinance. Science, 341.

Beaman, L., Duflo, E., Pande, R., Topalova, P., 2012. Female leadership raises aspirations and educational attainment for girls: A policy experiment in India. Science 335, 582-586.

Bernard, T., Dercon, S., Orkin, K., Taffesse, A.S., 2014. The Future in Mind: Aspirations and Forward-Looking Behaviour in Rural Ethiopia. Centre for the Study of African Economies, University of Oxford, Working paper.

Bernard, T., Dercon, S., Taffesse, A.S., 2011. Beyond fatalism-an empirical exploration of self-efficacy and aspirations failure in Ethiopia.

Bernard, T., Taffesse, A., 2014. Aspirations: an approach to measurement with validation using Ethiopian data. J. Afr. Econ. 23, $189-224$.

Bertrand, M., Mullainathan, S., Shafir, E., 2004. A behavioral-economics view of poverty. Am. Econ. Rev. 94, 419-423.

Besley, T., Coate, S., Loury, G., 1993. The economics of rotating savings and credit associations. Am. Econ. Rev. 83, 792-810.

Bogliacino, F., Ortoleva, P., 2013. The Behavior of Others as a Reference Point. Columbia Business School Research Paper, pp. $13-55$.

Comola, M., Fafchamps, M., 2017. The missing transfers: Estimating mis-reporting in dyadic data. Econ. Develop. Cult. Change.

Comola, M., Fafchamps, M., 2014. Testing unilateral and bilateral link formation. Econ. J. 124, 954-976.

Conley, T.G., Udry, C.R., 2010. Learning about a new technology: Pineapple in Ghana. Am. Econ. Rev. 100, 35-69.

Dalton, P.S., Ghosal, S., Mani, A., 2016. Poverty and aspirations failure. Econ. J. 126, 165-188.

Deusenberry, J., 1949. Income, Saving and the Theory of Consumer Behavior. Harvard University Press, Cambridge, Mass.

Duflo, E., 2012. Lack of Hope and the Persistence of Poverty. Marshall Lecture Series.

Duflo, E., Kremer, M., Robinson, J., 2011. Nudging Farmers to Use Fertilizer: Theory and Experimental Evidence from Kenya. Am. Econ. Rev. 101, $2350-2390$

Fafchamps, M., Shilpi, F., 2008. Subjective welfare, isolation, and relative consumption. J. Develop. Econ. 86, 43-60.

Ferrer-i Carbonell, A., 2005. Income and well-being: an empirical analysis of the comparison income effect. J. Public Econ. 89, 997-1019.

Flory, J.A., 2012. Formal Savings Spillovers on Microenterprise Growth and Production Decisions Among Non-Savers in Villages: Evidence from a Field Experiment. In: Annual Meeting of the Agricultural and Applied Economics Association.

Genicot, G., Ray, D., 2017. Aspirations and inequality. Econometrica 85, 489-519.

Jack, W., Suri, T., 2011. Mobile money: the economics of M-PESA. National Bureau of Economic Research, Working paper.

Jensen, R., 2010. The (perceived) returns to education and the demand for schooling. Quar. J. Econ., 125.

Kahneman, D., Tversky, A., 1979. Prospect theory: an analysis of choice under risk. Econometrica 47, $263-291$.

Knight, J., Gunatilaka, R., 2012. Income, aspirations and the hedonic treadmill in a poor society. J. Econ. Behav. Org. 82, 67-81.

Laajaj, R., 2017. Endogenous time horizon and behavioral poverty trap: Theory and Evidence from Mozambique. J. Develop. Econ. 127, 187-208.

Lind, J.T., Mehlum, H., 2010. With or Without U? The Appropriate Test for a U-Shaped Relationship. Oxford Bull. Econ. Stat. 72, 109-118.

Lybbert, T.J., Wydick, B., 2016. Hope as Aspirations, Agency, and Pathways: Poverty Dynamics and Microfinance in Oaxaca, Mexico. National Bureau of Economic Research, Working paper.

Lybbert, T.J., Wydick, B., Forthcoming. Poverty, Aspirations and the Economics of Hope. Econ. Develop. Cult. Change. 
Macours, K., Vakis, R., 2014. Changing Households' Investment Behaviour through Social Interactions with Local Leaders: evidence from a Randomised Transfer Programme. Econ. J. 124, 607-633

Malapit, H., Kadiyala, S., Quisumbing, A.R., Cunningham, K., Tyagi, P., 2015. Women's empowerment mitigates the negative effects of low production diversity on maternal and child nutrition in Nepal. J. Develop. Stud. 51, 1097-1123.

Manski, C.F., 1993. Identification of endogenous social effects: The reflection problem. Rev. Econ. Stud. 60, $531-542$.

Manski, C.F., 2004. Measuring expectations. Econometrica 72, 1329-1376.

Mookherjee, D., Ray, D., Napel, S., 2010. Aspirations, segregation, and occupational choice. Journal of the European Economic Association 8, 139-168.

Mullainathan, S., Thaler, R.H., 2000. Behavioral economics. National Bureau of Economic Research, Working paper.

Munshi, K., Rosenzweig, M., 2009. Why is mobility in India so low? Social insurance, inequality, and growth. National Bureau of Economic Research, Working paper.

Nguyen, T., 2008. Information, role models and perceived returns to education: Experimental evidence from Madagascar, Unpublished.

Oxford English Dictionary, 2016. Oxford Living Dictionary.

Ray, D., 2006. Aspirations, poverty and economic change. Understanding Poverty, vol. 28. Oxford University Press, USA, pp. 409-421.

Ross, P.H., 2016. Aspirations and Human Capital Investment: Evidence from Indian Adolescents, Unpublished.

Rotter, J.B., 1966. Generalized expectancies for internal versus external control of reinforcement. Psychol. Monogr.: Gen. Appl., 80.

Sierneels, P., Dercon, S., 2014. Aspirations, Poverty and Education: Evidence from India, Unpublished.

Skoufias, E., Parker, S.W., Behrman, J.R., Pessino, C., 2001. Conditional Cash Transfers and Their Impact on Child Work and Schooling: Evidence from the PROGRESA Program in Mexico [with Comments]. Economía 2, 45-96.

Stutzer, A., 2004. The role of income aspirations in individual happiness. J. Econ. Behav. Org. 54, 89-109.

USAID, 2013. Nepal Country Profile.

World Bank, 2011. World Development Report 2012: Gender equality and development. World Bank, Washington DC 